\title{
Quality of life and clinical outcomes in Type 2 diabetes patients at the primary care clinics of the West Virginia University Hospital
}

\author{
Murali Sundaram \\ West Virginia University
}

Follow this and additional works at: https://researchrepository.wvu.edu/etd

\section{Recommended Citation}

Sundaram, Murali, "Quality of life and clinical outcomes in Type 2 diabetes patients at the primary care clinics of the West Virginia University Hospital" (2005). Graduate Theses, Dissertations, and Problem Reports. 4198.

https://researchrepository.wvu.edu/etd/4198

This Thesis is protected by copyright and/or related rights. It has been brought to you by the The Research Repository @ WVU with permission from the rights-holder(s). You are free to use this Thesis in any way that is permitted by the copyright and related rights legislation that applies to your use. For other uses you must obtain permission from the rights-holder(s) directly, unless additional rights are indicated by a Creative Commons license in the record and/ or on the work itself. This Thesis has been accepted for inclusion in WVU Graduate Theses, Dissertations, and Problem Reports collection by an authorized administrator of The Research Repository @ WVU. For more information, please contact researchrepository@mail.wvu.edu. 


\title{
Quality of Life and Clinical Outcomes in Type 2 Diabetes Patients at the Primary Care Clinics of The West Virginia University Hospital
}

\author{
Murali Sundaram \\ Thesis submitted to the \\ School of Pharmacy \\ at West Virginia University \\ in partial fulfillment of the requirements \\ for the degree of \\ Master of Science \\ In \\ Pharmaceutical Sciences \\ Jan Kavookjian, M.B.A., Ph.D., Chair \\ S. Suresh Madhavan, M.B.A., Ph.D. \\ Lesley-Ann Miller, Ph.D. \\ Julie Hicks Patrick, Ph.D. \\ Virginia (Ginger) Scott, Ph.D.
}

Department of Pharmaceutical Systems and Policy

Morgantown, West Virginia 2005

Keywords: Diabetes, Quality of Life, A1C, Audit of Diabetes Dependent Quality Of Life (ADDQoL), Medical Outcomes Short Form 12 (SF-12) 


\title{
ABSTRACT \\ Quality of Life and Clinical Outcomes in Type 2 Diabetes Patients at the Primary Care Clinics of the West Virginia University Hospital
}

\author{
Murali Sundaram
}

This study examines relationships between quality of life (QoL) and clinical outcomes, specifically A1C, in Type 2 diabetes patients. Type 2 diabetes patients at the outpatient clinics of a university hospital completed a generic QoL measure (SF-12) and a diabetes-specific QoL measure (Audit of Diabetes Dependent Quality of Life (ADDQoL)). A cover letter signed by the patient's provider was sent with a mail out questionnaire. Patient reported data was merged with a retrospective collection of his/her clinical and utilization data, including A1C, from electronic medical records. A Charlson comorbidity score, diabetes complications score, BMI, and number of ER and hospital visits were also calculated. Usable response rate was $44.3 \%(n=385)$. Respondents were $57.1 \%$ female, $93.8 \%$ Caucasian, and $64.1 \%$ were in the $40-69$ age range; $49.1 \%$ were on oral medications only, 31.7\% were on oral medications and insulin, and 9.4\%, on insulin only. Mean A1C of respondents was $7.2(+1.4)$, mean diabetes duration was 10.2 (+9.1), and 62.1\% were obese (BMI>30). Patients were dichotomized into glycemic control levels based on the ADA recommended A1C level $<7.0$, versus $>7.0$. Cronbach's alphas for the ADDQoL, PCS (SF-12 Physical Component Score), and MCS (SF-12 Mental Component Score) were 0.92, 0.92, and 0.88, respectively. Only ADDQoL scores showed significant correlation with A1C $(r=-0.19, \mathrm{p}<0.000)$. Hierarchical regression models were used to separately explain ADDQoL, PCS, and MCS scores, using A1C as the primary independent variable, and controlling for demographics and clinical variables including comorbidities and complications. A1C was not a significant predictor in any regression model, although univariate analyses indicated significantly lower ADDQoL and SF-12 PCS in the group with A1C > 7.0, and in the group with one or more diabetes complications. Obesity was a significant predictor in models explaining only the PCS and MCS scores. These results support complementary use of generic and disease-specific QoL measures in Type 2 diabetes populations. Patient's perceptions of their own life may differ from what a biomedical measure like A1C suggests. 


\section{DEDICATION}

This research is dedicated to

\section{My Grandmothers}

The Late SMT. LAKSHMI SUBRAMANIAN

$\&$

SMT. SUBBULAKSHMI GOPALAKRISHNAN

\section{My Parents}

PROF. S. SUNDARAM \& THANGAMANI SUNDARAM 


\section{ACKNOWLEDGEMENTS}

I first began working with Dr. Jan Kavookjian (Dr. K, as we fondly call her) in the year 2003, on a collaborative research project that arose in the West Virginia University Diabetes Institute. This went on to become my Thesis project, and I thank Dr K. for this opportunity. I also appreciate her guidance all along as we went through the trials and tribulations in gaining IRB approval for the research, coordinating with several contacts outside of the department, and bringing this project to meaningful fruition.

I'd also like to acknowledge the special roles played by Dr. S. Suresh Madhavan, Dr. Lesley-Ann Miller, Dr. Julie Hicks Patrick, and Dr. Virginia (Ginger) Scott, who are the other members of my Thesis committee. Apart from the highly enriching academic learning experience, I have also gained an insight into the challenges posed in conducting research in real-world collaborative settings.

It was my desire to defend my Thesis while my parents were still visiting the U.S. through the summer and fall of 2004. I thought that this would be my little present to them for their invaluable influence and contribution to my life and education. That did not happen, but they left behind fondly cherished memories of their visit, and good wishes that seem inexhaustible. Being an academic for most of his life, Dad has been keenly observing my journey in graduate school and will be very glad to see me at this stage in my life. Mom has played roles with selfless zeal from providing me my earliest educational experiences, to enduring my daily tantrums about finishing up breakfast that went on right up to the day I prepared to leave India to attend Graduate school in the U.S. 
Dr. Kevin Halbritter and Michele Garlick from the Office of Medical Staff Affairs have been gracious in accommodating all our information needs from the time of this project's conception. I thank Michele for her patience and coordination efforts in putting together the list of patients, helping get the physicians’ signatures, with the return mail, and with the clinical data. Apart from getting achieving for me a Master's degree, this project also helped me make some good friends. Kelly White efficiently supported me during the tedious patient survey mail-out process. Tina Podolonski from the Family Medicine department is one of the nicest people I have met. She welcomed me into her office on several occasions to unravel the information contained in the medical databases, in spite of her very busy schedule.

My graduate student colleagues have played multiple roles all along. They have helped me feel proud of my own work, engaged in stimulating discussions as I planned the study and analyzed the data, and especially provided me solace during a rather lean phase in 2004 when personal issues compounded matters in my life. In particular, I’d like to mention Anna D’souza, Reema Mody, Mariam Hassan and Vivek Pawar, most of whom I will miss as they graduate and move along with their lives.

I'd also like to thank all other individuals who I have not mentioned above, but have in some way contributed to this research. 


\section{TABLE OF CONTENTS}

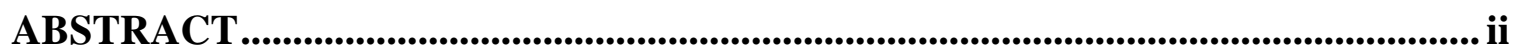

DEDICATION...........................................................................................................................ii

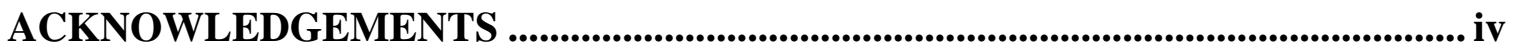

LIST OF TABLES

LIST OF FIGURES …...........................................................................................ii

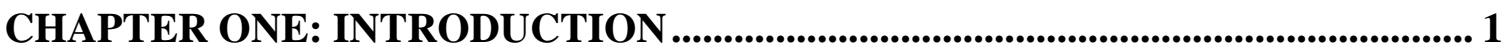

Part One - Diabetes Overview............................................................................................... 1

Prevalence of Diabetes and its Cost Implications ...................................................... 1

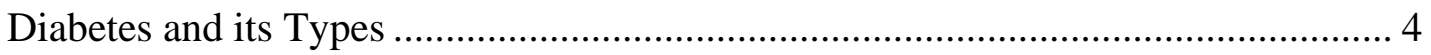

Part Two - Quality of Life and Diabetes .......................................................................... 5

Conceptualizing Quality of Life and Health Related Quality of Life.......................... 5

Patient-Reported Outcomes Like Quality of Life in Persons With Diabetes .............. 8

Part Three - About the Study ................................................................................................. 9

Problem Definition....................................................................................... 9

Conceptual Framework of the Study .................................................................... 10

Research Questions and Hypotheses........................................................................ 13

Assumptions of the Study ................................................................................. 14

Significance of the Study .................................................................................. 15

CHAPTER TWO: LITERATURE REVIEW.................................................................. 17

Blood Glucose Monitoring and A1C levels.............................................................. 17

Implications of the Diabetes Control and Complications Trial and Other Studies... 21

Quality of Life Assessments in Patients with Diabetes ............................................. 23 
Influence of Diabetes Treatment on Quality of Life........................................... 26

Generic and Disease-Specific Instruments to Assess QoL .................................... 28

Generic Quality of Life Measures................................................................ 30

Disease-Specific Quality of Life Measures ...................................................... 32

Psychometric Properties of QoL Measures Used in the Study ........................... 36

The Medical Outcomes Study Short Form SF-12............................................. 36

The Audit of Diabetes-Dependent Quality of Life .............................................. 41

Rationale for the Combination of Instruments Used .......................................... 47

A1C levels and Quality of Life.................................................................. 48

Evaluation of A1C Levels in Diabetes Management Programs ............................. 51

Other Factors Influencing Quality of Life.................................................................... 53

CHAPTER THREE: STUDY METHODOLOGY .......................................... 55

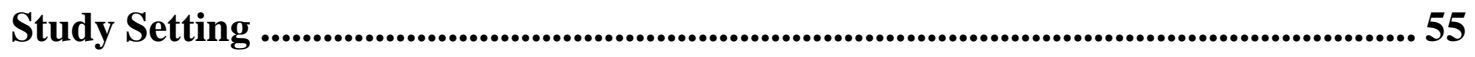

Study Design ............................................................................................................ 56

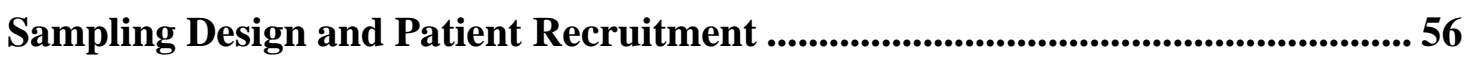

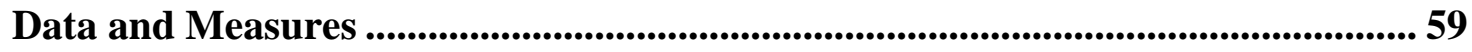

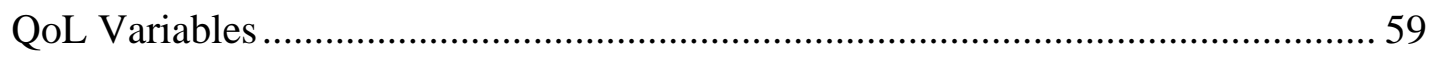

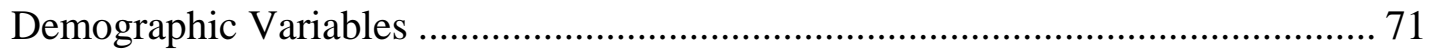

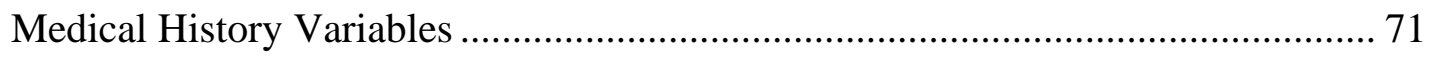

Data Analyses ................................................................................................................ 75

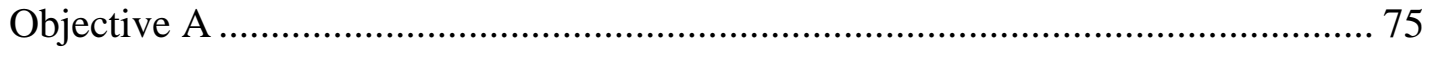

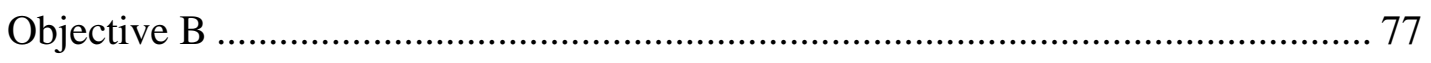

Sample Size Calculations and Power ........................................................................ 80 


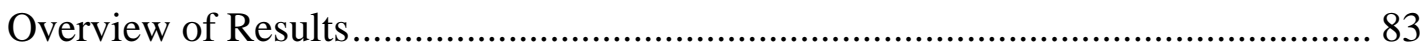

Descriptive Statistics for Total Sample Response Data.................................................. 84

Overview of Descriptive Statistics........................................................................... 84

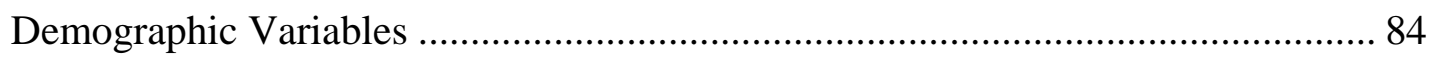

Medical History Variables .................................................................................. 85

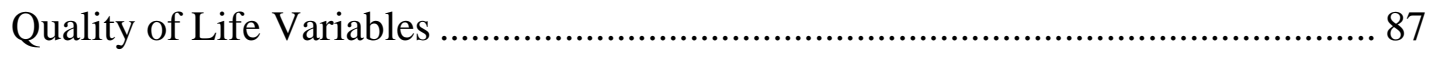

Results for Objective A............................................................................................................ 94

Factor Structure and Reliability of the ADDQoL ........................................................ 94

Construct Validity of the ADDQoL ......................................................................... 97

Factor Structure and Reliability of the SF-12 ……………..................................... 100

Construct Validity of the SF-12 ........................................................................... 103

Results for Objective B...................................................................................................... 104

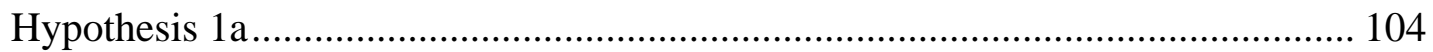

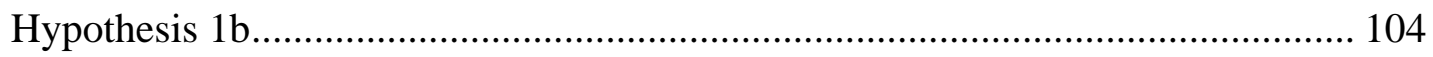

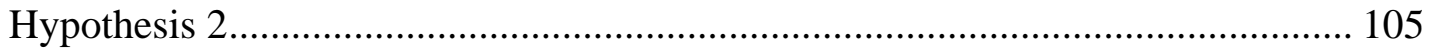

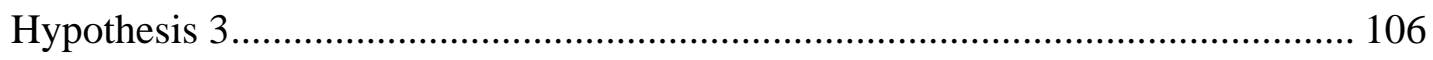

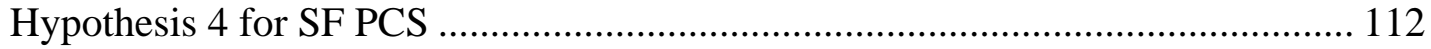

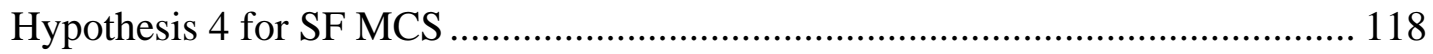

Power of the Study Results ................................................................................................ 124

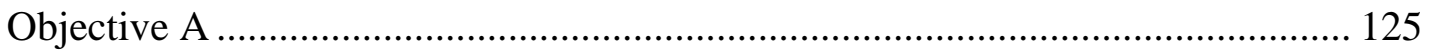

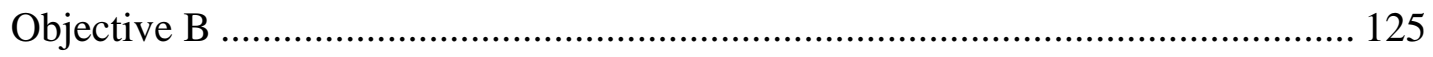




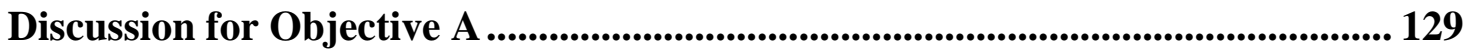

The ADDQoL in Type 2 Diabetes Patients ...................................................... 129

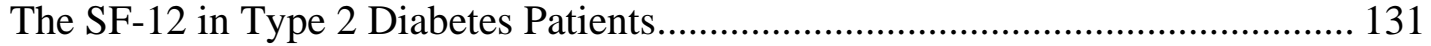

Discussion for Objective B ................................................................................ 132

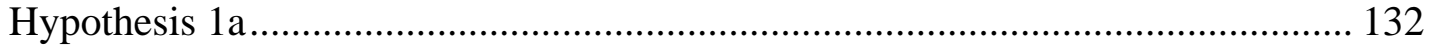

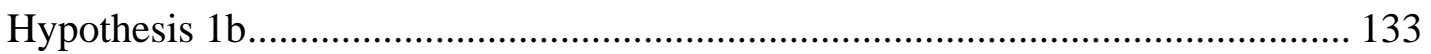

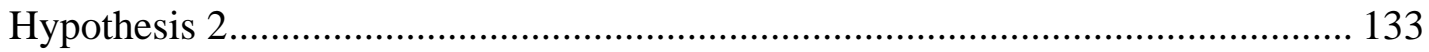

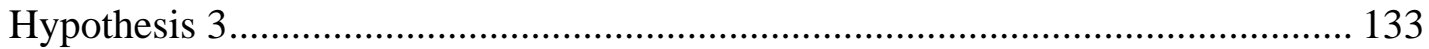

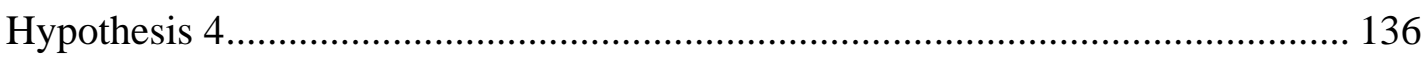

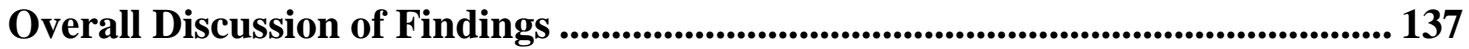

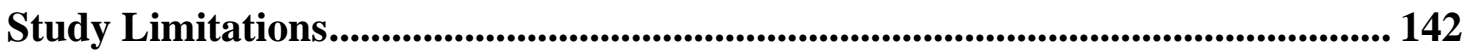

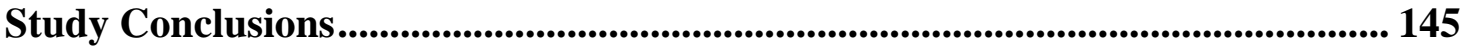

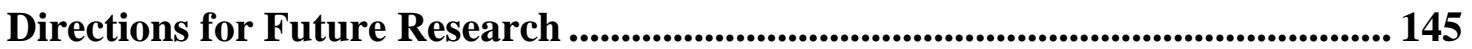

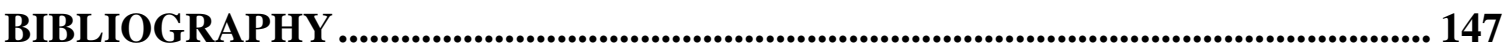

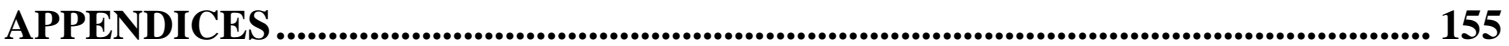

Appendix A: Physician Cover Letter .......................................................... 156

Appendix B: Measures Booklet ....................................................................................... 157

Appendix C: Reminder Card............................................................................. 174

CURRICULUM VITAE............................................................................................ 175 


\section{LIST OF TABLES}

Table 1: Relationship of Average Blood Glucose and A1C Results 19

Table 2: Relationship of A1C to Average Whole Blood and Plasma Glucose Levels .... 20

Table 3: Domains of the Medical Outcomes Study Short Form SF-36 ............................ 39

Table 4: Domains of the Medical Outcomes Study Short Form SF-12 …......................... 40

Table 5: Domains of the Audit of Diabetes Dependent Quality of Life ............................ 43

Table 6: Format of the Two Overview Items of the ADDQoL Showing Scores Assigned

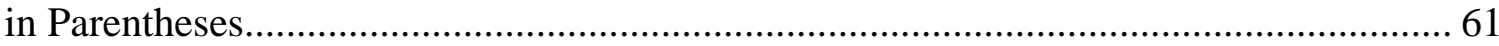

Table 7: Format of the Domain-Specific Items of the ADDQoL Showing Scores

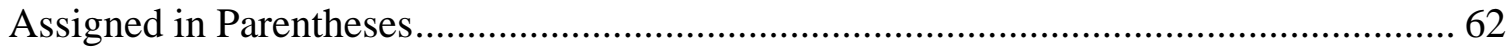

Table 8: Summary: Scoring Specific Domains in the ADDQoL........................................ 63

Table 9: Calculating SF-12 Raw Domain Scores from the Recoded Items....................... 66

Table 10: Calculating SF-12 Standardized Domain Scores from Raw Domain Scores ... 67

Table 11: Calculating SF-12 Aggregate Physical and Mental Summary Scores from SF-

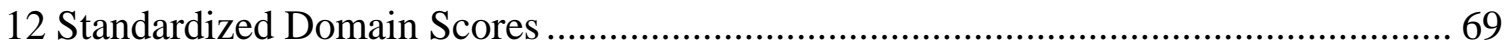

Table 12: Calculating SF-12 Physical and Mental Summary Scores ................................ 70

Table 13: Demographic Profile of Respondents.............................................................. 89

Table 14: Mean Weighted Impact Scores for ADDQoL Domains..................................... 91

Table 15: Mean Scores on the ADDQoL, SF-PCS, and SF-MCS, and Significance of

Sub-group Differences ................................................................................................ 92

Table 16: Loadings of ADDQoL Domains on the Single-Factor Solution ....................... 95

Table 17: Loadings of SF-12 Domains on the Two-Factor Solution................................ 101 
Table 18: Summary of the Block-wise Entry of Predictors in the Hierarchical Regression Model Predicting ADDQoL Scores Using Average A1C 107

Table 19: Results of the Hierarchical Regression Model Predicting ADDQoL Scores

Using Average A1C 108

Table 20: Summary of the Block-wise Entry of Predictors in the Hierarchical Regression Model Predicting ADDQoL Scores Using Recent A1C. 110

Table 21: Results of the Hierarchical Regression Model Predicting ADDQoL Scores

Using Recent A1C

Table 22: Summary of the Block-wise Entry of Predictors in the Hierarchical Regression Model Predicting SF-PCS Scores Using Average A1C

Table 23: Results of the Hierarchical Regression Model Predicting SF-PCS Scores Using Average A1C 114

Table 24: Summary of the Block-wise Entry of Predictors in the Hierarchical Regression Model Predicting SF-PCS Scores Using Recent A1C 116

Table 25: Results of the Hierarchical Regression Model Predicting SF-PCS Scores Using

Recent A1C 117

Table 26: Summary of the Block-wise Entry of Predictors in the Hierarchical Regression Model Predicting SF-MCS Scores Using Average A1C 119

Table 27: Results of the Hierarchical Regression Model Predicting SF-MCS Scores

Using Average A1C 120

Table 28: Summary of the Block-wise Entry of Predictors in the Hierarchical Regression Model Predicting SF-MCS Scores Using Recent A1C. 
Table 29: Results of the Hierarchical Regression Model Predicting SF-MCS Scores

Using Recent A1C

Table 30: Bivariate Correlations and 95\% Confidence Intervals for the Results of

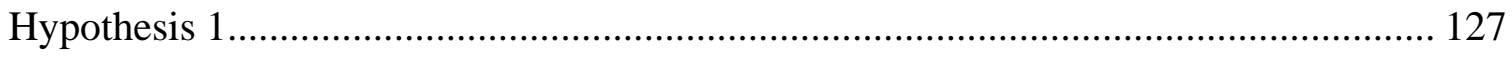

Table 31: Observed Power of the Hierarchical Regressions Models .............................. 128

Table 32: Summary of Hierarchical Regression Models in Hypotheses 3 and 4 ........... 135 


\section{LIST OF FIGURES}

Figure 1: Impact of Diabetes on QoL as Reflected in ADDQoL Scores, by Insulin Use 98 


\section{CHAPTER ONE: INTRODUCTION}

\section{Part One - Diabetes Overview}

\section{Prevalence of Diabetes and its Cost Implications}

The World Health Organization (WHO) states that a diabetes epidemic is underway. While an estimated 30 million people worldwide had diabetes in 1985, this number had increased to 135 million by 1995 (WHO, 2002). The latest WHO figure for the number of people with diabetes worldwide in 2000 was estimated at 177 million and is projected to increase to at least 300 million by 2025. The number of annual deaths attributed to diabetes was previously estimated at just over 800,000 worldwide (WHO, 2002), but this may be underestimated. The WHO estimates a more likely figure would be around four million diabetes-related deaths per year, and represents nine percent of the total deaths around the globe (WHO, 2002). With an increasing number of patients with diabetes worldwide, the disease will require a growing proportion of funding from national health care budgets. Diabetes is projected to become one of the world's main disablers and killers within the next twenty-five years (WHO, 2002).

Diabetes is the sixth leading cause of death by disease in the U.S. (Kochanek and Smith, 2004). In 2002, approximately 73,119 deaths were attributable to diabetes, with a death rate of 25.4 per 100,000 people in the U.S. (Kochanek and Smith, 2004). One million new cases of diabetes are diagnosed per year in the U.S. among people aged 20 years or older (NDIC, 2003). In 2002, annual direct medical expenditures totaling \$92 billion were attributed to diabetes (compared to $\$ 44$ billion in 1997) and were comprised 
of $\$ 23.2$ billion for diabetes care, $\$ 24.6$ billion for chronic diabetes-related complications, and $\$ 44.1$ billion for excess prevalence of general medical conditions (Hogan, Dall \& Nikolov, 2003). The total health care cost of a person with diabetes in the U.S. was found to be between two and three times the costs for people without the condition (WHO, 2002). Diabetes is associated with higher rates of lost work time, disability, and premature mortality, and imposes a significant burden to families and friends of those with diabetes as well (Hogan, Dall \& Nikolov, 2003). The economic expense to the U.S. economy, due to the indirect costs of lost productivity resulting from lost workdays, restricted activity days, permanent disability, and mortality due to diabetes in 2002 is conservatively estimated to be $\$ 40$ billion. Therefore, the resulting total direct and indirect costs estimated at \$132 billion in 2002 comprise one out of every ten health care dollars spent in the U.S. This forms a tremendous national economic burden (Hogan, Dall \& Nikolov, 2003).

The costs of diabetes are not only a financial problem. Intangible costs (pain, anxiety, inconvenience, generally lower quality of life, and others) also have great impact on the lives of patients and their families and are the most difficult to quantify (WHO, 2002). In addition, diabetes is associated with a higher risk for heart disease, blindness, kidney failure, extremity amputations, and other serious chronic conditions. Overall, the risk for death among people with diabetes is about two times that of people without diabetes (NDIC, 2003).

The 2002 Behavioral Risk Factor Surveillance System (BRFSS) revealed an estimated diabetes prevalence of 10.2\% among West Virginia (WV) adults (CDC, 2002). WV was ranked second in prevalence, and is among only two states and territories in the 
U.S. with greater than $10 \%$ prevalence, for the disease (CDC, 2002). Diabetes prevalence has been recorded consistently higher in WV than in the U.S. through most of the 1990s (WV Department of Health and Human Resources [WVDHHR], 2003). Diabetes was the sixth leading cause of death in $\mathrm{WV}$, ranking second among the states and territories of the U.S. in diabetes-related deaths (WVDDHR, 2003). There are other factors contributing to the high rate of diabetes in WV. The prevalence of obesity in WV has also been consistently higher than that in the U.S. (WVDHHR, 2002). In 2002, the WV prevalence rate of obesity was $27.6 \%$, compared to $22.2 \%$ nationally (CDC, 2002). Further complicating this trend is the fact that a large percent of West Virginians live in very rural areas, with limited access to healthcare and low education and income levels (WVDDHR, 2001).

Diabetes is a chronic disease associated with complications and other comorbid conditions that add to the burden of diabetes. Some of the more significant complications resulting from the inefficient management of diabetes are eye disease (blindness, retinopathy), kidney disease (nephropathy, end stage renal disease), and nervous system damage (neuropathy, foot ulcers), among others. Heart disease is the leading cause of diabetes-related deaths; the risk of heart disease is two to four times higher in persons with diabetes (CDC, 2003). The risk of stroke is two to four times greater, and an estimated $73 \%$ of persons with diabetes have hypertension (CDC, 2003). Diabetes is also the leading cause of adult blindness and end stage renal disease accounting for $44 \%$ of new cases of kidney failure (CDC, 2003). Approximately 60-70\% of persons with diabetes have neuropathies; severe forms of diabetic nerve disease are a major contributing cause of lower-extremity amputations (CDC, 2003). Other less common 
complications associated with diabetes include periodontal disease, complications of pregnancy and acute life-threatening events such as diabetic ketoacidosis and hyperosmolar coma. People with diabetes are also more susceptible to many other illnesses and once they acquire these illnesses, their prognoses worsens (CDC, 2003).

\section{Diabetes and its Types}

Diabetes mellitus consists of a group of diseases characterized by high levels of blood glucose resulting from defects in insulin production, insulin action, or both.

\section{Types of diabetes}

Type 1 diabetes. Type 1 diabetes was previously called insulin-dependent diabetes mellitus (IDDM) or juvenile-onset diabetes. This form of diabetes usually strikes children and young adults, who need several insulin injections a day or an insulin pump to survive. Type 1 diabetes may account for five to ten percent of all diagnosed cases of diabetes (CDC, 2003). Risk factors for Type 1 diabetes include autoimmune, genetic, and environmental factors.

Type 2 diabetes. Type 2 diabetes was previously called non-insulin-dependent diabetes mellitus (NIDDM) or adult-onset diabetes. Type 2 diabetes may account for about 90 to 95 percent of all diagnosed cases of diabetes (CDC, 2003). Type 2 diabetes is most often associated with older age, obesity, family history of diabetes, prior history of gestational diabetes, impaired glucose tolerance, physical inactivity, and race/ethnicity. Type 2 diabetes is increasingly being diagnosed in children and adolescents. It is treated using a class of drugs known as oral hypoglycemic agents (OHAs), which include 
sulfonylureas, biguanides, and some newer agents like thiazolidinediones, meglitinides, and alpha-glucosidase inhibitors.

Gestational diabetes. Gestational diabetes is a form of glucose intolerance that is diagnosed in some women during pregnancy. It is also more common among obese women and women with a family history of diabetes. During pregnancy, gestational diabetes requires treatment to normalize maternal blood glucose levels to avoid complications in the infant. After pregnancy, five to ten percent of women with gestational diabetes are found to have developed type 2 diabetes. Women who have had gestational diabetes have a 20 to 50 percent chance of developing diabetes in the next five to ten years (CDC, 2003).

Other types of diabetes result from specific genetic conditions such as maturityonset diabetes of youth, genetic defects of the beta cells of the pancreas, and genetic defects in insulin action. Other causes include other illnesses, drugs that impair insulin secretion, malnutrition, infections, and certain viruses that are associated with beta cell destruction and endocrinopathies. Such types of diabetes may account for 1 to 5 percent of all diagnosed cases of diabetes (CDC, 2003).

\section{Part Two - Quality of Life and Diabetes}

\section{Conceptualizing Quality of Life and Health Related Quality of Life}

In 1948, the World Health Organization defined health from a multi-dimensional perspective. Absence of disease and infirmity on one hand, but also the presence of physical, mental and social well being, was regarded as constituting health. In the 
following years, there has been great interest in studying the effect of psychosocial factors on health outcomes. Quality of life (QoL) is being referred to as a multidimensional construct that comprises the individual's subjective perception of psychological, social, and physical well being (Snoek, 2000). The key aspects to note are that QoL encompasses multiple domains that influence overall QoL in their own way and that it should be based on the patient's self-report rather than the health care professional's point of view (Snoek, 2000). Quality of Life, a patient self-reported measure, can be differentiated from objective physical health status that is assessed by physicians' reports of symptoms and/or the presence of complications (Rubin \& Peyrot, 1999). Quality of life comprises the individual's subjective perception of physical, emotional and social well being, including both a cognitive component (like satisfaction) and an emotional component (like happiness) (Rubin, 2000; Rubin \& Peyrot, 1999).

Testa (2000) states that QoL is not a static measure, but is a health assessment approach that focuses on patient reports, feelings, and expectations. By QoL, the reference is not only to the health aspects of life, but also to the broadest range of human experiences (Polonsky, 2000). Narrowing down the scope of QoL to aspects of functioning directly related to disease, medical treatments, or both, the term Health Related Quality of Life (HRQOL) was introduced, which concerns with how overall QoL happens to be influenced by health and disease (Polonsky, 2000). In measuring the various dimensions of health, the physical, psychological and social aspects to represent the complete spectrum of life functioning are considered.

There is now increasing recognition that the impact of chronic illnesses and their treatments must be assessed for their influences on QoL in addition to more traditional 
measures of medical outcomes, such as morbidity and mortality (Jacobson, De Groot \& Samson, 1994). Hareendran (2004) summarizes the value that patient reported outcomes like QoL can add to the evaluation of new treatments: They are key measures of treatment outcomes when there are no objective markers of symptoms and no objective markers of the impact of symptoms. They also complement traditional endpoints to evaluate the significance of a treatment effect from a patient's perspective. Information on QoL outcomes can facilitate patients' involvement in treatment decision-making. Finally, Hareendran (2004) states that QoL outcomes can provide guidance for health care decision making by enabling a better understanding of the burden of illnesses and in making healthcare allocation decisions.

Quality of Life has been recognized as one of the important goals for public health in the report of Healthy People 2010, which is a set of health objectives for the U.S. to achieve over the first decade of the $21^{\text {st }}$ century. Healthy People 2010 presents 467 objectives to improve the health of Americans by the year 2010. The first goal of Healthy People 2010 is "to help individuals of all ages increase life expectancy and improve their quality of life" (U.S. Department of Health and Human Services, 2000). The year 2010 goals for diabetes care in WV focus on the following challenges: 'increasing the demand for better diabetes care through public awareness; increasing early detection of Type 2 diabetes; improving management of diabetes care; increasing the collection of statewide diabetes data; and monitoring and evaluating the effectiveness of diabetes care statewide' (WVDHHR, 2001). The stated overall main goal in the report is to increase the 'quality of life' for persons with diabetes living in WV. However, 
'quality of life' from the perspective of a government public health document may be interpreted as a more general indicator of the quality and standard of life of people.

\section{Patient-Reported Outcomes Like Quality of Life in Persons With Diabetes}

Landmark studies like the Diabetes Control and Complications Trial (DCCT) and the United Kingdom Prospective Diabetes Study (UKPDS) showed that maintaining blood glucose levels as close to normal as possible slows the onset and progression of some of the complications caused by diabetes, like eye, kidney, and nerve conditions (DCCT Research Group, 1993 and UKPDS Group, 1998). As a result of the dissemination of these study findings into clinical practice by organizations like the American Diabetes Association (ADA), glycemic control became the essential outcome focus of diabetes treatment in clinical practice.

Medical research and care is becoming more patient-focused, and there is increasing appreciation of patient-reported outcomes, or the patient's perspective on health, disease, and medical treatments (Polonsky, 2000). Diseases can affect QoL of people in different ways depending on the aspects of life that are compromised due to the presence of that disease. The management of diabetes itself has a major impact on people's lives, in terms of physical and psychological well being. This is due to the considerable demands imposed by current care practices on persons with diabetes. Complications associated with diabetes have been found to substantially increase the morbidity and mortality of affected persons and to reduce their QoL (ADA, 2001). Polonsky (2000) states that the true impact of a successful medical intervention can reflect the degree to which it has a positive influence on a patient's health and well being. Applying a similar thought in the area of diabetes care, there is a suggestion to not limit 
the goals of diabetes care only to strict glycemic control, but also to perform comprehensive assessments of the impact of glucose control regimens on health and QoL (Anderson, Fitzgerald, Wisdom, Davis \& Hiss, 1997).

\section{Part Three - About the Study}

\section{Problem Definition}

In the case of chronic illnesses like diabetes, it takes time before the benefits of the treatment become apparent. Researchers have attempted to ascertain the relationship between glycemic control and QoL in patients with diabetes using different measures, either generic or diabetes-specific, or both. Two major longitudinal epidemiological studies that investigated the benefits of metabolic control in managing reported no differences in QoL between patients undergoing conventional treatment versus intensive treatment aimed at achieving better glycemic control (The DCCT Research Group, 1996; UKPDS Group, 1999). Correlational studies have found relationships between A1C and well being and QoL (Van der Does et al., 1996; Nerenz, Repasky, Whitehouse \& Kahkonen, 1992; Guttmann-Bauman, Strugger, Flaherty, \& McEvoy, 1998; Polonsky, Anderson and Lohrer, 1995). Some other studies report no such association (Weinberger et al.,, 1994; Lloyd, Sawyer and Hopkinson, 2001).

In designing new research to assess the relation between glycemic control and QoL, it is useful to examine the QoL instruments used in these studies. The DCCT group used a diabetes-specific instrument called DQoL, among others and the UKPDS group used a generic instrument called the EQ5D. The possibility that the QoL instruments used 
in these studies lacked sensitivity to detect QoL differences between groups has not been ruled out by the researchers of these studies (The DCCT Research Group, 1996; UKPDS Group, 1999). Correlational studies reporting the relation between glycemic control and QoL have used a range of generic measures (Weinberger et al., 1994; Lloyd, Sawyer and Hopkinson, 2001; Nerenz, Repasky, Whitehouse \& Kahkonen, 1992), diabetes-specific measures (Guttmann-Bauman, Strugger, Flaherty, \& McEvoy, 1998; Polonsky, Anderson and Lohrer, 1995), while others have used measures describing physical and emotional well being (Van der Does et al., 1996).

Hence, existing evidence is mixed on the nature of association between glycemic control and QoL. Some researchers have expressed the need to distinguish between measures of health status from those assessing QoL. Stating that health status measures that broadly measure aspects of physical and mental functioning, and other specific body functions and symptoms that are important in diabetes research, Bradley (1996) cautions that they should not be confused with measures of the QoL of individuals.

\section{Conceptual Framework of the Study}

Overview

This study was conducted with the broad aim of performing an analysis of QoL of patients with Type 2 diabetes receiving care at the West Virginia University (WVU) Hospital outpatient primary care clinics. The study had a cross-sectional, descriptive design. The specific objectives of the study were to assess the validity of the SF-12 and the ADDQoL in the study population of Type 2 diabetes patients and to discuss the 
associations between QoL, demographic characteristics, and medical history of patients, chiefly A1C levels.

\section{Data and Measures}

Patients with Type 2 diabetes at the WVU hospital outpatient clinics completed a generic measure, the SF-12 and a diabetes-specific measure, the Audit of Diabetes Dependent Quality of Life (ADDQoL). Other patient-reported data collected by mail out questionnaire, included demographics, insulin use and diabetes duration.

Patient reported data was merged with a retrospective collection of patient clinical and utilization data via patient's electronic medical records. A comorbid disease score, diabetes complications score, BMI and the number of ER \& hospital visits in the past were calculated from the retrospective data. A1C levels were directly abstracted from electronic patient clinical records; both the most recent A1C value as well as the average of $\mathrm{A} 1 \mathrm{C}$ values in the past one-year were obtained.

The variables collected and analyzed in the study are categorized below: QoL variables

- The Audit of Diabetes Dependant Quality of Life (ADDQoL) score

- Physical Component Score (PCS) score of the Medical Outcome Study Health Survey 12-item Short Form (SF-12)

- Mental Component Score (MCS) score of the SF-12 Demographic variables

- Gender

- Age 
- Marital status

- Ethnicity

- Education

- Type of health insurance

Medical history variables

- Duration of diabetes

- A1C (most recent A1C, and average value of A1Cs in the past year)

- $\quad$ Body Mass Index (BMI)

- Insulin use

- Diabetes Complication Score

- Charlson Comorbidity Index

- Number of emergency room visits in the past 12 months.

- Number of hospital admissions in the past 12 months.

Objectives of the Study

\section{Objective A}

This part of the study examines the dimensionality, internal consistency, and construct validity of a the SF-12 and the ADDQoL in the study setting consisting of patients with Type 2 diabetes, and report how they compare to the published findings from other studies.

\section{Objective B}

One main objective of the study is to find out the relationship between a clinical measure like A1C and a patient reported outcome like QoL. While a generic measure 
indicates a general degree of health-related well being, diabetes-specific measures ask patients to relate evaluations of well being to having and treating diabetes. Hence, this question also examined differences in relationship between a generic and diabetesspecific measure, and A1C. The three categories of variables being studied are demographic variables, clinical variables, and QoL variables. This question attempts to determine the role of these variables, if any, in influencing generic and diabetes-specific QoL.

\section{Research Questions and Hypotheses}

Research Questions for Objective A

One aim of the current study was to determine the reliability of the SF-12 and the ADDQoL in the given study setting involving Type 2 diabetes patients. Additionally, the study also tested the prevailing two-factor approach for the SF-12 and the single factor approach for the ADDQoL. Construct validity of the instruments was also studied.

\section{Research Questions for Objective B}

In addition to assessing the psychometric properties of the ADDQoL and the SF12 in diabetes research, this study examines relationships between QoL and demographic and clinical variables, including A1C levels. Specific research questions are mentioned below:

Q1. Is there a relationship between between A1C and QoL (generic and disease-specific) in Type 2 diabetes patients?

- Hypothesis 1a - A1C level and ADDQoL score are not correlated 
- Hypothesis $1 b$ - A1C level, and PCS and MCS scores of the SF-12 are not correlated

- Hypothesis 2 - There is no difference in the correlations between A1C level and ADDQoL score, and A1C level and PCS \& MCS scores of the SF-12.

Q2. What are the significant variables influencing generic QoL, measured by the SF-12 scores (PHC and MHC), and diabetes-specific QoL, measured by ADDQoL score, in Type 2 diabetes patients?

- Hypothesis 3 - A1C is a not a significant predictor of ADDQoL score.

- Hypothesis 4-A1C is a not a significant predictor of PCS score and MCS score.

\section{Assumptions of the Study}

This study depends on patients' perspectives about the impact of diabetes on their QoL. Indeed, this is the principle behind patient-reported outcomes. Any patient- reported measure is influenced by biases. Hence, it is possible that in spite of a negative impact of a disease on aspects of QoL, a patient may be unwilling to report that on a survey. The study assumes that patients are capable of perceiving aspects of diabetes as it influences their QoL, and also are willing to accurately report that on a survey.

The study uses the subjective appraisal of our primary contact physician at the WVU Diabetes Institute in identifying Type 2 diabetes patients as potential participants. It is assumed that these patients have been correctly identified, and that their medical records also correctly identify their Type 2 diabetes status. In addition, the study uses existing medical records to generate medical history variables for use in the study. It is 
assumed that patient information contained in these records has been coded appropriately and is accurate.

\section{Significance of the Study}

The ADDQoL is a relatively new instrument providing a measure of individualized QoL in patients with diabetes, and the SF-12 is increasingly being used alongside other disease-specific measures. Although the reliability of the SF-12 has been reported from its developmental work (Ware, Kosinski \& Keller, 1996), there is little research done on the reliability of the instrument among Type 2 diabetes patients. In one recent study on the performance of the SF-12 in Type 2 diabetes patients, Johnson and Maddigan (2004) reported that the PCS and MCS scores of the SF-12 were unable to distinguish between groups of differing disease severity. However, data on psychometric properties of SF-12 in this population was not provided in the study. The ADDQoL is a relatively newer measure among diabetes-specific QoL measures. Apart from the developer's paper on the 20-item ADDQoL, no other published work discusses the psychometric properties of the instrument. A one-factor solution for the ADDQoL has been proposed (et al., 1999; Bradley \& Speight, 2001), and the instrument has been stated to be highly reliable, with reliability coefficient of 0.85 (Bradley et al., 1999).

This study benefits from recommendations of past research regarding the complementary use of a generic and a disease-specific instrument in the assessment of impact of the disease on patients' QoL. This study will provide further information on the reliability and construct validity of these two instruments when used in Type 2 
diabetes patients. Since there are currently no published studies that use both the ADDQoL and the SF-12, this study will be the first to use the two QoL instruments.

As mentioned in an earlier section, researchers have used a variety of generic and disease-specific measures, while some have used instruments measuring aspects of physical and mental functioning and other specific body functions and symptoms. There is no consensus on the relationship between A1C and QoL from these studies. In analyzing the factors influencing QoL in diabetes, existing studies have examined different types of variables, including demographics and medical history variables. While patient report of comorbidities, complications, and medical resource may suffer from recall bias, this study obtains such information from retrospective medical records, eliminating threats to validity from this type of bias. 


\section{CHAPTER TWO: LITERATURE REVIEW}

\section{Blood Glucose Monitoring and A1C levels}

Checking blood glucose levels through regular blood glucose testing shows how well diabetes is in control over a period of few hours. Another blood test that is recommended for checking diabetes control over longer periods of time is an A1C (also known as glycated hemoglobin) test. The test measures the amount of blood glucose chemically attached to red blood cells; the higher the blood glucose, the greater the percentage of glucose accumulated on the red blood cells. Hence, an A1C result reflects the average blood glucose level for the previous 2-3 months, in comparison to blood glucose testing which identifies control on a day-to-day basis. Not only can A1C allow healthcare professionals to judge how well a patient's diabetes treatment plan is working, it can also assist in evaluating the long-term effects of diabetes management. Although the A1C test is an important tool, it doesn't really replace daily self-testing of blood glucose as A1C tests don't provide day-to-day control information. The relationship of average blood glucose and A1C results is depicted in Table 1.

The American Diabetes Association (ADA) recommends A1C testing when first diagnosed with diabetes, and then at least two times a year if blood sugar is in the target range and stable (ADA, 2001). In the case of patients taking insulin, or experiencing a treatment change, or with very high blood sugar levels, an A1C test is recommended at least every 3 months until blood sugar level improves (ADA, 2001). As illustrated in Table 2, The ADA recommends that action be taken when A1C results are over $8 \%$, and considers the diabetes to be under control when the A1C result is less than $7 \%$. One of 
the Healthy People 2010 objectives for WV is to increase the proportion of persons with diabetes who have an A1C test at least once a year to 85\% (WVDDHR, 2001). 
Table 1: Relationship of Average Blood Glucose and A1C Results*

\begin{tabular}{ccc}
\hline A1C & Level of Control & Corresponding Average Blood Glucose \\
$\%$ A1C & Based on A1C level & $\mathrm{mg} / \mathrm{dl}$ \\
\hline $14.0-10.1$ & Poor Control & $360-240$ \\
$10.0-9.1$ & Marginal Control & $240-210$ \\
$9.0-7.1$ & Good Control & $210-150$ \\
$7.0-5.0$ & Excellent Control & $150-90$ \\
\hline
\end{tabular}

* obtained from Buckley \& Goldstein, (1993) 
Table 2: Relationship of A1C to Average Whole Blood and Plasma Glucose Levels *

\begin{tabular}{|c|c|c|c|}
\hline $\begin{array}{c}\text { A1C } \\
\%\end{array}$ & $\begin{array}{c}\text { Mean Blood Glucose } \\
(\mathrm{mg} / \mathrm{dL})\end{array}$ & $\begin{array}{l}\text { Average Plasma } \\
\text { Glucose (mg/dL) }\end{array}$ & Interpretation \\
\hline 4 & 61 & 65 & \multirow{3}{*}{ Non-Diabetic Range } \\
\hline 5 & 92 & 100 & \\
\hline 6 & 124 & 135 & \\
\hline 7 & 156 & 170 & Target for Diabetes in Control \\
\hline 8 & 188 & 205 & \multirow{5}{*}{$\begin{array}{l}\text { Action Suggested according to ADA } \\
\text { guidelines }\end{array}$} \\
\hline 9 & 219 & 240 & \\
\hline 10 & 251 & 275 & \\
\hline 11 & 283 & 310 & \\
\hline 12 & 314 & 345 & \\
\hline
\end{tabular}

*obtained from Rohlfing and colleagues, (2002) 


\section{Implications of the Diabetes Control and Complications Trial and Other Studies}

The DCCT was a multi-center prospective controlled clinical trial that demonstrated the beneficial effect of intensive diabetes treatment on reducing risk for retinopathy, nephropathy, and neuropathy in subjects with Type 1 diabetes. Conducted between 1983 and 1993, it was a randomized clinical trial designed to compare the effects of intensive diabetes therapy with those of conventional diabetes therapy on the development and/or progression of long-term complications of Type 1 diabetes.

Two groups of patients were followed long term: one treated conventionally with a goal of clinical well being, and called the standard treatment group; and another treated intensively with a goal of normalization of blood glucose, and called the intensive treatment group. The goal of intensive therapy was to achieve glycemic control as close to the non-diabetic range as possible, while minimizing hypoglycemia. While the principal study endpoint was to study the development and progression of retinopathy, other outcomes assessments included evaluations of renal, neurological, cardiovascular, neuropsychological, and quality of life status.

The DCCT demonstrated the impact of glycemic control on the early manifestations of microvascular complications. Results of the DCCT demonstrated that intensive treatment led to strong reductions in the onset and progression of retinopathy, nephropathy, and neuropathy (DCCT Research Group, 1993). The benefit of intensive therapy resulted in a delay in the onset and a major slowing of the progression of these three complications. These benefits were seen in all categories of patients irrespective of age, sex, or duration of diabetes (DCCT Research Group, 1993). 
Patients with Type 2 diabetes were not studied in the DCCT. The UKPDS (United Kingdom Prospective Diabetes Study) is one of the largest and longest studies performed with Type 2 diabetes patients, and is another landmark diabetes study supporting the value of glycemic control. The primary aim of the UKPDS was to determine whether an intensive policy of improving blood glucose control with metformin, sulfonylureas or insulin therapy protects patients from diabetic complications compared to a conventional protocol that aims to improve blood glucose control through diet alone (UKPDS Group, 1998). The study results showed fewer incidences of diabetes-related complications like retinopathy, nephropathy, and possibly neuropathy by lowering blood glucose levels in Type 2 diabetes with intensive therapy described above (UKPDS Group, 1998). Thus, the UKPDS results confirmed the results of the DCCT about the role of controlled glucose levels in preventing diabetes-related complications.

Other large epidemiological studies have been planned since the DCCT and UKPDS. One of them is the Wisconsin Epidemiologic Study of Diabetic Retinopathy (WESDR), which examined diabetes patients to determine the prevalence and severity of diabetic retinopathy and associated risk variables. The study found that the severity of retinopathy was related to high A1C levels, among other conditions (Klein, Klein, Moss, Davis and DeMets, 1984). A collaborative study between the DCCT and the WESDR compared the DCCT cohort to a population-based Type 1 diabetes cohort from the WESDR. The study concluded that the validity of generalizing the DCCT results to patients with Type 1 diabetes in the general population was supported by the similar rates of progression of retinopathy in conventionally treated patients, and the similar 
associations between the A1C levels and progression of retinopathy in the DCCT and WESDR cohorts (DCCT Research Group, Klein \& Moss, 1995).

Another study, the Epidemiology of Diabetes Interventions and Complications (EDIC), can be described as a long-term follow-up of the DCCT cohort. The DCCT cohort has been reported to be very stable ten years after the closeout of the DCCT, with 96\% enrolled in the EDIC study (EDIC Research Group, 1999). The EDIC study aims to achieve some scientific gains of conducting extended observational follow-up of subjects from completed randomized controlled trials. Some of the benefits are additional information on long-term effects, sub groups with different treatments and latest natural history data (EDIC Research Group, 1999). With comprehensive data characterized at baseline, the study group intends to examine hypotheses related to progression of cardiovascular disease, nephropathy, neuropathy, and retinopathy.

\section{Quality of Life Assessments in Patients with Diabetes}

Type 1 and Type 2 diabetes are chronic illnesses that can influence QoL because the treatments are burdensome and the complications can be debilitating and/or lifethreatening. For patients with diabetes, the disease and the demands of its day-to-day management can be very challenging. Patients have to deal with their diabetes almost every instant of their life and have to make continuous decisions that interfere with living a normal life. The management of diabetes itself imposes considerable demands on patients and their families, and affects patients both physically and psychologically. Patients with diabetes may feel overwhelmed by the management of the disease. Apart from the emotional and social burdens this may cause, they face the acute physical 
distresses of hypoglycemia or hyperglycemia and chronic physical distress of diabetesrelated complications (Rubin, 2000).

Polonsky (2000) has deliberated on the specific impact of diabetes on physical, psychological and social functioning as follows:

Impact of diabetes on physical functioning

Diabetes can negatively affect physical well-being in three major ways. The most important factor is the development of long-term complications like vision loss, kidney damage, peripheral neuropathy resulting in chronic pain, amputation, and/or difficulty walking. Other complications include sexual dysfunction, autonomic neuropathy problems, and acute conditions like ketoacidosis. The Pittsburgh Epidemiology of Diabetes Complications Study showed that patients with macrovascular disease or nephropathy reported significantly poorer QoL compared with those who were free from all complications, and that QoL significantly deteriorated according to the presence of multiple complications (Lloyd, Matthews, Wing and Orchard, 1992). The second factor is short-term complications and physical symptoms. Elevated blood glucose levels may lead to increased fatigue, sleep problems, and other associated problems. Tight glycemic control may lead to unwanted weight gain, hypoglycemia, and/or loss of hypoglycemic warning signs. The third major factor is the lifestyle changes resulting from the demands of the diabetes regimen. Polonsky (2000) suggests that to assess the impact of diabetes on physical functioning most effectively, evaluation should focus on a patient's perceived distress due to diabetes-specific symptoms as well as the perceived loss of physical function, interference with common activities and loss of independence due to diabetes. 
Impact of diabetes on psychological functioning

Diabetes care can have a short-term and long-term impact on mood of patients.

Frustration can emerge out of the fact that the disease may not seem to respond in spite of sincere efforts by patients. Cycles of elevated blood glucose levels and hypoglycemic episodes can be exhausting, and can worsen already dampened spirits. Depression is not generally listed as a complication of diabetes, but is widely prevalent in patients with diabetes. Lloyd and colleagues (1992) reported greater depressive symptoms in patients with macrovascular disease; greater number of complications were found related to higher depression symptom scores. There is some suggestion that the stress of depression may lead to neglect of diabetes care. Polonsky (2000) suggests that to assess this dimension, evaluation should focus on a patient's perceived emotional distress due to diabetes-related symptoms, self-care, and broader diabetes issues.

\section{Impact of diabetes on social functioning}

The management of diabetes itself poses many challenges to a patient, as this may necessitate changes in daily habits in order to manage the illness most effectively. For instance, some patients are embarrassed to check their blood glucose or inject insulin in front of others. For some, the requirement of meal planning may affect food choices at social events that may be different from family/friend preferences. Thus, a patient with diabetes may not receive all the cooperation from family and friends in social settings, be it home or outside of home. Polonsky (2000) suggests that to assess this dimension, evaluation should focus on a patient's perceived emotional distress due to diabetes-related social situations. 
Thus, diabetes has major psychosocial implications and it influences selfmanagement behavior in terms of diminished self-care, leading to worsened glycemic control in the long run. In this context, QoL assessments can play a role in predicting an individual's capacity to manage his or her disease and stay healthy in the long run (Rubin, 2000). Satisfactory diabetes control can be achieved when this interdependence between physical and psychological well being is addressed (Eiser \& Tooke, 1993).

The changing dynamics of the health care system have influenced how diabetes treatment is evaluated. With the emergence of managed care as a dominant influence on health care delivery, there is an increasing emphasis on assessing the costs associated with new and existing therapies and interventions. Health care planners are focusing on short-term patient outcome measures like QoL and functional health status and satisfaction with care. Patient assessed measures of health outcome are increasingly being used alongside traditional biomedical measures for the evaluation of treatment and management of diabetes (Garratt, Fitzpatrick \& Schmidt, 2002).

\section{Influence of Diabetes Treatment on Quality of Life}

As described earlier, diabetes and its complications can adversely influence QoL. In today's clinical practice, achieving better glycemic control is a therapeutic goal for both Type 1 and Type 2 diabetes patients. While the DCCT demonstrated that better glycemic control can decrease the prevalence of complications in patients with Type 1 diabetes, the UKPDS proved that these results were applicable to patients with Type 2 diabetes as well (UKPDS Group, 1999). Diabetes treatments focus on achieving better glycemic control, but these treatments itself can impose a burden on the patient and affect 
QoL (Rubin, 2000). Clinicians are becoming increasingly aware that maximizing their patients' QoL is an important measure of the effectiveness of health care (Weinberger et al., 1994).

Anderson and colleagues (1997) suggest not limiting the goals of diabetes care only to strict glycemic control, but also performing comprehensive assessments of the impact of glucose control regimens on health and QoL. Testa (2000) lists the following as areas on which the QoL literature on diabetes treatment has focused:

- The state of health of individuals with serious health complications associated with diabetes like renal failure, foot damage, blindness, and others

- Psychological considerations of impact of diabetes and treatment regimen

- Impact of newer dosage delivery systems, classes of drugs and treatment regimen. Research may be able to determine whether lifestyle changes required to improve glycemic control like and self-care behaviors (medication adherence, dietary restrictions, glucose self-monitoring, exercise, and others) adversely influence QoL or not. If such changes are not seen to be negatively influencing QoL, then this may be viewed positively by physicians who are concerned that a particular treatment may produce the required clinical benefits at the risk of compromising patients’ QoL (et al., 1994).

Alternatively, patients may find treatments intrusive in the immediate future and report adverse influence on QoL. If such patients perceive improvements in QoL in the future in the form of prevention of long-term complications, they may adhere to regimens and report no effect of intrusive regimens on their QoL (Weinberger et al., 1994).

In keeping with the observations of major studies like the DCCT and UKPDS on the relation between glycemic control and complications, it can be expected that better 
glycemic control may be associated with better QoL. Some researchers assume that QoL at the start of treatment influences metabolic control and vice versa; some studies report associations only in sub-populations of populations. In one such attempt, Weinberger and colleagues (1994) discussed the following possible relationships between glycemic control and QoL that could exist in patient populations seeking treatment for their diabetes:

1) With fewer hyperglycemic episodes and decreased rate of complications, patients with good glycemic control might report better quality of life.

2) With an added burden of complex regimens, along with more hypoglycemic symptoms, patients with good glycemic control might report negative impact on quality of life.

3) Patients with very good or very poor glycemic control may report relatively worse quality of life.

Thus, it is possible to think of several different ways in which QoL and glycemic control are related.

\section{Generic and Disease-Specific Instruments to Assess QoL}

Two broad categories of health-related QoL instruments have emerged - generic or global, and disease-specific measures. Generic QoL scales are designed to be used with any population regardless of the specific disease. Since they allow comparison across disease categories and illness groups, broad-based policy decisions can be made from generic QoL data (Anderson et al., 1997). However, the domains contained in 
generic measures may have little or no relevance to a specific patient group or disease entity in which they are intended to be used. Generic measures may also lack items or domains that are necessary to gain complete understanding of patients' QoL in that disease state. Generic measures offer the benefit of being applicable across disease categories, but this can be a disadvantage when specific disease categories and research questions particular to those diseases are being studied.

Rubin and Peyrot (1999) suggest that even a well-designed generic QoL scale may not be able to address some aspects of living with diabetes that strongly affect QoL, such as hypoglycemia, insulin injections, self-monitoring of blood glucose, and dietary restrictions. Rubin and Peyrot (1999) also state that generic measures may not be specific enough to detect effects in some areas of functioning, like the fear of diabetes-related complications that may influence mental health. The Medical Outcomes Study (MOS), which evaluated a generic measure of QoL, did not distinguish between the types of diabetes under study and did not examine the effects of complications or type of treatment (Jacobson, De Groot and Samson, 1994). Snoek (2000) has compiled a list of domains relevant to diabetes QoL: symptom distress, general physical functioning, mental/emotional state, social functioning, perceived burden of treatment regimen, treatment satisfaction, and an overall sense of well-being.

Jacobson, De Groot and Samson (1994) also provide suggestions for assessing QoL with multiple instruments that measure generic and illness-specific issues. If the primary goal is to compare the results of a particular study with those conducted on different illness populations, generic measures are valuable. If the purpose of QoL assessment is to study disease-specific problems, disease-specific instruments should be 
used. Since each measure may offer different information, it may be useful to incorporate both (Jacobson, De Groot and Samson, 1994).

In order to identify the factors most relevant to the QoL of people with a specific disease, disease-specific measures are being added to generic measures (Rubin\& Peyrot, 1999). However, Kaplan (1990) argues that biological variables are important only to the extent that they are associated with key patient behaviors and long-term outcomes such as physical and social functioning, hospitalization, and mortality.

\section{Generic Quality of Life Measures}

The Medical Outcomes Study Short-Form General Health Survey

One of the most widely used generic measures of QoL in studies of people with diabetes is the Medical Outcomes Study (MOS) Short-Form General Health Survey, or known as SF in short. The SF series numbers indicate the number of items that each SF health questionnaire contains. The instrument originally developed, the SF-36, consists of 36 questions covering eight dimensions of health status (Ware and Sherbourne, 1992). Shorter versions of the SF-36 have been developed. Ware, Kosinski, and Keller (1994) generated two summary scores from the SF-36: The Physical Component Summary Score (PCS) and the Mental Component Summary Scales Score (MCS). Ware, Kosinski, and Keller (1995) later developed the SF-12, a subset of 12 items of the SF-36. Different versions of the MOS Health Survey, commonly the SF-36, the SF-12, and the SF-8 (collectively referred to as the SF series), have been used in patients with a wide variety of illnesses and backgrounds. 
The developers of the SF series recommend that the instrument be used to assess outcomes of interventions, since the instrument is very sensitive to change. Generic measures like the SF series are most useful for comparing QoL in people with different diseases or the QoL in people who have no diseases with the QoL in people who have a disease (Rubin \& Peyrot, 1999). One study reported tight glycemic control to be associated with lower ratings on the various SF-36 scales (Nerenz, Repasky, Whitehouse \& Kahkonen, 1992). The SF-36 has been validated among people with Type 2 diabetes in general practice, with the finding that SF-36 scores were strongly affected by nondiabetic comorbidity (Woodcock, Julious, Kinmoth, and Campbell, 2001).

Other measures reported in the literature to assess general QoL in diabetes patients include:

World Health Organization Quality of Life Assessment (WHOQOL-100) (WHOQOL Group, 1998),

World Health Organization Quality of Life Assessment - Abbreviated Version (WHOQOL-BREF) (WHOQOL Group, 1998),

Duke Health Profile (Parkerson, et al., 1981), The Nottingham Health Profile (Hunt, McEwen \& McKenna, 1981), The Sickness Impact Profile (Bergner, Bobbitt, Carter, \& Gilson, 1981), and The Rand Quality of Well-Being Self-Administered survey (QWB-SA) (Anderson, Kaplan, Berry, Bush, \& Rumbaut, 1989). 


\section{Disease-Specific Quality of Life Measures}

Disease-specific scales focus on specific problems posed by a particular illness and reflect particular limitations or restrictions associated with specific disease states. They can include aspects of health considered by patients or clinicians to be of greatest importance. The targeted focus of disease-specific instruments has the potential to make them more responsive to changes in health. At this time, there are several measures that attempt to evaluate the many aspects of diabetes-specific QoL as defined earlier. Some of the different diabetes-specific QoL instruments are described below:

\section{The Diabetes Quality of Life Measure (DQOL)}

The DQOL is one of the more widely used instruments in the assessment of diabetes related QoL. The instrument was developed for use in the DCCT, in patients with Type 1 diabetes. Since the DCCT compared QoL of patients in intensive versus conventional therapy, it was felt that the demands imposed by the two types of treatment would lead to different levels of patient burden. The DQoL was hence developed to assess patients’ perceptions of impact and satisfaction with specific features of diabetes management. It has 46 items covering five dimensions: treatment satisfaction, treatment impact, worries about long-term complications, worries about social and vocational issues, and overall well being. Response to the items is on a 5-point Likert scale (Jacobson, Barofsky, Cleary and Rand, 1998). A 15-item DQOL Brief Clinical Inventory has been recently developed and tested (Burroughs, Desikan, Waterman, Gilin \& McGill, 2004). Only in Type 1 diabetes patients were both self-reported diabetes care behaviors 
and satisfaction with diabetes control predicted as effectively as the full version of the instrument.

In a review of health outcome measures for diabetes Garratt and colleagues (2002) state that this instrument has good evidence for reliability, and internal and external construct validity. The DQOL has been tested and validated in patients with Type 2 diabetes (Jacobson, De Groot and Samson, 1994). Others are of the view that the DQoL was designed specifically for Type 1 diabetics with intensive insulin treatment, and may have deficiencies with assessing the quality of life for persons with Type 2 diabetes (Mannucci, Ricca, Bardini \& Rotella, 1996). Jacobson, De Groot and Samson (1994) showed that the DQOL compared favorably to the SF-36, although the SF-36 was seen to be less sensitive to lifestyle issues such as diet or treatment.

\section{The Audit of Diabetes-Dependent Quality of Life (ADDQoL)}

The ADDQoL is an 20-item instrument that presents a comprehensive list of 18 life domains that diabetes might affect. It is applicable in both Type 1 and Type 2 diabetes (Bradley, Todd, Gorton, Symonds, Martin, and Plowright, 1999). Patients are asked to indicate, on a 7- point Likert scale, the degree to which each particular domain might be different "if I did not have diabetes". The respondent is allowed to indicate if an item is not applicable to them and should be dropped from consideration (et al., 1999). Having only 20 items, the measure does not require a great deal of time to administer. Garratt and colleagues (2002) state that this instrument has good evidence for reliability, and internal and external construct validity. Internal reliability as measured by Cronbach's alpha (0.85) is very good for this instrument (Bradley et al., 1999). 
Woodcock and colleagues (2001), who used the ADDQoL in conjunction with the SF-36, found that the SF-36 was strongly affected by non-diabetic comorbidity in patients with Type2 diabetes, supporting the complementary use of a diabetes-specific measure.

\section{Diabetes Care Profile (DCP)}

The DCP is a self-administered questionnaire that assesses the social and psychological factors related to diabetes and its treatment. The instrument contains 234 items and sixteen scales. These scales assess the patient's diabetes attitudes, diabetes beliefs, self-reported diabetes self-care, and difficulties with diabetes self-care. The DCP also contains questions concerning demographic information and self-care practices (Fitzgerald et al., 1996). With 234 questions and taking 30-40 minutes to complete, it is a long survey tool. Anderson and colleagues (1997) compared the DCP with the SF-36 and found good correlation between the two measures and the number of complications for patients who have Type 2 diabetes. The DCP has been reported as having predictive validity regarding glycemic control (Fitzgerald et al., 1996).

\section{The Appraisal of Diabetes Scale (ADS)}

The ADS aims to assess how a person with diabetes evaluates the disease and its impact. Instrument content is based on theory and previous research. The seven items use a five-point scale and measure control, uncertainty, coping, affect of diabetes on life goals, predictive view of diabetes and the degree of distress caused by diabetes. Carey and colleagues (1991) state that the ADS can be useful as a quick (five minute) screening 
tool to assess a patient's adjustment to diabetes or risk for noncompliance with a care regimen. Garratt and colleagues (2002) state that this instrument shows good reliability, validity, and test-retest analysis results. But the content validity of the instrument is questionable since it was developed without patient input.

\section{The Well-Being Enquiry for Diabetics (WED)}

The Well-Being Enquiry for Diabetics (WED) is a measure of disease-related quality of life intended for application in different clinical settings. The 50 items use a five-point scale and measure four dimensions: symptoms, discomfort, serenity and impact. These subscales were derived from an a priori categorization rather than from a statistical analysis. The questionnaire has been validated in both Type 1 and Type 2 diabetes patients (Mannucci et al., 1996).

Other diabetes-specific QoL measures reported in the literature are listed below: The Diabetes Impact Measurement Scale (DIMS) (Hammond \& Aoki 1992), The Diabetes-Specific Quality of Life Scale (DSQOLS) (Bott, Muhlhauser, Overmann \& Berger, 1998),

The Diabetes Health Profile (Meadows et al., 1996; Meadows, Abrams \& Sandbaek, 2000),

The Problem Areas in Diabetes Scale (PAID-1) (Polonsky et al., 1995), The ATT-39 (Dunn, Smartt, Beeney \& Turtle,1986), The Type 2 Diabetes Symptom Checklist (Grootenhuis, Snoek, Heine \& Bouter, 1994), and

The Diabetes -39 (D-39) (Boyer \& Earp, 1997). 


\section{Psychometric Properties of QoL Measures Used in the Study}

\section{The Medical Outcomes Study Short Form SF-12}

The SF-36, as a generic QoL measure, has gained popularity as a measure of outcome in a wide variety of patient groups and social surveys. The questionnaire contains 36 questions covering eight dimensions of health status, shown in Table 3.

In addition to those above domains, the instrument has one self-reported health transition item. In an effort to reduce the SF-36 from an eight-scale profile described above without major loss of information, Ware, Kosinski, and Keller (1994) used data from the Medical Outcomes Study to generate two summary scores from the SF-36: The Physical Component Summary Score (PCS) and the Mental Component Summary Scales Score (MCS). Consequently, Ware, Kosinski, and Keller (1996) suggested a subset of 12 items obtained from the SF-36 and christened the instrument as the 'SF-12'. The SF-12 has 12 items in common with the SF-36, covering eight domains as displayed in Table 4.

Rationale for Choosing the SF-12: A Comparison of the SF-12 and the SF-36

Although the SF-36 has proved to be a versatile instrument to assess general QoL, it is considered long for inclusion in some large-scale health measurement and monitoring efforts (Ware, Kosinski and Keller, 1996). Shorter measures can reduce the respondent burden, but in doing so, it is important to balance the number of questionnaire items against other important considerations like comprehensiveness of content and the statistical precision of the scores (Ware, Kosinski, and Keller, 1996). 
The SF-12 was able to produce the two summary scales developed from the original SF-36 with considerable accuracy, yet with far less respondent burden. PCS and MCS scores calculated from the SF-36 and the SF-12 were almost identical. When regression methods were used to select and score 12 items of the SF-36, the 12 items predicted more than $90 \%$ of the variance in the PCS and MCS scores of the original SF36 (Ware, Kosinski, and Keller, 1996). Test-retest correlations of 0.89 and 0.76 were observed for the 12-item PCS and MCS respectively. Correlations between SF-12 and SF-36 versions of the PCS and MCS were 0.951 and 0.969 respectively, while the testretest reliability were 0.890 and 0.760 respectively (Ware, Kosinski, and Keller, 1996).

In another study, it was found that the level of change detected by the summary scores of the SF-12 was the same as gained from the longer form instrument (Jenkinson et al., 1997). Average scores for the two summary measures in the SF-12 closely mirrored those for the SF-36. The summary scores may make trial and other longitudinal data sets more easily interpretable due to the reduction of the number of statistical comparisons from eight to two (Ware, Kosinski and Bayliss, 1995). Thus, the validity, practicality and suitability of the SF-12 as a shorter form measure for the assessment of the summary scales in longitudinal studies was demonstrated. Studies have indicated favorable psychometric properties including the internal consistency and construct validity of the SF-12 subscales. Jenkinson and colleagues (1997) caution that the summary scores gained from the SF-12 are not identical to those gained from the SF-36. However, this difference is small and the developers of the original instrument have stated that such small differences are not meaningful either subjectively or clinically 
(Ware, Snow, Kosinski, and Gandek, 1993). Ware, Kosinski, and Keller (1996), however recommend not producing an eight-scale summary from the SF-12. 
Table 3: Domains of the Medical Outcomes Study Short Form SF-36

\begin{tabular}{lc}
\hline SF-36 Domain & Number of items representing the domain \\
& \\
\hline Physical functioning & 2 \\
Social functioning (2 items) & 2 \\
Pain (2 items) & 5 \\
General health perception (5 items) & 5 \\
Mental health (5 items) & 4 \\
Energy/vitality (4 items) & 3 \\
Role limitations due to emotional problems (3 items) & 4 \\
Role limitations due to physical problems (4 items) & \\
\hline
\end{tabular}


Table 4: Domains of the Medical Outcomes Study Short Form SF-12

\begin{tabular}{lc}
\hline SF-12 Domain & Number of items representing the domain \\
\hline Physical functioning & 2 \\
Social functioning (2 items) & 1 \\
Pain (2 items) & 1 \\
General health perception (5 items) & 1 \\
Mental health (5 items) & 2 \\
Energy/vitality (4 items) & 1 \\
Role limitations due to emotional problems (3 items) & 2 \\
Role limitations due to physical problems (4 items) & 2 \\
\hline
\end{tabular}




\section{The Audit of Diabetes-Dependent Quality of Life}

\section{Description}

The Audit of Diabetes-Dependent Quality of Life (ADDQoL) is a 20-item scale that presents a comprehensive list of 18 life domains that diabetes might affect for patients with diabetes (Table 5). Two additional items report estimates of overall quality of life, comparing life with and without diabetes.

\section{Instrument Design}

The design of the ADDQoL is influenced by the development of the Schedule for the Evaluation of Individual Quality of Life (SEIQoL), an interview-based approach to QoL measurement. The SEIQoL method involved asking the respondents to generate domains of life that are important to them, evaluate how good or bad each aspect was currently felt to be, and indicate the importance of each for their own QoL. Since respondent-generated domains may be more feasible in face-to-face interviews, an approach of providing domains was felt to be more practical, with an option of excluding domains when not applicable. This approach was adapted to address diabetes-specific issues and presented in a questionnaire format, resulting in the creation of the initial 13domain ADDQoL.

The ADDQoL attempts to evaluate diabetes-specific quality of life from an attributional perspective (how diabetes may be perceived as interfering with well-being). In contrast, the majority of the other scales assess QoL from an intrinsic perspective (how the different aspects of diabetes may be perceived as burdensome). Rather than asking about the degree to which problems associated with diabetes are occurring, this scale asks 
patients to imagine how life might be different without diabetes and compares it to their current QoL with diabetes. This is a more complex task, one step removed from direct questions about diabetes-specific quality of life (Polonsky, 2000). One advantage of this approach is that it allows respondents to indicate how diabetes may be having a positive effect in certain domains. Bradley and colleagues (1999) assert that none of the other diabetes specific QoL measures allow the patient to indicate

1) which domains of life apply to them, and

2) the perceived importance of each domain for their QoL.

Respondents rate how diabetes impacts individual domains on a seven-point scale (the impact rating), as well as how important the individual domains are to their QoL (the importance rating), on a four-point scale. A 'not applicable’ (N/A) option is provided for domains that may not be applicable to a given individual. Impact ratings when multiplied by the respective importance ratings yield scores ranging from -9 to 9 for each domain. An average weighted impact score is derived by summing the weighted impact scores for each domain and dividing the number of applicable domains. Thus, the patient's 18 scores can then be arithmetically weighted, such that the total score is more strongly influenced by those domains that a patient has selected as being most important.

The authors of the ADDQoL have given consideration to face or content validity in instrument development. Patients and diabetes experts were involved in the generation and confirmation of items. 
Table 5: Domains of the Audit of Diabetes Dependent Quality of Life

\begin{tabular}{cc}
\hline Item Number & Domain that the Item Represents \\
\hline 1 & Working life \\
2 & Family life \\
3 & Social life \\
4 & Sex life \\
5 & Physical appearance \\
6 & Physical activities \\
7 & Holidays/ leisure \\
8 & Travel \\
9 & Confidence in ability \\
10 & Motivation \\
11 & Society reaction \\
12 & Future \\
13 & Finances \\
14 & Dependence \\
15 & Living conditions \\
16 & Freedom to eat \\
17 & Enjoyment of food \\
18 & Freedom to drink \\
\hline
\end{tabular}




\section{Psychometric properties}

In the developer's published study on ADDQoL, Bradley and colleagues (1999) have reported the following results for the 13-domain (15-item) ADDQoL:

- Factor analysis revealed the existence of one factor when subjected to a forced one-factor solution, suggesting that all items were associated together on this single factor.

- All the domain-specific ADDQoL items were relevant and important for a substantial number of the respondents.

- Insulin users reported significantly greater negative impact of diabetes on most domains than those not using insulin.

- People with complications of diabetes reported greater negative impact of diabetes on their quality of life than people without complications. The mean weighted average ADDQoL score correlated significantly with the number of reported complications (Spearman $\mathrm{r}=-0.2141$, $\mathrm{p}<0.005$ ).

- People reporting higher frequency of unacceptable hypoglycemia had greater QoL impairment.

- The diabetes specific ADDQoL score was predicted to be more sensitive to change and responsive to subgroup differences than a generic instrument. The rationale stated was that diabetes would have a greater reported impact on diabetes specific domains of the ADDQoL such as enjoyment of food, worries about the future and travel, than on standard QoL domains such as work, social life, friends and family. 
Bradley and Speight (2002) in their DIABQoL+ study, have reported the following results in the development paper for the 18-domain (20-item)ADDQoL:

- As in the previous study, forced one-factor analysis revealed that all 18 items loaded greater than 0.5 on one factor, indicating that the 18-item scale is highly reliable.

- The Diabetes Treatment Satisfaction Questionnaire (DTSQ), used along with the ADDQoL in this study showed high satisfaction with treatment even as the weighted ADDQoL scores were reported to be largely negative. Thus, the instrument was able to report negative influence of diabetes on QoL even as satisfaction with the treatment was found to be high.

\section{Subsequent Studies}

The DAFNE Study Group (2002) studied whether a course teaching flexible intensive insulin treatment combining dietary freedom and insulin adjustment can improve both glycemic control and QoL in patients with Type I diabetes. They used the ADDQoL to measure QoL changes due to an educational program. A QoL difference was not apparent after six months in the program, but became significantly improved after one year (DAFNE Study Group 2002).

\section{Reliability and validity of the ADDQoL}

Reliability for the ADDQoL was assessed by Bradley and colleagues (1999), revealing a Cronbach's coefficient of 0.85 . This, along with the results of the forced one-factor factor analysis, provided support for combining the weighted items into a 
single ADDQoL score. As a measure of the construct validity of the measure, insulindependent subjects generally scored lower (=greater impact) on the ADDQoL than noninsulin-dependent subjects, and patients with diabetes complications reported significantly greater negative impact of diabetes on QoL than did those without complications (Bradley et al., 1999 and Bradley and Speight, 2002).

Rationale for choosing the ADDQoL

Wildes, Greisinger and O'Malley (2003) have performed a critical assessment of twenty-four QoL measures for patients with diabetes. They have recommended the use of the ADDQoL in diabetes QoL assessments, describing it as a brief and recent instrument with good reliability and generated with patient input. Support for the psychometric properties of the ADDQoL has been discussed earlier in this report.

In summarizing the properties of other well known diabetes-specific instruments, Wildes, Greisinger and O’Malley (2003) describe the DQoL as having low to good internal consistency reliability, and good test-retest reliability. They also note that the DQoL is not a recent measure, is slightly long, and does not have strong evidence of validity, in comparison to the other measures studied. In a review of health outcome measures for diabetes, Garratt and colleagues (2002) state that this instrument has good evidence for reliability, and internal and external construct validity. It is useful for both insulin-dependent and non-insulin-dependent subjects. It allows the subject to judge the relevance or importance of each item and to eliminate non-relevant or non-important items from consideration before calculating the final weighted score. 
In summary, some of the considerations that went into the choice of the ADDQoL as the diabetes-specific measure for the proposed study were its psychometric properties (including good internal reliability, good face validity and construct validity), and low respondent burden. The measure is designed for both Type 1 and Type 2 diabetes patients although only Type 2 patients will be enrolled in the proposed study.

\section{Rationale for the Combination of Instruments Used}

The rationale behind the individual choice of the SF-12 and the ADDQoL has been explained in earlier sections. Woodcock and colleagues (2001) validated the SF-36 among people with Type 2 diabetes in general practice, and made comparisons with the ADDQoL. They reported that SF-36 dimension scores correlated best with relevant diabetes-specific ADDQoL scores among respondents reporting no comorbidity. They concluded that SF-36 scores are strongly affected by non-diabetic comorbidity in type 2 diabetes, supporting the complementary use of a diabetes-specific measure. They suggested that sociodemographic and health variables be considered when comparing the SF-36 scores with the ADDQoL scores.

While SF-36 scales have been found to be highly reliable given the extensive use of this instrument, the ADDQoL is a relatively new measure providing a measure of individualized QoL, and the SF-12 is increasingly being used alongside other diseasespecific measures. Published research has reported good reliability for these two instruments, as described in an earlier section. 


\section{A1C levels and Quality of Life}

One of the traditional outcome focuses of most clinical investigations of diabetes is glycemic control. Researchers are increasingly studying psychosocial variables including QoL, utilizing various available measures along with measuring clinical outcome variables. This added focus evolved with speculation that controlling glucose levels might do more than prevent acute, life-threatening events. Since the DCCT advocated more aggressive management of diabetes, there was need to address the potential negative psychosocial effects of such intrusive treatment, while realizing the importance of such measures and their role in therapy.

In an effort to examine the effect of intensive versus conventional diabetes treatment on the emotional state of patients in greater depth, the DCCT group incorporated multiple indices of QoL. They included a diabetes-specific measure called Diabetes Quality of Life index (DQoL), the Symptom Checklist-90R (SCL-90R), the SF36, and a psychiatric event rate indicator, called intercurrent psychosocial events (The DCCT Research Group, 1996). As mentioned earlier, the DQoL was developed for use in the trial. The conclusion was that patients treated intensively with the goal of achieving glycemic control as close to normal as possible did not face deterioration in QoL. One reason proposed was that the increased stress associated with intensive diabetes management may have been countered by a sense of well-being derived from improved glycemic control. On the other hand, the measures used in the study may not have been sufficiently sensitive to group differences to detect clinically meaningful changes in QoL. Barring the DQoL, none of the measures used were diabetes-specific. 
In contrast to the DCCT findings on the relationship between glycemic control and QoL, a study on adolescent patients with Type 1 diabetes found significant correlation between the total score on the DQoL and A1C levels, leading to the conclusion that adolescents in better metabolic control reported better QoL (GuttmannBauman, Strugger, Flaherty, \& McEvoy, 1998). Two types of A1C levels were employed in the study: single A1C (value at the time of the study) as a measure of short-term control, and mean A1C (in the year preceding the visit) as a measure of long-term control. While both were correlated with quality of life, mean A1C level over a year correlated more strongly with the DQoL assessment.

Several other studies have described cross-sectional relationships between glycemic control and/or symptoms, and well-being or QoL in patients with Type 2 diabetes. As in patients with insulin-dependent diabetes, patients with Type 2 diabetes also benefit from optimization of metabolic control by resultant reductions in risks of long-term complications. Van der Does and colleagues (1996) concluded that higher A1C levels were significantly associated with higher symptom scores, with worse mood, and with worse general well being. Symptom scores were reported in the form of a hyperglycemic score, a neuropathic score and a total score of the Type 2 Diabetes Symptom Checklist (DSC-Type 2), while mood scores were reported using the Profile of Mood States (POMS) and the Affect Balance Scale (ABS) was used to describe general well-being. De Sonnaville and colleagues (1998) have assessed well being and symptoms in Type 2 diabetes patients on insulin therapy. As with the results of the DCCT, insulin therapy was found to improve glycemic control, but with little influence on the physical and psychological well being dimensions studied. 
The UKPDS Group (1999) used two cross-sectional studies and one longitudinal study of patients with Type 2 diabetes to determine the effects of therapies for improving glycemic control on QoL. The first cross-sectional study used domain-specific questionnaires including the Profile of Mood State, Cognitive Failures Questionnaire, and other measures for symptoms and work satisfaction. The second cross-sectional study used the EQ5D, a generic QoL questionnaire, while the longitudinal study used the domain-specific questionnaires indicated above. The results showed that there were no detectable differences in QoL between patients allocated to different therapies in the UKPDS in the three sub-studies indicated above, leading to the conclusion that the therapies could be given according to clinical requirements without concerns about the negative impact on quality of life.

Weinberger and colleagues (1994) also studied the relationship between glycemic control (represented by A1C levels) and QoL (using the SF-36) in patients with Type 2 diabetes in a Veteran's Administration general medical clinic. Controlling for important covariates defined a priori, no correlation was found between A1C levels and QoL, both cross-sectionally, and longitudinally, over a period of one year. The researchers suggested that this lack of association could explain the high non-compliance rates among patients who were prescribed complex regimens. This lack of association may have occurred due to the use of the SF-36, a QoL measure, or due to the nature of the study population, with a high prevalence of diabetes-related complications skewing the results. They concluded that it was important for patients to perceive a benefit from following diabetes regimens in order to achieve good glycemic control, especially in patients with a long duration of the disease. 
Reporting tight glycemic control to be associated with lower ratings on the various SF-36, Nerenz and colleagues (1992) attributed this result to a complex combination of demographic and medical variables rather than to the complexity of the treatment regimen.

\section{Evaluation of A1C Levels in Diabetes Management Programs}

The impact of glycemic control on patient-reported outcomes such as QoL in clinical trials has been discussed in the preceding section. In a similar manner, the impact of chronic care clinics (or diabetes clinics, in this case), and diabetes management interventions can be analyzed. In the assessment of effects of an intervention, it is useful to use outcome measures like the patients' QoL, in addition to physiological and anatomical markers of disease progression. Assessment of QoL in an intervention should focus on the patient's illnesses and treatment experiences, by including patients' satisfaction with treatment, and other domains influencing QoL (The DCCT Research Group, 1996). This outcome is as important as glycemic control in comprehensively evaluating new treatment approaches for patients with diabetes.

In an era of tighter health care budgets, reimbursement issues and financing crises, a great deal of attention is being devoted to health and economic outcomes assessments of new therapies and interventions. Quality of Life evaluation can make important contributions to diabetes treatment effectiveness evaluations. Testa (2000) is of the view that QoL can also help compare diabetes specialty care with non-specialty care in terms of the overall health outcomes they produce. 
Glasgow and Osteen (1992) used published studies from Brown’s (1992) meta analysis to state that studies performed in the setting of diabetes management programs research have consistently reported on three outcomes: (1) Demographic characteristics of the final participating sample, (2) changes in knowledge, and (3) A1C levels or mean levels of blood glucose. In their observation, physiological outcomes that have most often been measured are: A1C levels (53\% of all studies), mean blood glucose levels (50\%) and, weight (59\%).

Glasgow and Osteen (1992) conclude that published literature on diabetes education program evaluations have focused too narrowly on assessing knowledge and A1C outcomes to the exclusion of other important health outcomes like patient functioning and QoL. They provide several suggestions about critically important outcomes that either have been completely ignored in the evaluation of diabetes education programs, or have been included very infrequently. These are:

- Social and environmental context: impact of health insurance status and social status;

- Patient characteristics: demographic and medical variables of the target population in addition to those of the final sample; rate of participation among the eligible patients and characteristics of those electing versus those declining to participate; attrition rates and characteristics of drop-outs versus those who completed the program; and characteristics of patients who do well in the program versus those who do not; and

- Short-term health outcomes: patient functioning and quality of life assessments (only 1 out of the 59 published studies included in Brown's (1992) meta analysis 
reported on QoL outcomes); coronary risk factor outcome measures like cholesterol, blood pressure; smoking status; utilization measures like number of diabetes-related emergency room visits and overnight hospital stays; and diabetes complications.

\section{Other Factors Influencing Quality of Life}

In order to explain the factors that influence QoL in patients with diabetes, researchers have used different kinds of variables. These include demographic characteristics, clinical values, and indicators of health status.

Using the SF-36, Lloyd, Sawyer and Hopkinson (2001) reported the significant impact of clinically diagnosed diabetes complication on QoL. Jacobson, De Groot and Samson (1994) found that DQoL scores as well as the SF-36 scores were lower in diabetes patients with greater severity of complications. In the same study, they reported greater impact of diabetes on QoL due to insulin treatment in a population consisting of patients with Type 1 and Type 2 diabetes. The DCCT Research group (1996) found no impact of intensive treatment using insulin, on QoL represented by DQoL scores. Other researchers have considered the type of treatment that diabetes patients were on, including the use of oral medications, insulin, or simply diet and exercise (Glasgow, 1997; Jacobson, De Groot and Samson, 1994).

Similarly, the impact of cormorbid health status and past history of medical conditions in patients with diabetes have been assessed for their impact on QoL (Van der Does et al., 1996; Glasgow et al., 1997; Kerr, Smith, Kaplan and Hayward, 2003). Kerr 
and colleagues (2003) used an administrative database to determine the number of outpatients visits and specific comorbid conditions, in order to account for the influence of the health status of patients with diabetes on their QoL. Some of the other variables considered by researchers include the number of previous hospitalizations (Glasgow et al., 1997), BMI (Van der Does et al., 1996; Lloyd, Sawyer and Hopkinson, 2001) and duration of diabetes (Van der Does et al., 1996; Glasgow et al., 1997).

The methodology employed in the study is discussed in the next chapter. 


\section{CHAPTER THREE: STUDY METHODOLOGY}

\section{Study Setting}

The West Virginia University Diabetes Institute (WVUDI) is a collaborative effort to standardize outpatient diabetes education and care imparted by the department of Family Medicine and the Physician Office Center’s Medical General Practice (MGP) and Endocrinology clinics. While the department of Family Medicine sees patients of all ages including children, the MGP and Endocrinology clinics provide care for patients older than 18 years of age. At the time of designing the study in July 2004, Family Medicine had an annual patient enrollment of around 11,500 (12, 263, as of Februrary 2005), with approximately 18 physicians (not including residents) in the last 12 months, of which 1,100 patients had Type 1 or Type 2 diabetes. During the same period, MGP with 17 physicians had a patient enrolment of around 8,000, of which 3,300 had Type 1 or Type 2 diabetes.

The WVUDI plans to introduce a guidelines-based care program called Staged Diabetes Management (SDM) in the WVU Hospital outpatient clinics. SDM was developed by diabetes professionals at the International Diabetes Center (IDC), which is based in Minneapolis, MN, USA. WVU researchers successfully competed for a development grant from the IDC for conducting research on the effectiveness of the SDM program. Prior to introduction of SDM, a baseline quality-of-care review is being conducted in the process of meeting the grant obligations. For this purpose, patients with Type 2 diabetes were being recruited by the WVU Hospital's Office of Medical Staff 
Affairs. On a separate group of patients, this study provided an assessment of the relationship between QoL and clinical outcomes of these patients, prior to the implementation of the SDM care algorithm.

\section{Study Design}

The study was a cross-sectional, descriptive study of QoL in persons with Type 2 diabetes at the WVU outpatient clinics. The study was observational in nature, in which the variables of interest in the study, described earlier, were measured at a single time period. QoL and demographic variables were measured using a self-report questionnaire booklet (measures booklet), while the respective medical history data of the participants were obtained from the hospital's electronic medical records. These variables were collected in order to examine the nature of associations between the QoL of patients attending the clinics, and their medical history indicators, and demographic characteristics.

\section{Sampling Design and Patient Recruitment}

As mentioned in a previous section, WVUDI has a combined diabetes patient population of approximately 4, 400 patients had Type 1 or Type 2 diabetes in the three different clinics. For the purpose of this study, an individual from the WVU Hospital's Office of Medical Staff Affairs (OMSA) served as a coordinator for identifying patients with Type 2 diabetes from the WVU hospital's medical records, while maintaining 
HIPAA compliance. There was a separate effort on the part of the OMSA to contact around 250 patients with Type 2 diabetes for obtaining baseline information prior to the introduction of SDM.

Since one of the major objectives of the present study was to assess the relationship between A1C and QoL, it was necessary that A1Cs used in the study be done within the past 90-120 days to provide a temporally associated reflection of their level of glycemic control at the time of QoL assessment. The protocol of the present study did not include taking a separate measurement of A1C for each participating patient but relied on available medical records. Hence, an inclusion criterion was to only sample patients who had an A1C performed anytime in the previous 90-120 days from the date of assessment of QoL. With an anticipated date of commencement of mailing as the last week of October 2004, it was decided to target the whole population of patients with Type 2 diabetes who had at least one A1C performed as of July 1, 2004. Records available from the OMSA indicated 989 such patients.

At the time of designing the study, a decision had been made to obtain the support of those physicians who patients met the study criteria, and have them endorse the study in writing to their patients. Records were updated, to identify the physicians who were currently responsible for the care of each patient among the target population of interest. Once the population was identified, the clinic physicians providing care to these patients were contacted and informed about the purpose of the research. A few of the physicians had ceased working for WVUH, and in some cases, referrals of patients to other physicians had been made. In all these cases, the names of physicians were updated and the letters of endorsement were obtained, in which the physician's signature was affixed 
to a personalized letter addressed to individual patients. Eleven physicians in the department of Family Medicine, 14 from MGP, and three from Endocrinology signed the letters, which were printed on OMSA letterhead. Three physicians did not participate and their patients were excluded from the study. This brought the population of patients with Type 2 diabetes available to be contacted, and who met the inclusion criteria, to 869 .

The mailing commenced in the first week of November 2004. The following items were included:

- A personalized, signed cover letter from the patient's specific physician, explaining the purpose of the study and providing the contact information of the research investigators of the current study, and the co-investigators at OMSA (see Appendix A);

- A measures booklet containing the SF-12, ADDQoL, and additional measures used by other collaborating investigators (see Appendix B). The booklet also included measures for data collected by other investigators on the protocol. These other measures are beyond the scope of this study and will not be discussed; and - A postage-paid envelope addressed to OMSA.

Patients were given instructions to return the questionnaire packet to OMSA. Follow-up reminder post cards were sent two weeks after the commencement of the mailing (see Appendix C). Booklets were sent a second time to patients who responded to the reminder cards and requested an additional copy. In order to reduce the burden on volunteered time of a very busy OMSA staff, there were no additional follow-up mailings. The co-investigators at OMSA coordinated the collection process of patient responses with the clinical and medical history values to be used in the study. 


\section{Data and Measures}

The use of the various kinds of variables in explaining QoL of patients with diabetes has been explaining in Chapter 2. In this study, three categories of variables were collected: QoL, demographics, and medical history and disease severity.

\section{QoL Variables}

The impact of diabetes on QoL among the participating patients with Type 2 diabetes was evaluated using the SF-12 and the ADDQoL. The psychometric properties of these measures, as well as the rationale for their inclusion in this study, have been described in Chapter 2.

Scoring the ADDQoL

The ADDQoL consists of two overview items designed for audit purposes: generic ‘present QoL’ and diabetes-specific ‘impact of diabetes on QoL’. The instrument has an additional 18 items that concern the impact of diabetes on specific aspects of life, of which three have a 'not applicable' (NA/) option [see Appendix A]. The instrument, in the first step, requires respondents to rate the impact of diabetes on applicable domains (part 'a' of an item) on a scale -3 (maximum negative impact) to +3 (maximum positive impact). Domains with responses indicated as N/A were excluded from the scoring for that individual. In the second step, respondents rate the importance of those domains for their QoL (part 'b' of an item) on a scale 3 (very important) to 0 (not at all important). The necessary steps to convert the responses obtained on the ADDQoL into QoL scores were sent by the instrument's developers at the time of obtaining the license to use it. The 
scoring algorithm is also summarized in the published work of the developers (Bradley, Todd, Gorton, Symonds, Martin, and Plowright, 1999).

In the first step towards scoring the ADDQoL, responses recorded in the data set were recalibrated to reflect the impact of diabetes on QoL, as depicted in Tables 6 and 7. Impact ratings are multiplied by the corresponding importance rating to provide a weighted-impact score for each domain from -9 (maximum negative impact) to +9 (maximum positive impact). Weighted impact scores are summed and divided by the number of applicable domains, to give a final Average Weighted-Impact (AWI) score, as summarized in Table 8. Thus, the ADDQoL scoring ignores non-applicable (N/A) domains and gives greater emphasis to domains of greater importance to the individual. The summary of scoring is shown in Table 8. 
Table 6: Format of the Two Overview Items of the ADDQoL Showing Scores Assigned in Parentheses

I) In general, my present quality of life is:
$\mathrm{O}$
$\mathrm{O}$
$\mathrm{O}$
$\mathrm{O}$
$\mathrm{O}$
$\mathrm{O}$
$\mathrm{O}$

excellent

very good

good

neither good

bad very bad

extremely nor bad

bad

(3)

(2)

(1)

(0)

$(-1) \quad(-2)$

$(-3)$

II) If I did not have diabetes, my quality of life would be:

$\begin{array}{ccccccc}\text { O } & \mathrm{O} & \mathrm{O} & \mathrm{O} & \mathrm{O} & \mathrm{O} & \mathrm{O} \\ \text { very } & \text { much } & \text { a little } & \text { the } & \text { a little } & \text { much } & \text { very } \\ \text { much } & \text { better } & \text { better } & \text { same } & \text { worse } & \text { worse } & \text { much } \\ \text { better } & & & & & & \text { worse }\end{array}$

$(-3)$

$(-2)$

$(-1)$

$(0)$

(1)

(2)

(3) 
Table 7: Format of the Domain-Specific Items of the ADDQoL Showing Scores Assigned in Parentheses

1a) If I did not have diabetes, my working life and work-related opportunities would be:

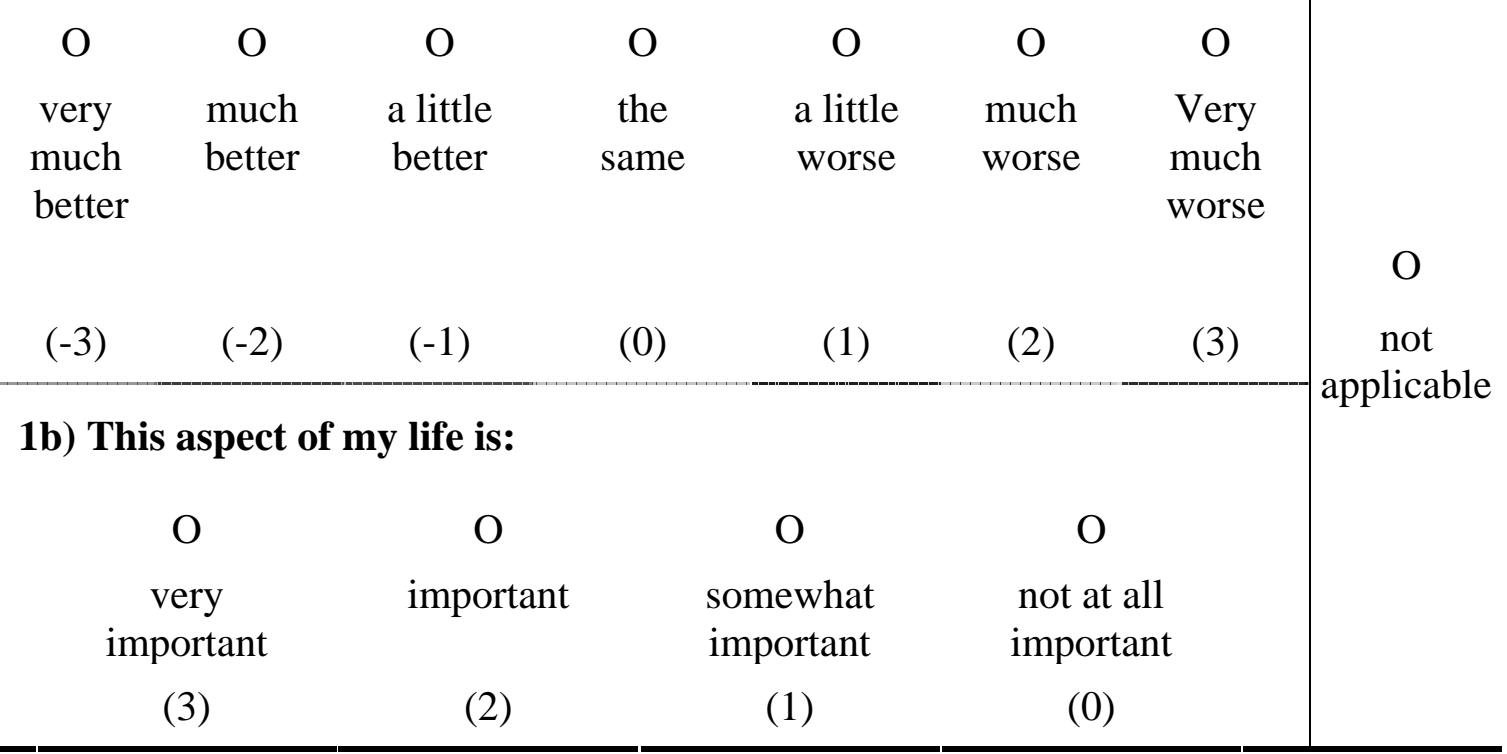


Table 8: Summary: Scoring Specific Domains in the ADDQoL

\begin{tabular}{|c|c|c|}
\hline Weighted ratings & $=$ & $\begin{array}{l}\text { [unweighted rating }(-3 \text { to }+3) \text { ] x ]importance rating ( } 0 \text { to } 3) \\
\text { for each domain] }\end{array}$ \\
\hline & & $\begin{array}{l}\text { Unimportant domains score } 0 \text {, regardless of magnitude of effect } \\
\text { of diabetes. Domains unaffected by diabetes score } 0 \text {, regardless } \\
\text { of their importance for QoL. Any non-applicable domains are } \\
\text { not scored. }\end{array}$ \\
\hline ADDQoL score & $=$ & $\frac{\text { Sum of weighted ratings of applicable domains }}{\mathrm{N} \text { of applicable domains }}$ \\
\hline Scores vary from: & & -9 (maximum negative impact of diabetes) \\
\hline to: & & +9 (maximum positive impact of diabetes) \\
\hline
\end{tabular}


Since the ADDQoL includes a number of different life domains that may be variously impacted by diabetes and of varying importance for overall QoL, missing data were left as missing. Hence missing data for a domain would not contribute to the weighted impact score for that domain, and this would be reflected in the number of domains to be included to calculate the final AWI score. Since the instrument provides the N/A option only for select life-domains, respondents may have chosen not to respond to some other domains in part a) at all since there was no N/A option provided for them. In such a case, imputing for missing data would have meant imputing a value for a domain that a patient did not consider applicable to the impact of diabetes on his QoL. Imputing in the above scenario may not have been a problem if the patient had indicated in part b) that the domain was not at all important to his life, because the weighted impact would eventually be zero. In the end, ADDQoL AWI scores could be calculated for 385 patients.

Scoring the SF-12

The necessary steps to convert the responses obtained on the SF-12 into QoL scores were obtained from the SF-12 scoring manual (Ware, Kosinski, Bowker and Gandek, 2002). The SF-12 consists of a subset of 12 items from the longer generic QoL measure, the SF-36. Two of those items had a 3-point Likert scale, while the remaining ten items had a 5-point Likert scale (See Appendix A). Recoding of some of the items was needed for similar reasons as was done for the ADDQoL. In the case of the SF-12, four such items were recoded such that a higher value indicated better heath on all SF-12 items. 
As has been explained in a previous section, the 12 items of the SF-12 represent eight domains. After item recoding, a raw score was computed for each domain. This raw score is the simple algebraic sum of responses for all items in that domain, as shown in Table 9.

The next step involves transforming each of the eight raw domain scores to a 0 100 scale using the formula shown below:

Transformed scale $=$

[(Actual raw score-lowest possible raw score) / Possible raw score range] * 100

In the next step, the eight raw domain scores were standardized using a z-score transformation using means and standard deviations (SD) of the respective SF-12 domains as obtained from a 1998 U.S. general population (See Table 10). A z-score for each domain is computed by subtracting the 1998 general U.S. population mean from each SF-12 domain score (on a 0-100 scale) and dividing the difference by the corresponding domain SD (on a 0-100 scale) from the 1998 general U.S. population. 
Table 9: Calculating SF-12 Raw Domain Scores from the Recoded Items

\begin{tabular}{lcc}
\hline SF-12 Domain & Contributing items & $\begin{array}{c}\text { Lowest and highest } \\
\text { possible raw scores }\end{array}$ \\
\hline Physical Functioning (PF) & & 2,6 \\
Role Physical (RP) & Items 2a+2b & 2,10 \\
Bodily Pain (BP) & Items 3a+3b & 1,5 \\
General Health (GH) & Item 5 & 1,5 \\
Vitality (VT) & Item 1 & 1,5 \\
Social Functioning (SF) & Item 6b & 1,5 \\
Role Emotional (RE) & Item 7 & 2,10 \\
Mental Health (MH) & Items 4a+4b & 2,10 \\
\hline
\end{tabular}


Table 10: Calculating SF-12 Standardized Domain Scores from Raw Domain Scores

SF-12 Domain Z score

Physical Functioning Z-score (PF_Z)

Role Physical Z-score (RP_Z)

Bodily Pain Z-score (BP_Z)

General Health Z-score (GH_Z)

Vitality Z-score (VT_Z)

Social Functioning Z-score (SF_Z)

Role Emotional Z-score (RE_Z)

Mental Health Z-score (MH_Z)
Formula for Z-score

PF_Z $=(\mathrm{PF}-81.18122) / 29.10558$

RP_Z $=(\mathrm{RP}-80.52856) / 27.13526$

BP_Z $=(B P-81.74014) / 24.53019$

GH_Z $=(\mathrm{GH}-72.19795) / 23.19041$

VT_Z $=(V T-55.59090) / 24.84380$

SF_Z $=(S F-83.73973) / 24.75775$

RE_Z $=(\mathrm{RE}-86.41051) / 22.35543$

MH_Z $=(\mathrm{MH}-70.18217) / 20.50597$ 
After z-scores were computed for each of the eight domains, aggregate scores for the physical and mental health summary measures were calculated (See Table 11). In doing so, each of the eight domains contributes to a different extent towards both summary measures, depending on a physical factor score coefficient for the domain on the summary measure.

In the final step, the aggregate physical and mental health summaries were transformed to the norm-based $(50,10)$ scoring $(\mathrm{NBS})$. This method entials performing linear transformation of scores to achieve a mean of 50 and a SD of 10 in the general U.S. population, for both the physical and mental health summary measures, as shown in Table 12.

For the sake of consistency, missing data on the SF-12 were left as missing. All the above procedures resulted in final PCS and MCS scores being obtained for 348 patients. 
Table 11: Calculating SF-12 Aggregate Physical and Mental Summary Scores from SF-12 Standardized Domain Scores

\section{SF-12 Aggregate summary score Formula}

\begin{tabular}{|c|c|}
\hline Aggregate Physical & $($ PF_Z * 0.42402) $+($ RP_Z * 0.35119) $+($ BP_Z * 0.31754) + \\
\hline Summary scores (AGG_PHYS) & $\begin{array}{l}\left(\mathrm{GH} \_\mathrm{Z} * 0.24954\right)+\left(\mathrm{VT} \_\mathrm{Z} * 0.02877\right)+\left(\mathrm{SF} \_\mathrm{Z} *-0.00753\right)+ \\
\left(\mathrm{RE} \_\mathrm{Z} *-0.19206\right)+\left(\mathrm{MH} \_\mathrm{Z} *-0.22069\right)\end{array}$ \\
\hline Aggregate Mental & $\left(P F \_Z *-0.22999\right)+\left(R P \_Z *-0.12329\right)+\left(B P \_Z *-0.09731\right)+$ \\
\hline Summary Score (AGG_MENT) & $\begin{array}{l}\left(\mathrm{GH} \_\mathrm{Z} *-0.01571\right)+\left(\mathrm{VT} \_\mathrm{Z} * 0.23534\right)+\left(\mathrm{SF} \_\mathrm{Z} * 0.26876\right)+ \\
\left(\mathrm{RE} \_\mathrm{Z} * 0.43407\right)+\left(\mathrm{MH} \_\mathrm{Z} * 0.48581\right)\end{array}$ \\
\hline
\end{tabular}


Table 12: Calculating SF-12 Physical and Mental Summary Scores

\begin{tabular}{ll}
\hline SF-12 Aggregate summary score & Formula \\
\hline Physical Component Summary (PCS) & $=50+($ Aggregate Physical Health Summary *10) \\
Mental Component Summary (MCS) & $=50+($ Aggregate Mental Health Summary *10) \\
& \\
\hline
\end{tabular}




\section{Demographic Variables}

Demographic variables were obtained by patient self-report from the measures booklet. These included the respondent's age category, gender, education, race and health insurance providers. These variables were re-categorized to run regression models. Age was dichotomized as 'equal to or less than 60 years of age' and 'more than 60 years of age’. Marital status was dichotomized as being 'married or with a partner', or not ('single, divorced, separated or widowed'). Race was dichotomized as 'white' and 'nonwhite'. Education was re-categorized as 'up to high school', 'some college / vocational course', and 'college degree and beyond', while insurance was re-categorized as 'no insurance’, ‘state/federal insurance’, and ‘private insurance/managed care’.

\section{Medical History Variables}

Self-reported variables

Patients self-reported whether or not they use insulin, the type of treatment for their diabetes ('diet and exercise only', 'oral medications only', 'insulin only', and ‘oral medications and insulin'), and duration of diabetes (in years) in the measures booklet.

\section{Variables collected from medical databases}

$A 1 C$ and $B M I$

The Diabetes Clinic Database can be described as a lab-value database consisting of records of patients who consult physicians at the WVUDI clinics for the management of their diabetes. The database includes A1Cs, lipid profile, blood pressure, and other clinical information for each patient along with the dates when the respective lab values/ 
information was obtained. At the time of most visits, nurses measure the blood pressure of patients and weigh the patients. Other lab values like AIC, lipid profile and others are ordered periodically per physician recommendation. These lab values, as well as physician transcriptions notes, are also available on the electronic interface system called Medsite. The OMSA, that coordinated the mailing on behalf of the study, also tracked the patients who agreed to respond and participate, and made available the desired lab and BMI values for all patients who participated. A1Cs were updated to include the most recent values, considering the month of November 2004 as the period of QoL assessment, and in keeping with the duration of applicability of an A1C reading as discussed earlier. Missing height and weight information for a few patients were obtained from chart reviews in order to calculate BMI.

Height (in feet) and weight (in pounds) information of respondents obtained from chart review was used to calculate BMIs using the formula (CDC, n.d.):

BMI $=\left[\right.$ Weight in pounds / (height in inches) $\left.{ }^{2}\right] * 703$

\section{Hospital admissions and ER visits in the past year}

Two databases were used to obtain diagnosis information for physician office visits, emergency department visits, and hospitalizations for all patients participating in the study. Treatment information was abstracted not just pertaining to the treatment of their diabetes, but for all disease conditions that the patients had. The University Health Associates (UHA) database derives its information from the IDX billing system, which is a software package that tracks patient appointments and billings. After receiving care from a provider, the patient receives a fee slip that is tracked by the IDX system within 
two days of the visit. In addition to the charges, the fee slip also consists of diagnosis information that is later coded into ICD-9 format by the coding department. The WVU Hospital database provides information on hospital and ER encounters. It tracks the bills that patients receive upon discharge from the hospital, and among others, it contains ICD9 diagnosis codes associated with each hospital and ER visit. For purpose of the study, the information used from these databases included ICD-9 codes for different types of medical services utilization, and the number of ER visits and hospital admissions in the twelve-moth period between December 1, 2003 to November 30, 2004.

\section{Charlson Comorbidity Index}

The Charlson co-morbidity index based on medical claims in the 12-month period described above was used to measure co-morbidity. The Charlson Index consists of a list of 19 medical conditions, with each condition being assigned a weight from one to six. This weight was derived from relative risk estimates of proportional hazard regression models using clinical data (Charlson, Pompei, Ales and MacKenzie, 1987). The Charlson index for an individual is the sum of weights for all prevalent conditions (among the list of 19 conditions) during a specified time period. There are a few indices that are primarily based on the Charlson comorbidity index. The version by D’Hoore and colleagues (1996), is one of the few Charlson indices for use with administrative claims data and was used in this study. This version is based on only the first three digits of ICD-9 codes. Diagnosis codes related to diabetes were excluded in the computation of this index. 


\section{Diabetes Complications Score}

In addition to the Charlson co-morbidity index, a diabetes complications score was computed. The complications score is a sum of the dummy variables that code for the presence or absence of ICD 9 codes for four diabetes-related complications: renal, ophthalmic, and neurological complications, and peripheral circulatory disorders. Thus, the diabetes complications score can take values from zero to four.

A unique identification number, known only to the OMSA co-investigators, was assigned to each participant across databases, while de-identifying the dataset. Every patient in the database was identified by a unique identification number. The risk of identifying patients was minimal due to the use of this delimited data set and due to absence of any Protected Health Information (PHI).

In summary, the diabetes severity variables collected were A1C, insulin use status and treatment type, duration of diabetes and the diabetes complication score. The relationship between the QoL, medical history and disease severity, and demographic variables was then assessed in order to answer the research hypotheses, as explained in the next section. 


\section{Data Analyses}

\section{Objective A}

In order to evaluate the factor structure of the ADDQoL and the SF-12, and perform instrument reliability assessment, the following methods were used:

Two tests were initially conducted in order to assess the adequacy of the sample for conducting factor analysis. In the Kaiser-Mayer-Olkin (KMO) measure of sampling adequacy, high values (close to 1.0) generally indicate that a factor analysis may be useful with the data. The second test for adequacy of the sample for factor analysis is the Bartlett test of sphericity. Very small values (less than .05) indicate that there are probably significant relationships among variables; this would indicate that the sample does not produce an identity matrix and is adequate for factor analysis.

Both the ADDQoL and the SF-12 are QoL instruments with established factor loadings derived from exploratory factor analyses performed by the respective developers. The ADDQoL has a single-factor structure (Bradley, Todd, Gorton, Symonds, Martin, and Plowright, 1999), and the SF-12 has been shown to have a twofactor structure ((Ware, Kosinski \& Keller, 1996). Exploratory factor analysis attempts to explain the number of factors that are required to explain the relations among a set of indicators and with the estimation of factor loadings (Pedhazur, 1991). One of the major purposes of confirmatory factor analysis is to test hypotheses regarding the number of factors underlying the relations among a set of indicators, among others (Pedhazur, 1991). Hence, confirmatory factor analyses, using principal components method, were conducted by specifying a priori, on the basis of previous research, the number of factors 
to be extracted. Varimax rotation was used within the principal components analysis. For the ADDQoL, the eighteen items were used, while for the SF-12, the z-scores of the eight subscales were used to perform the above-mentioned procedures. The following criteria were used to make a decision on the prevailing dimensionality of the instruments: the scree plot, the total percentage variance explained by the factors forced into the solution, and the loading of items or subscales on the factors emerging from the rotated solution. Once the factors were reduced, scales were analyzed for their reliability.

Indices of reliability give an indication of the extent to which the scores produced by a particular measurement procedure are consistent and reproducible. A measurement procedure is reliable to the extent that items within the same scale give the same results or to the extent that an individual scores the same across repeated administrations of the scale (Nunally and Bernstein, 1994). Of the methods available to estimate reliability, one of the most frequently used and recognized is the internal consistency reliability method, which examines the equivalence of responses within the same test from a single administration (Nunally and Bernstein, 1994). Internal consistency reliability using Cronbach's alpha was used to estimate the reliability of the scales emerging from the factor analytic procedure described above.

An instrument is said to be valid to the extent that it measures what it purports to measure, and research data are said to be valid to the extent that the results of the measurement process are accurate (Huck, 1996). A widely used classification used with types of validity of measures is content, criterion, and construct. It was decided to assess the construct validity of the instruments being used in the study, the ADDQoL and the SF-12, since it was within the scope of the study. Construct validation is concerned with 
validity of inferences about unobserved variables (the constructs) on the basis of observed variables (their presumed indicators) (Pedhazur, 1991). Three basic techniques to discuss construct validity are logical analysis, internal-structure analysis, and crossstructure analysis (Pedhazur, 1991). In logical analysis, certain conceptual relationships that are connected with the construct in question in some logical way are selected, and correlational evidence is examined to determine strength of relationships between the construct in question and other variables. Internal structure analysis involves performing factor analysis. In cross-structure analysis, probable high and low scoring groups on an instrument are identified on logical grounds a priori, and it is demonstrated that certain groups obtain higher scores on an instrument than other groups. Construct validity of the ADDQoL and the SF-12 was examined by investigating sub-group differences.

\section{Objective B}

In order to assess the bivariate relationship between A1C and QoL (generic and diabetes- specific), the following methodology was employed: Spearman’s rank correlation was used to calculate the significance of the direction and magnitude of relationship between the uncategorized A1C value and the average weighted ADDQoL score and PCS \& MCS scores. For those respondents for whom both ADDQoL and PCS \& MCS scores were available, Hotelling's t statistic was calculated to compare the correlations between ADDQoL and A1C, and PCS\& MCS scores and A1C. This is a ttest used to test for the significance of the difference between two dependent correlations from the same sample. 
In order to identify the variables significantly influencing QoL (generic and diabetes- specific), the following methodology was employed: Univariate analyses using ANOVA were used to test the effect of individual variables on QoL. Multivariate regression analyses were also used to control for the effect of covariates in order to test if A1C is a significant predictor of generic QoL or diabetes-specific QoL. Three sets of regression models were used, with ADDQoL average weighted scores as the dependent variable in a model predicting diabetes-specific QoL, SF-PCS score as the dependent variable in the second model and SF-MCS score as the dependent variable in the third model. The effects of recent A1C and average A1C in the past year, on QoL were independently assessed in separate models.

Sequential regression (also called hierarchical regression) models and statistical regression (also called stepwise regression) models were built in order to explain the relationship between QoL and the various predictors. In sequential regression, the order of entry of variables is assigned by the researcher according to logical or theoretical considerations (Tabachnick and Fidell, 2001). One point of view is to accord early entry to variables of greater theoretical importance, or to those variables that are presumed (or manipulated) to be causally prior, while the opposite view is to introduce the relatively unimportant variables first, and test the added prediction obtained by the introduction of the other variables in the model. Hierarchical regression is used in explanatory situations when there is some basic knowledge on the relationships between at least some of the variables being employed. In this study, covariates were entered sequentially into the model the following order in groups in order to separate their effects from the effect of the primary independent variable, A1C: 
Block 1: A1C, insulin use, complications score, duration of diabetes

Block 2: BMI, Charlson comorbidity score, number of hospital visits, number of ER visits

Block 3: Demographic variables: Age, gender, race, marital status, type of insurance.

In statistical regression, the order of entry of variables is not decided by the researcher, but is based only on statistical criteria. In this technique, predictors are automatically introduced into the model in the order that they contribute significantly to the total model fit, with those predictors contributing most to total $\mathrm{R}^{2}$ entering first. Statistical regression enables identification of a subset of independent variables (IV) that can predict the dependent variables (DV) by eliminating those IVs that do not provide added prediction to the IVs already in the model (Tabachnick and Fidell, 2001). Given the nature of the technique, it is employed in exploratory research situations and for purposes of prediction (Cohen, Cohen, West and Aiken, 2003). Hence the technique may be used when a large pool of independent variables is available, but backed by little theory to guide selection among them (Cohen, Cohen, West and Aiken, 2003). As explained in an earlier section, there is no consistent relationship between generic and diabetes-specific QoL in Type 2 diabetes patients and other predictors employed in the study, as reported in literature. Hence the statistical regression technique was additionally employed to identify those independent variables most significantly predicting QoL in the current study data. Specifically, any variable was allowed to be introduced as a predictor in the model if the significance level of its F value was less than the entry criterion of 0.05 , and was removed if the significance level was greater than the removal criterion of 0.10. Correlation among predictors was checked before-hand (Tabachnick 
and Fidell, 2001) in order to prevent the loss of variables for consideration in the stepwise regression procedure due to multicollinearity situations within the data.

SPSS 10.0 was used for all the analyses in the study.

\section{Sample Size Calculations and Power}

Power is the likelihood that a study will detect a true effect of a given magnitude if it actually exists (a true positive). Power can also be broadly termed as the probability that a statistical significance test will reject the null hypothesis for a specified value of an alternative hypothesis. Hence, power of a study is also the probability of avoiding a beta error, in which we fail to reject the null hypothesis which is false. It is important to consider power in research designs because studies with low power analyses may be inconclusive.

A priori power analyses are conducted in order to ascertain the sample size required to perform the analyses necessary for a study at a level of power desired prior to the start of the study. For this purpose, it is necessary to decide upon the alpha level (the probability of making an alpha or Type 1 error) for the analysis, the desired power (1 minus the probability of making a beta or Type 2 error), and the effect size. Effect size can be conceived of as a measure of the distance between the null hypothesis and the alternate hypothesis. Hence, effect size refers to the underlying population rather than a specific sample. While specifying effect size in research that has clinical implication, it is typical to decide the degree of deviation from the null hypothesis that is large enough to be clinically relevant. 
In order to perform power calculations for the various analyses in the study, a software package called G-Power (Faul \& Erdfelder, 1992, and Erdfelder, Faul \& Buchner, 1996) was used.

\section{Objective A}

There is no consensus on the sample size required to perform factor analysis, and methodologists differ in this regard. Certain rules of thumb include requiring at least 10 cases for each item in the instrument being used. Bryant and Yarnold (1995) recommend that the subjects-to-variables ratio be no lower than 5 .

\section{Objective $B$}

As explained in a previous section, evidence is mixed about the association between A1C and QoL. While the magnitude of correlations calculated to test hypotheses 1a and $1 \mathrm{~b}$ were used as the effect size (deviation from the null hypothesis), the alpha level was decided as 0.05. Since a variety of QoL instruments have been used in literature, there was no standard effect size to use while calculating the sample size required in conducting the correlation analyses. Hence, a conservative medium effect size (0.3) (Cohen, 1998) was chosen along with a required power of 0.8 to 0.9 . This resulted in a required sample size of 64 for a power of 0.8 , and 111 for a power of 0.9 . The a priori calculation of required sample size necessitated making a decision on the anticipated effects size index for regression, $\mathrm{f}^{2}$ (Cohen, 1988). $\mathrm{f}^{2}$ reflects the proportion of variance accounted for by some source in the population (PVs) relative to the residual 
variance proportion (PVe), such that $\mathrm{f}^{2}=\mathrm{PVs}$ / PVe. Using multiple regression with a set of predictors, the hypothesis tested was that the correlation of a set of predictors with a dependent variable is zero in the population. While $\mathrm{f}^{2}$ would be equal to $\mathrm{R}^{2} / 1-\mathrm{R}^{2}$ (where $\mathrm{R}^{2}$ is the coefficient of determination obtained from the regression using the set of predictors), the required power was between 0.8 and 0.9 , with an alpha level of 0.05 . For a set of predictors explaining $20 \%$ of the variance in the dependent variable, $\mathrm{f}^{2}$ would be 0.25 , and with 14 predictors, a sample size of 86 is needed to achieve a power of 0.8 and 105 is needed to achieve a power of 0.9 . For a set of predictors explaining $10 \%$ of the variance in the dependent variable, $\mathrm{f}^{2}$ would be 0.11 , and with 14 predictors, a sample size of 179 is needed to achieve a power of 0.8 and 222 is needed to achieve a power of 0.9 . 


\section{CHAPTER FOUR: RESULTS}

The previous chapter discussed the methodology employed, and data sources collection procedures. The current chapter first provides a descriptive overview of the study results, and then explains the results of each hypothesis indicated in Chapter one.

\section{Overview of Results}

The total number of responses received was 412 . This study included only patients with Type 2 diabetes, so it was decided to scrutinize the medical charts of those respondents who reported using only insulin for the treatment of their diabetes to be sure they were not Type 1 patients. Physicians increasingly prescribe insulin to patients with Type 2 diabetes, but the need was felt to check if the respondents reporting insulin-only treatment were indeed Type 2 diabetes patients. In addition, chart reviews were performed for all respondents whose hospital records indicated only ICD-9 diagnoses related to Type 1 diabetes. After careful review of all these medical records, and consulting with our co-investigator physician at the OMSA, it was decided to drop 27 respondents from the study since they were resolved as patients with Type 1 diabetes. All other patients were regarded as Type 2 diabetes patients; hence there were 385 usable responses, leading to a usable response rate of $44.3 \%$. All of these met the inclusion criterion of having had at least one A1C measurement as of June 1, 2004; this study, during its inception, was designed as a population study based on this criterion. For each of the 385 respondents, the average of available A1C measurements in the past one year 
was also calculated. In order to provide a temporally appropriate assessment of the relationship between a recent level of A1C and QoL, a subset of 360 respondents was identified, for whom the latest A1C measurement was taken no more than 120 days prior to the commencement of the study in November 2004. As explained earlier, this decision was taken from prevailing knowledge, and in agreement with our physician coinvestigator's observation that an $\mathrm{A} 1 \mathrm{C}$ is a reflection of the average blood glucose level over 90-120 days.

\section{Descriptive Statistics for Total Sample Response Data}

\section{Overview of Descriptive Statistics}

The demographic and diabetes/medical history variables and responses to the QoL instruments were collected from the measures booklet. The information obtained from chart reviews included A1C levels, BMI, lipid profile, and ICD-9 diagnoses (to calculate the number of ER visits and hospitalizations in the previous year, the Charlson comorbidity score, and the diabetes complications score).

\section{Demographic Variables}

The distribution of the respondents by the various demographic variables is depicted in Table 13. Data on age was collected as a categorical variable, since the IRB protocol did not allow for collection of actual respondent age. About 28\% respondents were in the age group of 50-59 years, while $26 \%$ respondents were in the age group of 60-69 years. Given this distribution, the variable for age in the dataset was dichotomized 
such that $47.4 \%$ of the sample was less than 60 years of age. Other demographic variables were dichotomized wherever appropriate, as described in an earlier section. Nearly $57 \%$ of respondents were female, and $94 \%$ respondents were white. About $63 \%$ of respondents reported being married or with a partner while more than $37 \%$ were single, divorced, or separated. Response regarding the highest level of education indicated that about $53 \%$ of respondents completed high school or below. Only $7.5 \%$ of respondents reported not having insurance; $67.5 \%$ reported having some kind of government insurance as their primary insurance. It was possible to identify the clinics where patients were receiving care for their diabetes at the time of sending questionnaires via survey mail out. Forty percent of the respondents received care for their diabetes from the Family Medicine clinics, 31.4\% were from Endocrinology, while 28.6\% were from MGP.

\section{Medical History Variables}

The mean self-reported duration of diabetes was 10.2 yrs $( \pm 9.1)$. Insulin use status was also obtained from self-report, in the form of a yes/no question.

Approximately $42 \%$ of Type 2 respondents reported being on insulin. From the responses to questions that were a part of another co-investigator's research objectives, it was possible to identify type of diabetes treatment of the respondents. While $50.3 \%$ of the respondents reported that they were on oral medications alone, $31.7 \%$ were on both oral medications and insulin, and 9.4\% were on insulin alone.

Mean A1C (recent) for the respondents was $7.2( \pm 1.4)$ among the 360 respondents for whom the value was available. A1C values were categorized into levels of glycemic control, with 55\% of the respondents in excellent glycemic control (A1C $\leq 7.0$ ), 33.9\% in 
good glycemic control (A1C between 7.1 and 9.0), 7.8\% in marginal glycemic control (A1C between 9.1 and 10.0), and 3.3\% in poor glycemic control (A1C above 10.1). The mean of respondents’ average A1C over the previous year was $7.24( \pm 1.3)$ among the 384 respondents for whom the average A1C could be calculated. Paired samples t-test revealed that there was no significant difference between respondents' recent $\mathrm{A} 1 \mathrm{C}$ value and the average A1C value. Since almost $89 \%$ of respondents were in excellent to good glycemic control (A1Cs equal to or below 9.0), it was decided to dichotomize the respondents into two groups: one group that had A1Cs below 7.0 and the second group that had A1Cs equal to or above 7.0. This classification was based on the ADA's clinical practice recommendation that providers should adjust management plans for their patients in order to achieve an A1C goal of below 7.0 (ADA, 2005).

Height (in feet) and weight (in pounds) information of respondents obtained from chart review was used to calculate BMIs using the formula (CDC, n.d.):

BMI $=\left[\right.$ Weight in pounds $/$ (height in inches) $\left.^{2}\right] * 703$ Mean BMI for the respondents was $33.5( \pm 8.1)$. BMI values were categorized into a weight status variable, with $12.3 \%$ of respondents in a normal BMI range (BMI between 18.5 and 24.9), 23.8\% of respondents being overweight (BMI between 25 and 29.9), and $63.9 \%$ of respondents being obese (BMI of 30 or more). A dichotomous obesity status variable was also calculated for use in analyses.

Based on the number of ER visits in the past one year obtained from hospital medical records, it was observed that $72.2 \%$ of the respondents did not have a single ER visit, 22.2\% had between one and two ER visits, and the remaining 5.7\% had more than two ER visits in the past year. Based on the number of hospital admissions in the past 
one year obtained from hospital medical records, it was observed that $79.7 \%$ of respondents had no hospitalizations, while $20.3 \%$ had at least one hospitalization in the past year.

ICD-9 diagnoses information obtained from medical records was used to calculate a Charlson comorbidity index for each respondent. The mean Charlson score was 1.18 ( \pm 2.56$)$, with $62 \%$ of respondents having a score of zero. About $5 \%$ of respondents had an ICD-9 diagnosis corresponding to renal complications due to diabetes, $40.9 \%$ had eye complications due to diabetes, $10.7 \%$ had neurological complications due to diabetes, and 0.5\% had peripheral vascular disease as a complication of diabetes. When a diabetes complications score was calculated on the basis of presence of these complications, $50.8 \%$ of respondents had no such complication related to diabetes, while the remaining 49.2\% had at least one such complication.

\section{Quality of Life Variables}

A total of 385 ADDQoL average weighted scores could be calculated. A negative score on the ADDQoL would indicate that diabetes was negatively affecting QoL of the individual, while a positive score would indicate a positive effect of diabetes. Intuitively, a person with diabetes is expected to report a negative influence of the disease on his or her QoL. At the same time, the bipolar scale allows for some respondents to have positive scores, although these were expected to be uncommon. The mean of an overview item assessing the impact of diabetes on QoL was $-1.31( \pm 1.00)$, while the average weighted impact ADDQoL score that was calculated was found to be $-1.95( \pm 1.76)$. As shown in Table 14, the maximum negative impact of diabetes was felt on 'freedom to eat', 
'enjoyment of food', and on 'finances', while diabetes least impacted 'society reaction', 'dependence', and 'living conditions'. The mean ADDQoL average weighted scores across demographic and medical history variables are shown in Table 15.

Upon transformation according to recommended procedures described in an earlier section, a total of 348 PCS and MCS scores (on a 0-100 scale, where 0 represents poorest general QoL) could be calculated. The mean PCS score was $45.54( \pm 12.30)$, while the mean MCS score was $38.44( \pm 13.1)$. This is comparable to the estimates presented in the scoring manual for PCS-12 and MCS-12 obtained from a U.S. population with Type 2 diabetes with mean age of 57.6 years, 55.4\% female respondents, and with mean PCS score of $41.52( \pm 11.07)$ and mean MCS score of $47.28( \pm 10.72)$. The mean PCS and MCS scores across demographic and medical history variables are shown in Table 15.

No significant differences in respondents' SF-PCS scores or SF-MCS scores were found between the three clinic settings. There was a significant overall ANOVA for difference in ADDQoL scores between the three clinic settings $[F(2,374)=3.16$, $p=0.044]$; however post-hocs tests did not show any significant results. One-way ANOVA also indicated that there were no significant differences in respondents' average $\mathrm{A} 1 \mathrm{C}$ or recent $\mathrm{A} 1 \mathrm{C}$ levels between the three clinics. 
Table 13: Demographic Profile of Respondents

\begin{tabular}{|c|c|c|c|}
\hline Variable & $\mathbf{N}$ & $\%$ & Mean (SD) \\
\hline \multicolumn{4}{|l|}{ Age } \\
\hline$<60$ years & 182 & 47.3 & \\
\hline$\geq 60$ years & 202 & 52.5 & \\
\hline \multicolumn{4}{|l|}{ Gender } \\
\hline Male & 165 & 42.9 & \\
\hline Female & 220 & 57.1 & \\
\hline \multicolumn{4}{|l|}{ Marital Status } \\
\hline Single & 47 & 12.2 & \\
\hline Married/ with partner & 238 & 61.8 & \\
\hline Divorced/ separated & 36 & 9.4 & \\
\hline Widowed & 59 & 15.3 & \\
\hline \multicolumn{4}{|l|}{ Race } \\
\hline White & 361 & 93.8 & \\
\hline Black & 14 & 3.6 & \\
\hline Asian & 4 & 1.0 & \\
\hline \multicolumn{4}{|l|}{ Education } \\
\hline Less than high school & 200 & 51.9 & \\
\hline Some college/ vocational & 85 & 22.1 & \\
\hline College degree and beyond & 93 & 24.2 & \\
\hline \multicolumn{4}{|l|}{ Insurance } \\
\hline No insurance & 28 & 7.3 & \\
\hline State/ Federal insurance & 223 & 57.9 & \\
\hline Private insurance/ managed care & 121 & 31.4 & \\
\hline \multicolumn{4}{|l|}{ Glycemic control } \\
\hline Excellent control & 210 & 54.5 & \\
\hline Good control & 133 & 34.5 & \\
\hline Marginal control & 28 & 7.3 & \\
\hline Poor control & 13 & 3.4 & \\
\hline \multicolumn{4}{|l|}{ Weight Status } \\
\hline Underweight & 2 & 0.5 & \\
\hline Normal & 44 & 11.4 & \\
\hline Overweight & 89 & 23.1 & \\
\hline Obese & 239 & 62.1 & \\
\hline
\end{tabular}


Treatment

Diet and exercise

29

7.5

Oral medications only

189

49.1

Insulin only

36

9.4

Oral medications and insulin

122

31.7

ER Utilization

No ER visits

278

72.2

1-2 ER visits

85

22.1

$>2$ ER visits

22

5.7

Hospitalizations

No hospitalizations

307

79.7

At least one hospitalization

78

20.3

Diabetes Complication Score

0

195

50.6

1

167

43.4

$>2$

22

5.8

Patient's Clinic

Family Medicine

$154 \quad 40.0$

Medical General Practice

110

28.6

Endocrinology

121

31.4

Charlson Comorbidity Score

$1.18(+2.56)$

Duration of diabetes in years

$10.17( \pm 9.10)$

Recent A1C

$7.20( \pm 1.40)$

Average A1C

$7.20( \pm 1.30)$

SF-12 PCS

$38.44( \pm 13.10)$

SF-12 MCS

$45.52( \pm 12.30)$

ADDQoL weighted impact

$-1.94( \pm 1.76)$ 
Table 14: Mean Weighted Impact Scores for ADDQoL Domains

\begin{tabular}{lll}
\hline Item no. & ADDQoL Domain & Mean (SD) \\
\hline 1 & & \\
2 & Working life & $-1.73( \pm 2.52)$ \\
3 & Family life & $-2.17( \pm 2.720$ \\
4 & Social life & $-1.56( \pm 2.34)$ \\
5 & Sex life & $-1.60( \pm 2.64)$ \\
6 & Physical Appearance & $-1.33( \pm 2.3)$ \\
7 & Physical activities & $-2.16( \pm 2.67)$ \\
8 & Holidays/ leisure & $-1.75( \pm 2.47)$ \\
9 & Travel & $-1.84( \pm 2.51)$ \\
10 & Confidence in ability & $-1.67( \pm 2.48)$ \\
11 & Motivation & $-1.59( \pm 2.38)$ \\
12 & Society reaction & $-0.88( \pm 1.84)$ \\
13 & Future & $-2.13( \pm 3.34)$ \\
14 & Finances & $-2.20( \pm 2.90)$ \\
15 & Dependence & $-1.23( \pm 2.89)$ \\
16 & Living Conditions & $-1.32( \pm 2.31)$ \\
17 & Freedom to eat & $-3.10( \pm 3.04)$ \\
18 & Enjoyment of food & $-2.89( \pm 3.10)$ \\
\hline
\end{tabular}


Table 15: Mean Scores on the ADDQoL, SF-PCS, and SF-MCS, and Significance of Sub-group Differences

\begin{tabular}{|c|c|c|c|c|c|c|}
\hline Variable & $\begin{array}{l}\text { Mean (SD) } \\
\text { ADDQoL }\end{array}$ & $\begin{array}{l}\mathbf{p} \\
\text { value }\end{array}$ & $\begin{array}{l}\text { Mean (SD) } \\
\text { SF-12 PCS }\end{array}$ & $\begin{array}{l}\mathbf{p} \\
\text { value }\end{array}$ & $\begin{array}{l}\text { Mean (SD) } \\
\text { SF-12 MCS }\end{array}$ & $\begin{array}{l}\mathbf{p} \\
\text { value }\end{array}$ \\
\hline Age & & 0.325 & & $0.044^{*}$ & & $0.000^{*}$ \\
\hline$<60$ years & $-2.04( \pm 1.78)$ & & $39.84( \pm 12.98)$ & & $42.61( \pm 12.55)$ & \\
\hline$\geq 60$ years & $-1.86( \pm 1.74)$ & & $37.01( \pm 13.15)$ & & $48.54( \pm 11.33)$ & \\
\hline Gender & & 0.121 & & 0.187 & & 0.335 \\
\hline Male & $-2.10( \pm 1.89)$ & & $39.52( \pm 13.11)$ & & $46.26( \pm 12.32)$ & \\
\hline Female & $-1.82( \pm 1.65)$ & & $37.64( \pm 13.07)$ & & $44.97( \pm 12.30)$ & \\
\hline Marital Status & & 0.331 & & $0.048^{*}$ & & $0.044^{*}$ \\
\hline Single & $-2.50( \pm 1.97)$ & & $37.19( \pm 12.54)$ & & $42.3( \pm 13.02)$ & \\
\hline Married/ with partner & $-1.95( \pm 1.75)$ & & $39.83( \pm 13.09)$ & & $46.49( \pm 12.06)$ & \\
\hline Divorced/ separated & $-1.79( \pm 1.91)$ & & $34.24( \pm 13.20)$ & & $41.87( \pm 12.48)$ & \\
\hline Widowed & $-1.63( \pm 1.52)$ & & $36.18( \pm 13.21)$ & & $47.04( \pm 12.21)$ & \\
\hline Race & & 0.506 & & 0.163 & & $0.023^{*}$ \\
\hline White & $-1.95( \pm 1.79)$ & & $38.02( \pm 13.02)$ & & $45.72( \pm 12.09)$ & \\
\hline Black & $-2.44( \pm 1.00)$ & & $42.82( \pm 14.25)$ & & $44.33( \pm 13.80)$ & \\
\hline Asian & $-1.53( \pm 0.67)$ & & $45.72( \pm 12.41)$ & & $46.36( \pm 9.38)$ & \\
\hline Education & & $<0.000^{*}$ & & $0.000^{*}$ & & 0.159 \\
\hline Less than high school & $-2.18( \pm 1.99)$ & & $36.65( \pm 11.89)$ & & $44.61( \pm 12.90)$ & \\
\hline Some college/ vocational & $-1.84( \pm 1.59)$ & & $35.56( \pm 14.31)$ & & $44.99( \pm 12.27)$ & \\
\hline College degree and beyond & $-1.60( \pm 1.29)$ & & $44.78( \pm 12.04)$ & & $47.64( \pm 11.23)$ & \\
\hline Insurance & & $0.012^{*}$ & & $0.001^{*}$ & & 0.257 \\
\hline No insurance & $-2.50( \pm 2.16)$ & & $34.91( \pm 12.37)$ & & $42.54( \pm 13.71)$ & \\
\hline State/ Federal insurance & $-1.08( \pm 1.91)$ & & $36.84( \pm 13.00)$ & & $45.16( \pm 12.50)$ & \\
\hline Pvt. insurance/ managed care & $-1.59( \pm 1.30)$ & & $42.10( \pm 12.99)$ & & $46.68( \pm 11.73)$ & \\
\hline Glycemic control (average A1C) & & 0.164 & & 0.526 & & 0.220 \\
\hline Excellent control & $-1.66( \pm 1.65)$ & & $39.44( \pm 13.08)$ & & $46.56( \pm 12.48)$ & \\
\hline Good control & $-2.25( \pm 1.82)$ & & $37.21( \pm 13.21)$ & & $43.96( \pm 12.16)$ & \\
\hline Marginal control & $-2.20( \pm 1.77)$ & & $38.52( \pm 12.17)$ & & $47.90( \pm 10.59)$ & \\
\hline Poor control & $-2.23( \pm 2.20)$ & & $38.74( \pm 15.20)$ & & $44.71( \pm 13.01)$ & \\
\hline
\end{tabular}




\begin{tabular}{|c|c|c|c|c|c|c|}
\hline Variable & $\begin{array}{l}\text { Mean (SD) } \\
\text { ADDQoL }\end{array}$ & $\begin{array}{l}\mathbf{p} \\
\text { value }\end{array}$ & $\begin{array}{l}\text { Mean (SD) } \\
\text { SF-12 PCS }\end{array}$ & $\begin{array}{l}\mathbf{p} \\
\text { value }\end{array}$ & $\begin{array}{l}\text { Mean (SD) } \\
\text { SF-12 MCS }\end{array}$ & $\begin{array}{l}\mathbf{p} \\
\text { value }\end{array}$ \\
\hline Weight Status & & 0.667 & & $0.002^{*}$ & & $0.002 *$ \\
\hline Underweight & -3.67 & & 43.25 & & 41.87 & \\
\hline Normal & $-1.99( \pm 1.77)$ & & $41.65( \pm 12.29)$ & & $51.57( \pm 9.15)$ & \\
\hline Overweight & $-1.80( \pm 1.82)$ & & $42.24( \pm 12.43)$ & & $46.38( \pm 10.87)$ & \\
\hline Obese & $-1.99( \pm 1.76)$ & & $36.36( \pm 12.94)$ & & $43.85( \pm 12.90)$ & \\
\hline Treatment & & $<0.000 *$ & & $0.009 *$ & & 0.074 \\
\hline Diet and exercise & $-1.19( \pm 1.03)$ & & $41.30( \pm 11.09)$ & & $43.70( \pm 14.00)$ & \\
\hline Oral medications only & $-1.66( \pm 1.69)$ & & $40.22( \pm 13.10)$ & & $46.59( \pm 11.84)$ & \\
\hline Insulin only & $-2.73( \pm 1.97)$ & & $35.95( \pm 14.90)$ & & $48.79( \pm 10.88)$ & \\
\hline Oral medications and insulin & $-2.32( \pm 1.73)$ & & $35.41( \pm 12.2)$ & & $43.6( \pm 12.46)$ & \\
\hline ER Utilization & & $0.038^{*}$ & & $0.000^{*}$ & & $0.013^{*}$ \\
\hline No ER visits & $-1.90( \pm 1.79)$ & & $40.11( \pm 13.10)$ & & $46.63( \pm 11.88)$ & \\
\hline 1-2 ER visits & $-1.85( \pm 1.67)$ & & $33.67( \pm 12.29)$ & & $43.12( \pm 12.99)$ & \\
\hline$>2$ ER visits & $-2.92(+1.53)$ & & $35.07( \pm 11.34)$ & & $40.12( \pm 12.95)$ & \\
\hline Hospitalizations & & 0.083 & & $0.000^{*}$ & & $0.032 *$ \\
\hline No hospitalizations & $-1.87( \pm 1.72)$ & & $39.99( \pm 12.9)$ & & $46.23( \pm 12.11)$ & \\
\hline At least one hospitalization & $-2.26( \pm 1.89)$ & & $32.32( \pm 12.12)$ & & $42.71( \pm 12.74)$ & \\
\hline Diabetes Complication Score & & $0.005^{*}$ & & $0.027 *$ & & 0.082 \\
\hline 0 & $-1.83( \pm 1.76)$ & & $40.13( \pm 13.15)$ & & $46.57( \pm 11.97)$ & \\
\hline 1 & $-1.93( \pm 1.73)$ & & $37.11( \pm 12.78)$ & & $45.08( \pm 12.67)$ & \\
\hline 2 or greater & $-3.15(+1.65)$ & & $33.78( \pm 13.25)$ & & $40.52( \pm 11.02)$ & \\
\hline Patient's Clinic & & $0.044 *$ & & 0.940 & & 0.668 \\
\hline Family Medicine & $-1.81( \pm 1.84)$ & & $38.18( \pm 14.02)$ & & $44.86( \pm 12.51)$ & \\
\hline Medical General Practice & $-1.76( \pm 1.57)$ & & $38.80( \pm 13.01)$ & & $45.66( \pm 12.21)$ & \\
\hline Endocrinology & $-2.27( \pm 1.79)$ & & $38.44( \pm 12.05)$ & & $46.24( \pm 12.20)$ & \\
\hline
\end{tabular}

* significant at 0.05 level 


\section{Results for Objective A}

\section{Factor Structure and Reliability of the ADDQoL}

Since the developers of the ADDQoL (Bradley et al., 1999) have reported a onefactor structure, it was decided to perform a forced one-factor confirmatory factor analysis in order to test the structure of the instrument from the data available from this sample of patients. Three criteria were used: the a priori hypothesis that the measure was uni-dimensional, the Scree plot, and the interpretability of the factor solution. Principal components analysis was used to obtain a forced one-factor solution from the 18 weighted item scores of the ADDQoL, by specifying the number of factors to be extracted as one regardless of their eigen values, rather than extracting all factors with an eigen value greater than one. The KMO test of sampling adequacy $(=0.9)$ and the Bartlett's test of sphericity $(\mathrm{p}<0.000)$ indicated that the data was factor analyzable.

The Scree plot did not support the uni-dimensionality hypothesis, since there were three factors with eigen values greater than one. No rotated solution was available since the number of factors requested was one. The single factor explained $45.63 \%$ of the variance from the 18 items of the ADDQoL. Factor loadings for each item on the single unrotated factor showed that 15 items loaded greater than 0.5 on that factor; the factor loadings for the other three items were $0.492,0.481$, and 0.375 respectively, as shown in Table 16. 
Table 16: Loadings of ADDQoL Domains on the Single-Factor Solution

\begin{tabular}{clc}
\hline Item no. & ADDQoL Domain & Factor Loading \\
\hline 7 & & \\
\hline 10 & Holidays/ leisure & 0.834 \\
9 & Motivation & 0.820 \\
8 & Confidence in ability & 0.810 \\
6 & Travel & 0.805 \\
3 & Physical activities & 0.773 \\
2 & Social life & 0.730 \\
15 & Family life & 0.722 \\
5 & Living Conditions & 0.720 \\
11 & Physical Appearance & 0.693 \\
1 & Society reaction & 0.679 \\
13 & Working life & 0.679 \\
14 & Finances & 0.642 \\
12 & Dependence & 0.613 \\
17 & Future & 0.555 \\
16 & Enjoyment of food & 0.507 \\
4 & Freedom to eat & 0.492 \\
18 & Sex life & 0.481 \\
\hline
\end{tabular}


Given the above results, it was decided to confirm the reliability of the ADDQoL with the prevailing one-factor structure. The 18 ADDQoL weighted impact item scores were analyzed for internal consistency using Cronbach's alpha. The alpha coefficient obtained was 0.92 .

Given the internal consistency of the 18-item scale structure as discussed above, it was decided to perform an unforced principal components factor analysis with Varimax rotation, to study the loading of the individual items of the ADDQoL on the factors that were noticed in the Scree plot discussed in the above analysis. This elicited three factors with eigen values greater than $1(8.213,1.967,1.132)$. The rotated component matrix showed that the first factor comprised eight items of the ADDQoL, the second factor comprised seven items, while the third factor comprised three items, with these factors explaining $45.63 \%, 10.93 \%$, and $6.29 \%$ of the total variance respectively. While the items loading on the third factor (items 16 through 18) were items that concerned food and drink-related activities, no broad description can be given to the eight items that loaded on factor one (items 1 through 7 and 11), or to the seven items that loaded on factor two (items $8,9,10,12,13,14$, and 15). Internal consistency reliability using Cronbach's alpha of the scale comprising the 7 items from factor two was found to be 0.87 ; for the scale comprising the 3 items from factor three it was 0.88 . 


\section{Construct Validity of the ADDQoL}

T-tests revealed significantly poorer average weighted ADDQoL scores in the insulin-treated group compared to the non-insulin treated group [t(372) $=3.98, \mathrm{p}<$ 0.000). Further analyses revealed that the insulin treated group had significantly poorer scores on the general QoL item, on the general item about the impact of diabetes on QoL, and on the average weighted impact ADDQoL score (See Figure 1).

A one-way ANOVA was performed to calculate differences in average weighted ADDQoL scores across diabetes treatment-related groups. The group reporting use of both insulin and oral medications for their diabetes had the greatest negative impact of diabetes on their QoL, followed by the group on insulin alone, the group on oral medication only, and the group on diet and exercise alone, in that order, as seen previously in Table 3. Overall F-test for this ANOVA was significant $[F(3,364)=7.787$, p $<0.000]$. Post-hoc tests using the Bonferroni method revealed significantly lower ADDQoL scores in the group on oral medications and insulin, as compared to the group on oral medications alone. T-tests revealed significantly lower ADDQoL scores in the group with A1Cs equal to or above 7.0 as compared to those with A1Cs below 7.0 [t(374) $=3.13, \mathrm{p}=0.002]$. 
Figure 1: Impact of Diabetes on QoL as Reflected in ADDQoL Scores, by Insulin Use

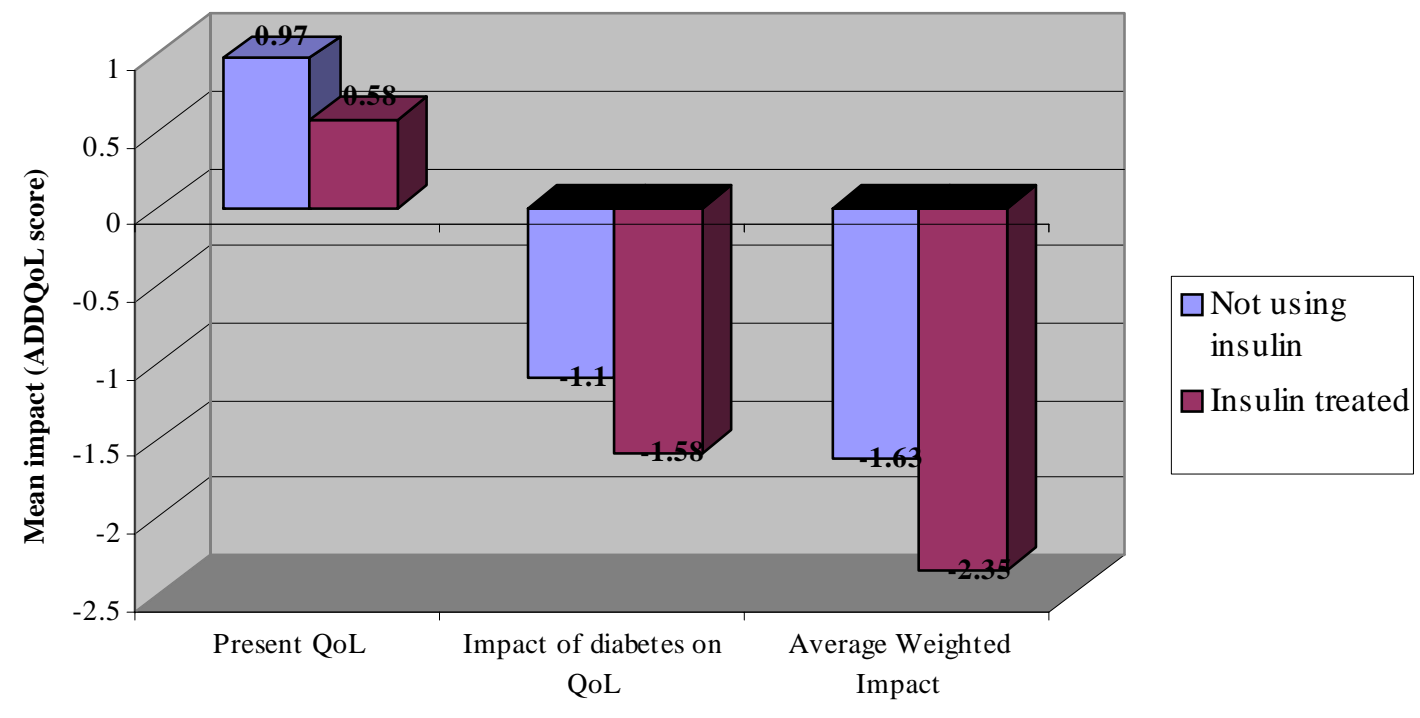


There were no significant differences in ADDQoL scores in patients who were obese versus those who were not. The average weighted ADDQoL score correlated significantly with diabetes complication score (Spearman $r=-0.115, n=376, p=0.025$ ). A one-way ANOVA on the categorized diabetes complications score (groups with 0,1 , and 2 or more complications respectively) for differences in ADDQoL scores yielded a significant overall $\mathrm{F}$ value $[\mathrm{F}(2,373)=5.42, \mathrm{p}=0.005]$. Post-hoc analysis using Bonferroni correction revealed significantly lower ADDQoL scores for patients with two or more complications compared to those with no complications $(\mathrm{p}=0.003)$, and also significantly lower ADDQoL scores for patients with two or more complications compared to those with one complication $(\mathrm{p}=0.008)$. On the other hand, no significant correlation was found with the Charlson comorbidity index (Spearman $\mathrm{r}=-0.032, \mathrm{n}=$ 376, $\mathrm{p}=0.576)$. T-tests for differences in hospital visits was also not significant. A oneway ANOVA, testing for differences in ADDQoL scores between those who did not have ER visits compared with those who had between one and 2 visits, and more than two visits, were significant overall $[\mathrm{F}(2,374)=3.30, \mathrm{p}<0.038]$. Post-hoc analysis using Bonferroni correction revealed significantly lower ADDQoL scores for patients with two or more ER visits compared to those with no ER visits ( $p=0.038)$, and also significantly lower ADDQoL scores for patients with two or more ER visits, compared to those with 1-2 ER visits $(p=0.044)$. 


\section{Factor Structure and Reliability of the SF-12}

Since the SF-12 has an established two-factor structure, it was decided to perform a forced two-factor confirmatory factor analysis in order to test the structure of the instrument from the data available from this study. Three criteria were used: the a priori hypothesis that the measure was bidimensional, the Scree plot, and the interpretability of the factor solution. Principal components analysis was used to obtain a forced two-factor solution from the z-scores of the eight SF-12 subscales, by specifying the number of factors to be extracted as one regardless of their eigen values, rather than extracting all factors with an eigen value greater than one. The z-scores for the eight SF-12 subscales were generated in the course of scoring the SF-12 in order to obtain the SF-12 PCS and the SF-12 MCS. In the process of scoring the SF-12, these z-scores were used in a specified combination to produce aggregate physical and mental summary scores, which were then finally transformed into the PCS and MCS. The KMO test of sampling adequacy $(=0.878)$ and the Bartlett's test of sphericity $(\mathrm{p}<0.000)$ indicated that the data was factor analyzable.

The Scree plot supported the bidimensionality hypothesis; there were two factors with eigen values greater than one $(4.805,1.003)$. The rotated component matrix showed that both the factors comprised four subscales each. The subscales loading on the first factor were physical functioning, role physical, bodily pain, general health, and vitality. The subscales loading on the second factor were social functioning, role emotional and mental general health. The two factors together explained $72.6 \%$ of the variance from the z scores of the eight SF-12 subscales. Factor loadings for each subscale on the two factors are shown in Table 17. 
Table 17: Loadings of SF-12 Domains on the Two-Factor Solution

\begin{tabular}{lcc}
\hline SF-12ADDQoL Domain & \multicolumn{2}{c}{ Factor Loading } \\
& Factor 1 & Factor 2 \\
\hline Physical Functioning Z Score & 0.887 & 0.189 \\
Role Physical Z Score & 0.861 & 0.317 \\
Bodily Pain Z Score & 0.768 & 0.267 \\
General Health Z Score & 0.737 & 0.247 \\
Vitality Z Score & 0.601 & 0.494 \\
Mental Health Z Score & 0.113 & 0.919 \\
Role Emotional Z Score & 0.371 & 0.786 \\
Social Functioning Z Score & 0.480 & 0.617 \\
\hline
\end{tabular}


Given the above results, it was decided to confirm the internal consistency reliability of the SF-12 with the prevailing two-factor structure, using Cronbach's alpha. The subscales loading on the two factors as explained above were each analyzed for internal consistency using Cronbach’s alpha. The first factor, comprising the physical functioning, role physical, bodily pain, general health, and vitality subscales showed a Cronbach's alpha coefficient of 0.85 , while the second factor, comprising the social functioning, role emotional and mental general health subscales showed a Cronbach’s alpha coefficient of 0.80 . Since the PCS and the MCS summary measures of the SF-12 are a linear combination of the eight domains measuring distinct health constructs (Ware, Kosinki, Bowker and Gandek, 2002), measurement of the reliability of the PCS and MCS subscales should take into account the interdependability of the domains. During development, each item of the SF-12 was selected because it contained unique reliable variance estimating physical or mental health, and the scoring algorithm provided in the SF-12 scoring manual for the PCS and MCS is reflective of this.

Hence, it is necessary to take into account the reliability of each domain as well as the covariances among them in estimating the reliability using the internal consistency method (Nunnally and Bernstein, 1994). The method suggested in the SF-12 scoring manual (Ware, Kosinki, Bowker and Gandek, 2002, p63) for the internal consistency estimation for the instrument is based on this principle. Using this method, the Cronbach's alphas for SF PCS and the SF MCS were found to be 0.92 and 0.88 , respectively. 


\section{Construct Validity of the SF-12}

Both PCS and MCS were able to detect significantly lower QoL in patients with Type 2 diabetes who were obese, compared with those who were not obese $[\mathrm{t}(335)=$ 3.96, $\mathrm{p}<0.000$ for PCS, and $\mathrm{t}(335)=3.05, \mathrm{p}=0.002$ for MCS]. The PCS score was significantly negatively correlated to the Charlson comorbidity score (Pearson's $\mathrm{r}=$ 0.193, $\mathrm{n}=347, \mathrm{p}<0.000)$. Both the PCS and MCS scores were significantly lower in patients who had one or more hospitalizations in the past one year, as compared to those who did not have any such hospitalizations $[\mathrm{t}(346)=4.5, \mathrm{p}<0.000$ for PCS, and $\mathrm{t}(346)=$ 2.1, $\mathrm{p}=0.032$ for MCS]. One way ANOVAs, testing for differences in PCS and MCS scores among those who did not have ER visits compared with those who had between one and 2 visits, and more than two visits, were significant overall $[\mathrm{F}(2,345)=7.96, \mathrm{p}<$ 0.000 for PCS, and $\mathrm{F}(2,345)=4.37, \mathrm{p}=0.013$ for MCS $]$.

Other tests were performed to compare the ability of the SF-12 to detect subgroup differences. T-tests revealed no significant differences in both PCS and MCS scores based on level of glycemic control. T-tests revealed significantly poorer PCS scores in the insulin-treated group compared to the non-insulin treated group $[\mathrm{t}(343)=$ 3.72, $\mathrm{p}<0.000$ ], but no such significant differences were found for MCS scores.

Similarly, a one-way ANOVA was performed to calculate difference in PCS score across diabetes treatment-related groups. The overall F-test for this ANOVA, was significant $[F(3,335)=3.96, p<0.000]$. The group reporting use of both insulin and oral medications for their diabetes had the greatest negative impact of diabetes on their PCS score, followed by the group on insulin alone, the group on oral medication only, and the group on diet and exercise alone, in that order, as reported earlier. Post-hoc tests using the 
Bonferroni correction revealed significantly lower PCS scores in the group on oral medications and insulin, as compared to the group on oral medications alone $(\mathrm{p}=0.014)$. No significant differences among diabetes treatment groups were found on MCS scores. The PCS score was significantly lower in patients with at least one diabetes-related complication [t $(345)=2.46, \mathrm{p}=0.014]$, but no significant differences were found for MCS scores.

\section{Results for Objective B}

\section{Hypothesis 1a}

Given the nature of the scoring of the ADDQoL, a normal spread of scores and normal distributions for the ADDQoL score cannot be expected. Spearman's rank order correlation coefficient between recent A1C and ADDQoL score was found to be significant at $-0.20(n=353, p<0.000)$, while the correlation coefficient between average A1C and ADDQoL score was also found to be significant at $-0.19(\mathrm{n}=376, \mathrm{p}<$ $0.000)$.

\section{Hypothesis 1b}

There was no significant correlation between recent A1C and PCS scores of the SF-12 (Spearman's $r=-0.06, n=324, p=0.276$ ), and no significant correlation between recent A1C and MCS scores of the SF-12 (Spearman's $r=-0.05, n=324, p=0.366$ ). Again, there was no significant correlation between average A1C and PCS scores of the SF-12 (Spearman's $\mathrm{r}=-0.047, \mathrm{n}=347, \mathrm{p}=0.388$ ), and no significant correlation 
between average A1C and MCS scores of the SF-12 (Spearman's $r=-0.08, n=347, p=$ $0.123)$.

\section{Hypothesis 2}

Hotelling's t-test was used to test for the difference of two dependent correlations from the same sample. The pairs of dependent correlations tested were: r(A1C, ADDQoL) versus r(A1C, PCS), and r(A1C, ADDQoL versus r(A1C, MCS). These comparisons were made for recent A1C levels as well as for average A1C levels. Only those cases were considered where ADDQoL, PCS and MCS scores were available. For recent A1Cs, the number of such cases was 319, while for average A1Cs, the number of such cases was 342. The difference between the two dependent correlations was considered significant at the 0.05 level if the value of the calculated t-statistic was $\geq 1.96$, and considered significant at the 0.01 level if the value of the calculated t-statistic was $\geq 2.16$.

Using recent A1C levels, the difference in the correlations, r(A1C, ADDQoL) versus $\mathrm{r}(\mathrm{A} 1 \mathrm{C}, \mathrm{PCS})$, was significant $(\mathrm{t}=-2.00, \mathrm{n}=319, \mathrm{p}<0.05)$; the difference in the correlations, $\mathrm{r}(\mathrm{A} 1 \mathrm{C}, \mathrm{ADDQ} \mathrm{L})$ versus $\mathrm{r}(\mathrm{A} 1 \mathrm{C}, \mathrm{MCS})$, was also significant $(\mathrm{t}=-2.6, \mathrm{n}=$ 319, $\mathrm{p}<0.05)$. Using respondents' average A1C levels, the difference in the correlations, r(A1C, ADDQoL) versus r(A1C, PCS), was significant $(t=-2.05, n=342, p<0.05)$, but the difference in the correlations, $\mathrm{r}(\mathrm{A} 1 \mathrm{C}$, ADDQoL) versus r(A1C, MCS), was not significant $(\mathrm{t}=-1.77, \mathrm{n}=342, \mathrm{p}<0.05)$. 


\section{Hypothesis 3}

Two sets of multiple regression analyses were conducted to predict ADDQoL using the hierarchical regression technique. One set used average A1C as the primary independent variable, while the second used recent A1C as the primary independent variable. Race was not included as a predictor in the models since $94 \%$ of the respondents were white, and other predictors were checked for the presence of multicollinearity. This was important since there were multiple indicators of disease severity and health status that were believed to influence QoL in some way. To further check for multicollinearity, tolerance and variance inflation statistics were also requested while running all of the regression analyses. Since multicollinearity was not detected in any of the regression models, all predictors were included in the models.

\section{Using average A1C:}

The results of the hierarchical regression are presented in Tables 18 and 19. The first block of variables, including average A1C, insulin use, complications score, and duration of diabetes, increased the $\mathrm{R}^{2}$ by $6.0 \%$, which was significant (F change $=4.79$, $\mathrm{p}$ $=0.001)$. Demographic variables introduced in the third block increased the $\mathrm{R}^{2}$ by $4.4 \%$, which was also significant $(\mathrm{F}$ change $=2.44, \mathrm{p}=0.026)$. The three models obtained including additional blocks of variables, were all significant (See Table 18). The final model had $\mathrm{R}^{2}=0.13$, adjusted $\mathrm{R}^{2}=0.09, \mathrm{~F}(14,290)=3.18, \mathrm{p}<0.000$. The significant predictors in the final model were diabetes duration $(\mathrm{p}=0.05)$, number of ER visits in the past year $(p=0.038)$, and age $(p=0.022)$ (See Table 19). 
Table 18: Summary of the Block-wise Entry of Predictors in the Hierarchical Regression Model Predicting ADDQoL Scores Using Average A1C

\begin{tabular}{llllllll}
\hline Model & R Square & $\begin{array}{l}\text { Adjusted R } \\
\text { Square }\end{array}$ & $\begin{array}{l}\text { R Square } \\
\text { Change }\end{array}$ & $\begin{array}{l}\text { F } \\
\text { Change }\end{array}$ & $\begin{array}{l}\text { Sig. F } \\
\text { Change }\end{array}$ & $\begin{array}{l}\text { F } \\
\text { Statistic }\end{array}$ & $\begin{array}{l}\text { Sig. F } \\
\text { Statistic }\end{array}$ \\
\hline $1^{\mathrm{a}}$ & 0.06 & 0.05 & 0.06 & 4.79 & 0.001 & 4.79 & 0.001 \\
$2^{\mathrm{b}}$ & 0.09 & 0.07 & 0.03 & 2.38 & 0.05 & 3.63 & 0.000 \\
$3^{\mathrm{c}}$ & 0.13 & 0.09 & 0.04 & 2.44 & 0.03 & 3.18 & 0.000 \\
& & & & & & & \\
\hline
\end{tabular}

Dependent Variable: ADDQoL average weighted impact score

a. Predictors: (Constant), Diabetes duration, Diabetes Complications Score, A1C (average) category, Insulin use status

b. Predictors: (Constant), Diabetes duration, Diabetes Complications Score, A1C (average) category, Insulin use status, Obesity Status, Charlson Comorbidity Score, Number of ER visits, Number of hospital visits

c. Predictors: (Constant), Diabetes duration, Diabetes Complications Score, A1C (average) category, Insulin use status, Obesity Status, Charlson Comorbidity Score, Number of ER visits, Number of hospital visits, Private Insurance, Government insurance, Gender, Education, Marital status, Age 
Table 19: Results of the Hierarchical Regression Model Predicting ADDQoL Scores Using Average A1C

\begin{tabular}{|c|c|c|c|c|c|}
\hline & $\begin{array}{l}\text { Predictor } \\
\text { Variable }\end{array}$ & Beta & $\begin{array}{l}\text { Std. } \\
\text { Error }\end{array}$ & $\begin{array}{l}\text { Test } \\
\text { statistic (t) }\end{array}$ & $\begin{array}{l}\text { Sig. } \\
\text { p }\end{array}$ \\
\hline 1. & A1C (average) category & -0.222 & 0.204 & -1.09 & 0.269 \\
\hline 2. & Insulin use & -0.305 & 0.230 & -1.32 & 0.187 \\
\hline 3. & Diabetes complications score & -0.180 & 0.153 & -1.18 & 0.239 \\
\hline 4. & Diabetes duration & $-0.024 *$ & 0.012 & -1.97 & 0.050 \\
\hline 5. & Obesity status & -0.237 & 0.210 & -1.13 & 0.260 \\
\hline 6. & Charlson comorbidity score & 0.071 & 0.047 & 1.50 & 0.134 \\
\hline 7. & Number of hospital visits & -0.104 & 0.213 & -0.49 & 0.625 \\
\hline 8. & Number of ER visits & $-0.162 *$ & 0.077 & -2.10 & 0.036 \\
\hline 9. & Govt. insurance & 0.310 & 0.373 & 0.83 & 0.406 \\
\hline 10. & Pvt. insurance & 0.737 & 0.383 & 1.93 & 0.055 \\
\hline 11. & Age & $0.492 *$ & 0.214 & 2.30 & 0.022 \\
\hline 12. & Gender & 0.344 & 0.204 & 1.68 & 0.093 \\
\hline 13. & Marital status & -0.096 & 0.210 & -0.46 & 0.648 \\
\hline 14. & Education & 0.401 & 0.231 & 1.73 & 0.084 \\
\hline
\end{tabular}

* significant at 0.05 level

Model fit statistics:

$R^{2}=0.13$, adjusted $R^{2}=0.09, F(14,290)=3.18, p<0.000$ 


\section{Using recent $\mathrm{A} 1 \mathrm{C}$ :}

The results of the hierarchical regression are presented in Tables 20 and 21. The first block of variables, including recent A1C, insulin use, complications score, and duration of diabetes, increased the $\mathrm{R}^{2}$ by $6.2 \%$, which was significant ( $\mathrm{F}$ change $=4.64$, $\mathrm{P}$ $=0.001)$. Demographic variables introduced in the third block increased the $\mathrm{R}^{2}$ by $5.2 \%$, which was also significant $(\mathrm{F}$ change $=2.74, \mathrm{p}=0.013$ ). The three models obtained including additional blocks of variables were all significant. The final model had $\mathrm{R}^{2}=$ 0.14 , adjusted $\mathrm{R}^{2}=0.10, \mathrm{~F}(14,270)=3.17, \mathrm{p}<0.000$ (See Table 20). The significant predictors in the final model were number of ER visits in the past year $(p=0.049)$, private insurance $(\mathrm{p}=0.025)$, and age $(\mathrm{p}=0.017)$ (See Table 21). 
Table 20: Summary of the Block-wise Entry of Predictors in the Hierarchical Regression Model Predicting ADDQoL Scores Using Recent A1C

\begin{tabular}{llllllll}
\hline Model & R Square & $\begin{array}{l}\text { Adjusted R } \\
\text { Square }\end{array}$ & $\begin{array}{l}\text { R Square } \\
\text { Change }\end{array}$ & $\begin{array}{l}\text { F } \\
\text { Change }\end{array}$ & $\begin{array}{l}\text { Sig. F } \\
\text { Change }\end{array}$ & $\begin{array}{l}\text { F } \\
\text { Statistic }\end{array}$ & $\begin{array}{l}\text { Sig. F } \\
\text { Statistic }\end{array}$ \\
\hline $1^{\mathrm{a}}$ & 0.06 & 0.05 & 0.06 & 4.64 & 0.001 & 4.64 & 0.001 \\
$2^{\mathrm{b}}$ & 0.09 & 0.06 & 0.03 & 2.02 & 0.09 & 3.36 & 0.001 \\
$3^{\mathrm{c}}$ & 0.14 & 0.10 & 0.05 & 2.74 & 0.01 & 3.17 & 0.000 \\
& & & & & & & \\
\hline
\end{tabular}

Dependent Variable: ADDQoL average weighted impact score

a. Predictors: (Constant), Diabetes duration, Diabetes Complications Score, A1C (recent) category, Insulin use status

b. Predictors: (Constant), Diabetes duration, Diabetes Complications Score, A1C (recent) category, Insulin use status, Obesity Status, Charlson Comorbidity Score, Number of ER visits, Number of hospital visits

c. Predictors: (Constant), Diabetes duration, Diabetes Complications Score, A1C (recent) category, Insulin use status, Obesity Status, Charlson Comorbidity Score, Number of ER visits, Number of hospital visits, Private Insurance, Government insurance, Gender, Education, Marital status, Age 
Table 21: Results of the Hierarchical Regression Model Predicting ADDQoL Scores Using Recent A1C

\begin{tabular}{|c|c|c|c|c|c|}
\hline & $\begin{array}{l}\text { Predictor } \\
\text { Variable }\end{array}$ & Beta & $\begin{array}{l}\text { Std. } \\
\text { Error }\end{array}$ & $\begin{array}{l}\text { Test } \\
\text { statistic (t) }\end{array}$ & $\begin{array}{l}\text { Sig. } \\
\text { p }\end{array}$ \\
\hline 1. & A1C (average) category & -0.298 & 0.211 & -1.41 & 0.159 \\
\hline 2. & Insulin use & -0.229 & 0.238 & -0.96 & 0.337 \\
\hline 3. & Diabetes complications score & -0.151 & 0.159 & -0.95 & 0.346 \\
\hline 4. & Diabetes duration & -0.025 & 0.013 & -1.93 & 0.055 \\
\hline 5. & Obesity status & -0.243 & 0.218 & -1.11 & 0.267 \\
\hline 6. & Charlson comorbidity score & 0.050 & 0.067 & 0.74 & 0.462 \\
\hline 7. & Number of hospital visits & -0.107 & 0.224 & -0.48 & 0.631 \\
\hline 8. & Number of ER visits & $-0.154 *$ & 0.078 & -1.98 & 0.049 \\
\hline 9. & Govt. insurance & 0.373 & 0.390 & 0.96 & 0.339 \\
\hline 10. & Pvt. insurance & $0.907 *$ & 0.402 & 2.26 & 0.025 \\
\hline 11. & Age & $0.548 *$ & 0.224 & 2.40 & 0.017 \\
\hline 12. & Gender & 0.320 & 0.213 & 1.50 & 0.134 \\
\hline 13. & Marital status & -0.063 & 0.219 & -0.29 & 0.772 \\
\hline 14. & Education & 0.453 & 0.238 & 1.90 & 0.059 \\
\hline
\end{tabular}

* significant at 0.05 level

Model fit statistics:

$R^{2}=0.14$, adjusted $R^{2}=0.09, F(14,270)=3.17, p<0.000$ 


\section{Hypothesis 4 for SF PCS}

Two sets of multiple regression analyses were conducted to predict SF PCS scores using the hierarchical regression technique. As for hypothesis 3, one set used average A1C as the primary independent variable, while the second used recent $\mathrm{A} 1 \mathrm{C}$ as the primary independent variable.

\section{Using average A1C:}

The results of the hierarchical regression are presented in Tables 22 and 23. The first block of variables, including average A1C, insulin use, complications score, and duration of diabetes, increased the $\mathrm{R}^{2}$ by $5.1 \%$, which was significant ( $\mathrm{F}$ change $=3.71$, $\mathrm{p}$ $=0.006$ ). The second block of variables, including obesity status, Charlson comorbidity score, number of hospital visits, number of ER visits increased the $\mathrm{R}^{2}$ by $11.2 \%$, which was also significant $(\mathrm{F}$ change $=9.04, \mathrm{p}<0.000)$. Demographic variables introduced in the third block increased the $\mathrm{R}^{2}$ by $8.3 \%$, which was also significant (F change $=4.86$, $\mathrm{p}<0.000$ ). The three models obtained including additional blocks of variables, were all significant. The final model had $\mathrm{R}^{2}=0.25$, adjusted $\mathrm{R}^{2}=0.21, \mathrm{~F}(14,264)=6.14$, $\mathrm{p}<0.000$ (See Table 22). The significant predictors in the final model were obesity status $(\mathrm{p}<0.000)$, number of hospital visits in the past year $(\mathrm{p}=0.001)$, and education $(\mathrm{p}<$ 0.000) (See Table 23). 
Table 22: Summary of the Block-wise Entry of Predictors in the Hierarchical Regression Model Predicting SF-PCS Scores Using Average A1C

\begin{tabular}{llllllll}
\hline Model & R Square & $\begin{array}{l}\text { Adjusted R } \\
\text { Square }\end{array}$ & $\begin{array}{l}\text { R Square } \\
\text { Change }\end{array}$ & $\begin{array}{l}\text { F } \\
\text { Change }\end{array}$ & $\begin{array}{l}\text { Sig. F } \\
\text { Change }\end{array}$ & $\begin{array}{l}\text { F } \\
\text { Statistic }\end{array}$ & $\begin{array}{l}\text { Sig. F } \\
\text { Statistic }\end{array}$ \\
\hline $1^{\mathrm{a}}$ & 0.05 & 0.04 & 0.05 & 3.71 & 0.006 & 3.71 & 0.006 \\
$2^{\mathrm{b}}$ & 0.16 & 0.14 & 0.11 & 9.04 & 0.000 & 6.59 & 0.000 \\
$3^{\mathrm{c}}$ & 0.25 & 0.21 & 0.08 & 4.86 & 0.000 & 6.17 & 0.000 \\
& & & & & & & \\
\hline
\end{tabular}

Dependent Variable: SF PCS

a. Predictors: (Constant), Diabetes duration, Diabetes Complications Score, A1C (average) category, Insulin use status

b. Predictors: (Constant), Diabetes duration, Diabetes Complications Score, A1C (average) category, Insulin use status, Obesity Status, Charlson Comorbidity Score, Number of ER visits, Number of hospital visits

c. Predictors: (Constant), Diabetes duration, Diabetes Complications Score, A1C (average) category, Insulin use status, Obesity Status, Charlson Comorbidity Score, Number of ER visits, Number of hospital visits, Private Insurance, Government insurance, Gender, Education, Marital status, Age 
Table 23: Results of the Hierarchical Regression Model Predicting SF-PCS Scores Using Average A1C

\begin{tabular}{|c|c|c|c|c|c|}
\hline & $\begin{array}{l}\text { Predictor } \\
\text { Variable }\end{array}$ & Beta & $\begin{array}{l}\text { Std. } \\
\text { Error }\end{array}$ & $\begin{array}{l}\text { Test } \\
\text { statistic (t) }\end{array}$ & $\begin{array}{l}\text { Sig. } \\
\text { p }\end{array}$ \\
\hline 1. & A1C (average) category & 0.947 & 1.524 & 0.62 & 0.535 \\
\hline 2. & Insulin use & -2.317 & 1.733 & -1.34 & 0.182 \\
\hline 3. & Diabetes complications score & 0.128 & 1.118 & 0.12 & 0.909 \\
\hline 4. & Diabetes duration & -0.165 & 0.093 & -1.78 & 0.077 \\
\hline 5. & Obesity status & $-6.278 *$ & 1.565 & -4.01 & 0.000 \\
\hline 6. & Charlson comorbidity score & -0.345 & 0.355 & -0.97 & 0.332 \\
\hline 7. & Number of hospital visits & $-5.044 *$ & 1.556 & -3.24 & 0.001 \\
\hline 8. & Number of ER visits & -0.084 & 0.557 & -0.15 & 0.879 \\
\hline 9. & Govt. insurance & 3.587 & 2.736 & 1.31 & 0.191 \\
\hline 10. & Pvt. insurance & 5.068 & 2.797 & 1.81 & 0.071 \\
\hline 11. & Age & -2.815 & 1.607 & -1.75 & 0.081 \\
\hline 12. & Gender & -0.321 & 1.516 & -0.21 & 0.832 \\
\hline 13. & Marital status & 1.266 & 1.565 & 0.81 & 0.419 \\
\hline 14. & Education & $6.917 *$ & 1.702 & 4.06 & 0.000 \\
\hline
\end{tabular}




\section{Using recent A1C:}

The results of the hierarchical regression are presented in Tables 24 and 25. The first block of variables, including recent A1C, insulin use, complications score, and duration of diabetes increased the $\mathrm{R}^{2}$ by $4.2 \%$, which was significant $(\mathrm{F}$ change $=2.78$, $p=0.027)$. The second block of variables, including obesity status, Charlson comorbidity score, number of hospital visits, number of ER visits increased the $\mathrm{R}^{2}$ by $11.4 \%$, which was also significant $(\mathrm{F}$ change $=8.41, \mathrm{p}<0.000)$. Demographic variables introduced in the third block increased the $\mathrm{R}^{2}$ by $8.5 \%$, which was also significant $(\mathrm{F}$ change $=4.54$, $\mathrm{p}<0.000$ ). The three models obtained including additional blocks of variables, were all significant. The final model had $\mathrm{R}^{2}=0.24$, adjusted $\mathrm{R}^{2}=0.20, \mathrm{~F}(14,244)=5.51$, $\mathrm{p}<0.000$ (See Table 24). The significant predictors in the final model were obesity status $(\mathrm{p}<0.000)$, number of hospital visits in the past year $(\mathrm{p}=0.009)$, education $(\mathrm{p}<0.000)$, and private health insurance $(\mathrm{p}=0.044)$ (See Table 25). 
Table 24: Summary of the Block-wise Entry of Predictors in the Hierarchical Regression Model Predicting SF-PCS Scores Using Recent A1C

\begin{tabular}{llllllll}
\hline Model & R Square & $\begin{array}{l}\text { Adjusted R } \\
\text { Square }\end{array}$ & $\begin{array}{l}\text { R Square } \\
\text { Change }\end{array}$ & $\begin{array}{l}\text { F } \\
\text { Change }\end{array}$ & $\begin{array}{l}\text { Sig. F } \\
\text { Change }\end{array}$ & $\begin{array}{l}\text { F } \\
\text { Statistic }\end{array}$ & $\begin{array}{l}\text { Sig. F } \\
\text { Statistic }\end{array}$ \\
\hline $1^{\mathrm{a}}$ & 0.04 & 0.03 & 0.04 & 2.78 & 0.03 & 2.78 & 0.027 \\
$2^{\mathrm{b}}$ & 0.16 & 0.13 & 0.11 & 8.41 & 0.000 & 5.76 & 0.000 \\
$3^{\mathrm{c}}$ & 0.24 & 0.20 & 0.09 & 4.53 & 0.000 & 5.51 & 0.000 \\
& & & & & & & \\
\hline
\end{tabular}

Dependent Variable: SF PCS

a. Predictors: (Constant), Diabetes duration, Diabetes Complications Score, A1C (recent) category, Insulin use status

b. Predictors: (Constant), Diabetes duration, Diabetes Complications Score, A1C (recent) category, Insulin use status, Obesity Status, Charlson Comorbidity Score, Number of ER visits, Number of hospital visits

c. Predictors: (Constant), Diabetes duration, Diabetes Complications Score, A1C (recent) category, Insulin use status, Obesity Status, Charlson Comorbidity Score, Number of ER visits, Number of hospital visits Private Insurance, Government insurance, Gender, Education, Marital status, Age 
Table 25: Results of the Hierarchical Regression Model Predicting SF-PCS Scores Using Recent A1C

\begin{tabular}{|c|c|c|c|c|c|}
\hline & $\begin{array}{l}\text { Predictor } \\
\text { Variable }\end{array}$ & Beta & $\begin{array}{l}\text { Std. } \\
\text { Error }\end{array}$ & $\begin{array}{l}\text { Test } \\
\text { statistic (t) }\end{array}$ & $\begin{array}{l}\text { Sig. } \\
\text { p }\end{array}$ \\
\hline 1. & A1C (average) category & 0.030 & 1.571 & 0.02 & 0.984 \\
\hline 2. & Insulin use & -1.606 & 1.785 & -0.90 & 0.369 \\
\hline 3. & Diabetes complications score & 0.883 & 1.157 & 0.76 & 0.446 \\
\hline 4. & Diabetes duration & -0.156 & 0.096 & -1.62 & 0.106 \\
\hline 5. & Obesity status & $-6.018 *$ & 1.616 & -3.72 & 0.000 \\
\hline 6. & Charlson comorbidity score & -0.705 & 0.520 & -1.36 & 0.177 \\
\hline 7. & Number of hospital visits & $-4.352 *$ & 1.643 & -2.65 & 0.009 \\
\hline 8. & Number of ER visits & -0.005 & 0.559 & -0.10 & 0.924 \\
\hline 9. & Govt. insurance & 4.005 & 2.839 & 1.41 & 0.160 \\
\hline 10. & Pvt. insurance & $5.895 *$ & 2.912 & 2.03 & 0.044 \\
\hline 11. & Age & -1.873 & 1.681 & -1.11 & 0.266 \\
\hline 12. & Gender & -0.853 & 1.572 & -0.54 & 0.588 \\
\hline 13. & Marital status & 0.741 & 1.621 & 0.46 & 0.648 \\
\hline 14. & Education & $7.081 *$ & 1.749 & 4.05 & 0.000 \\
\hline
\end{tabular}

* significant at 0.05 level

Model fit statistics:

$R^{2}=0.24$, adjusted $R^{2}=0.20, F(14,244)=5.51, p<0.000$ 


\section{Hypothesis 4 for SF MCS}

For the SF PCS, two sets of multiple regression analyses were conducted to predict SF MCS scores using the hierarchical regression technique. One set used average A1C as the primary independent variable, while the second used recent $\mathrm{A} 1 \mathrm{C}$ as the primary independent variable.

\section{Using average A1C:}

The results of the hierarchical regression are presented in Tables 26 and 27. The first block of variables, including average A1C, insulin use, complications score, and duration of diabetes increased the $\mathrm{R}^{2}$ by only $1.1 \%$, which was not significant ( $\mathrm{F}$ change $=$ 0.782, $\mathrm{p}=0.538$ ). The second block of variables, including obesity status, Charlson comorbidity score, number of hospital visits, number of ER visits increased the $\mathrm{R}^{2}$ by 5.5\%, which was also significant $(\mathrm{F}$ change $=3.96, \mathrm{p}=0.004)$. Demographic variables introduced in the third block increased the $\mathrm{R}^{2}$ by $6.9 \%$, which was also significant ( $\mathrm{F}$ change $=3.52, \mathrm{p}=0.002$ ). The models consisting of the second and third blocks, and three blocks all together were significant $[\mathrm{F}(8,270)=2.38, \mathrm{p}=0.017$, and $\mathrm{F}(14,264)=$ 2.95, $\mathrm{p}<0.000$ respectively] . The final model had $\mathrm{R}^{2}=0.14$, adjusted $\mathrm{R}^{2}=0.09$, $\mathrm{F}(14,264)=2.95, \mathrm{p}<0.000$ (See Table 26). The significant predictors in the final model were obesity status $(\mathrm{p}=0.014)$, and age $(\mathrm{p}<0.000)$ (See Table 27). 
Table 26: Summary of the Block-wise Entry of Predictors in the Hierarchical Regression Model Predicting SF-MCS Scores Using Average A1C

\begin{tabular}{llllllll}
\hline Model & R Square & $\begin{array}{l}\text { Adjusted R } \\
\text { Square }\end{array}$ & $\begin{array}{l}\text { R Square } \\
\text { Change }\end{array}$ & $\begin{array}{l}\text { F } \\
\text { Change }\end{array}$ & $\begin{array}{l}\text { Sig. F } \\
\text { Change }\end{array}$ & $\begin{array}{l}\text { F } \\
\text { Statistic }\end{array}$ & $\begin{array}{l}\text { Sig. F } \\
\text { Statistic }\end{array}$ \\
\hline $1^{\text {a }}$ & 0.01 & -0.003 & 0.01 & 0.78 & 0.538 & 0.78 & 0.538 \\
$2^{\mathrm{b}}$ & 0.07 & 0.04 & 0.06 & 3.96 & 0.004 & 2.39 & 0.017 \\
$3^{\mathrm{c}}$ & 0.14 & 0.09 & 0.07 & 3.52 & 0.002 & 2.95 & 0.000 \\
& & & & & & & \\
\hline
\end{tabular}

Dependent Variable: SF MCS

a. Predictors: (Constant), Diabetes duration, Diabetes Complications Score, A1C (average) category, Insulin use status

b. Predictors: (Constant), Diabetes duration, Diabetes Complications Score, A1C (average) category, Insulin use status, Obesity Status, Charlson Comorbidity Score, Number of ER visits, Number of hospital visits

c. Predictors: (Constant), Diabetes duration, Diabetes Complications Score, A1C (average) category, Insulin use status, Obesity Status, Charlson Comorbidity Score, Number of ER visits, Number of hospital visits, Private Insurance, Government insurance, Gender, Education, Marital status, Age 
Table 27: Results of the Hierarchical Regression Model Predicting SF-MCS Scores Using Average A1C

\begin{tabular}{|c|c|c|c|c|c|}
\hline & $\begin{array}{l}\text { Predictor } \\
\text { Variable }\end{array}$ & Beta & $\begin{array}{l}\text { Std. } \\
\text { Error }\end{array}$ & $\begin{array}{l}\text { Test } \\
\text { statistic (t) }\end{array}$ & $\begin{array}{l}\text { Sig. } \\
\text { p }\end{array}$ \\
\hline 1. & A1C (average) category & -0.678 & 1.556 & -0.44 & 0.663 \\
\hline 2. & Insulin use & 0.221 & 1.769 & 0.13 & 0.901 \\
\hline 3. & Diabetes complications score & -0.451 & 1.141 & -0.40 & 0.693 \\
\hline 4. & Diabetes duration & -0.008 & 0.095 & -0.92 & 0.356 \\
\hline 5. & Obesity status & $-3.963 *$ & 1.597 & -2.48 & 0.014 \\
\hline 6. & Charlson comorbidity score & 0.362 & 0.362 & 1.00 & 0.319 \\
\hline 7. & Number of hospital visits & -1.971 & 1.589 & -1.24 & 0.216 \\
\hline 8. & Number of ER visits & -0.747 & 0.568 & -1.31 & 0.190 \\
\hline 9. & Govt. insurance & 1.637 & 2.793 & 0.59 & 0.558 \\
\hline 10. & Pvt. insurance & 4.381 & 2.855 & 1.54 & 0.126 \\
\hline 11. & Age & $6.628 *$ & 1.640 & 4.04 & 0.000 \\
\hline 12. & Gender & 0.602 & 1.547 & 0.39 & 0.697 \\
\hline 13. & Marital status & 0.782 & 1.597 & 0.50 & 0.625 \\
\hline 14. & Education & 2.747 & 1.737 & 1.58 & 0.115 \\
\hline
\end{tabular}

* significant at 0.05 level

Model fit statistics:

$R^{2}=0.14$, adjusted $R^{2}=0.09, F(14,264)=2.95, p<0.000$ 


\section{Using recent A1C:}

The results of the hierarchical regression are presented in Tables 28 and 29. The first block of variables, including recent A1C, insulin use, complications score, and duration of diabetes increased the $\mathrm{R}^{2}$ by only $1.0 \%$, which was not significant. The second block of variables, including obesity status, Charlson comorbidity score, number of hospital visits, number of ER visits increased the $\mathrm{R}^{2}$ by $7.4 \%$, which was also significant $(\mathrm{F}$ change $=4.30, \mathrm{p}=0.002)$. Demographic variables introduced in the third

block increased the $\mathrm{R}^{2}$ by $8.1 \%$, which was also significant $(\mathrm{F}$ change $=3.88, \mathrm{p}=0.001)$. The models consisting of the second and third blocks, and three blocks all together were significant. The final model had $\mathrm{R}^{2}=0.16$, adjusted $\mathrm{R}^{2}=0.11, \mathrm{~F}(14,244)=3.19$, $\mathrm{p}<0.000$ (See Table 28). The significant predictors in the final model were obesity status $(\mathrm{p}=0.005)$ and age $(\mathrm{p}<0.000)$ (See Table 29). 
Table 28: Summary of the Block-wise Entry of Predictors in the Hierarchical Regression Model Predicting SF-MCS Scores Using Recent A1C

\begin{tabular}{llllllll}
\hline Model & R Square & $\begin{array}{l}\text { Adjusted R } \\
\text { Square }\end{array}$ & $\begin{array}{l}\text { R Square } \\
\text { Change }\end{array}$ & $\begin{array}{l}\text { F } \\
\text { Change }\end{array}$ & $\begin{array}{l}\text { Sig. F } \\
\text { Change }\end{array}$ & $\begin{array}{l}\text { F } \\
\text { Statistic }\end{array}$ & $\begin{array}{l}\text { Sig. F } \\
\text { Statistic }\end{array}$ \\
\hline $1^{\mathrm{a}}$ & 0.01 & -0.01 & 0.01 & 0.67 & 0.617 & 0.62 & 0.617 \\
$2^{\mathrm{b}}$ & 0.07 & 0.05 & 0.06 & 4.31 & 0.002 & 2.50 & 0.012 \\
$3^{\mathrm{c}}$ & 0.16 & 0.11 & 0.08 & 3.88 & 0.001 & 3.19 & 0.000 \\
& & & & & & & \\
\hline
\end{tabular}

Dependent Variable: SF MCS

a. Predictors: (Constant), Diabetes duration, Diabetes Complications Score, A1C (recent) category, Insulin use status

b. Predictors: (Constant), Diabetes duration, Diabetes Complications Score, A1C (recent) category, Insulin use status, Obesity Status, Charlson Comorbidity Score, Number of ER visits, Number of hospital visits

c. Predictors: (Constant), Diabetes duration, Diabetes Complications Score, A1C (recent) category, Insulin use status, Obesity Status, Charlson Comorbidity Score, Number of ER visits, Number of hospital visits Private Insurance, Government insurance, Gender, Education, Marital status, Age 
Table 29: Results of the Hierarchical Regression Model Predicting SF-MCS Scores Using Recent A1C

\begin{tabular}{|c|c|c|c|c|c|}
\hline & $\begin{array}{l}\text { Predictor } \\
\text { Variable }\end{array}$ & Beta & $\begin{array}{l}\text { Std. } \\
\text { Error }\end{array}$ & $\begin{array}{l}\text { Test } \\
\text { statistic (t) }\end{array}$ & $\begin{array}{l}\text { Sig. } \\
\mathbf{p}\end{array}$ \\
\hline 1. & A1C (average) category & -0.080 & 1.590 & -0.05 & 0.961 \\
\hline 2. & Insulin use & 0.378 & 1.806 & 0.21 & 0.834 \\
\hline 3. & Diabetes complications score & 0.070 & 1.171 & 0.06 & 0.950 \\
\hline 4. & Diabetes duration & -0.108 & 0.097 & -1.11 & 0.270 \\
\hline 5. & Obesity status & $-4.581 *$ & 1.635 & -2.80 & 0.005 \\
\hline 6. & Charlson comorbidity score & -0.083 & 0.527 & -0.16 & 0.874 \\
\hline 7. & Number of hospital visits & -1.850 & 1.663 & -1.11 & 0.267 \\
\hline 8. & Number of ER visits & -0.792 & 0.565 & -1.40 & 0.163 \\
\hline 9. & Govt. insurance & 2.193 & 2.872 & 0.76 & 0.446 \\
\hline 10. & Pvt. insurance & 5.412 & 2.946 & 1.84 & 0.067 \\
\hline 11. & Age & $7.104 *$ & 1.701 & 4.18 & 0.000 \\
\hline 12. & Gender & 0.891 & 1.591 & 0.56 & 0.576 \\
\hline 13. & Marital status & 1.026 & 1.640 & 0.63 & 0.532 \\
\hline 14. & Education & 3.111 & 1.770 & 1.76 & 0.080 \\
\hline
\end{tabular}

* significant at 0.05 level

Model fit statistics:

$R^{2}=0.16$, adjusted $R^{2}=0.11, F(14,244)=3.19, p<0.000$ 


\section{Power of the Study Results}

The a priori power analyses conducted in order to ascertain the sample size required for the statistical analyses in the study have been discussed in Chapter 3. Posthoc power analyses are conducted after a study has been completed in order to ascertain whether the study had the necessary power to be able to make conclusions out of the study findings. For this purpose, it is necessary to decide upon the alpha level for the analysis, the sample size that was available for the analysis, and the effect size. With this information, it is possible to ascertain the power of the study to detect this effect. Posthoc power analyses when conducted in this manner are sometimes termed as post-hoc power analyses based on observed effects, or a posteriori power procedures.

However, there is a disagreement on whether post hoc power based on observed effects can conclude whether a negative finding is truly negative, since observed power is determined by the observed p-value. When the p-value is small, the post hoc power using observed effects is large and when the p-value is large, the post hoc power is small (Knapp, 1996). If the observed effects were not significant, a power analysis could state that the study had the power to detect even a small effect, and that a non significant result indicates that the effect is indeed zero (Zumbo and Hubley, 1998). Hence, the utility of reporting an observed power calculation on reported effect has been questioned.

Opponents of post-hoc power calculations suggest the use of confidence intervals in the place of post-hoc power calculations (Smith and Bates, 1992). Statisticians convinced the American Psychological Association (APA) to this effect, and APA now suggests the use of confidence intervals in is publications (Wilkinson, 1999). Confidence intervals, the likely range of a true population value, give us an estimate of the amount of 
error involved in our data by telling us about the precision of the statistical estimates. Confidence intervals are related to the concept of the power. The larger the confidence interval, the less the precision in estimation (Hopkins, 2004), and the less power a study has to detect differences between treatment conditions in experiments or between groups of respondents in survey research. The lower (or numerically smaller) limit shows how small the effect might be in the population; the upper limit shows how large the effect might be (Hopkins, 2004). Another suggestion is to report the a priori power calculations

along with the confidence intervals. The discussion on power of the study results reported in this section take into account these viewpoints.

\section{Objective A}

Results of the factor analysis of 18 life-domains of the ADDQoL and eight domains of the SF-12 have been reported in an earlier section. Two standards were considered to build power for the factor analyses of the QoL measures used: at least 10 cases required for each item and a subjects-to-variables ratio no lower than 5 . Going by both these recommendations, the study had the necessary sample size.

\section{Objective B}

Choosing a medium effect size (0.3) (Cohen, 1998) with a required power of 0.8 to 0.9 , a required sample size of 64 to 111 was needed to perform correlation analyses. This study met the sample size requirements for the correlation analyses.

Post-hoc power to detect the significant correlation between average A1C and ADDQoL score $(r=-0.20, n=353, p<0.000)$, was 0.99 , while for the significant 
correlation between recent A1C and ADDQoL score ( $r=-0.19, \mathrm{n}=376, \mathrm{p}<0.000)$, posthoc power was 0.98 . Due to the negligible and non-significant correlations between both types of A1C levels and the SF PCS and SF MCS, post-hoc power analyses were not conducted for these. The 95\% confidence intervals for the correlations calculated for hypotheses $1 \mathrm{a}$ and $1 \mathrm{~b}$ are presented in Table 30.

For a set of predictors explaining $20 \%$ of the variance in the dependent variable and with 14 predictors, a sample size of 84 was needed to achieve a power of 0.8 and 102 was needed to achieve a power of 0.9 . For a set of predictors explaining $10 \%$ of the variance in the dependent variable, and with 14 predictors, a sample size of 174 was needed to achieve a power of 0.8 and 216 was needed to achieve a power of 0.9 . With the regression models used in the study explaining on an average $10 \%$ of the variance in ADDQoL and MCS scores, and 20\% of the variance in PCS scores, the sample size requirements were met.

Post-hoc power calculations, testing the variance accounted for by the predictors in the population QoL scores, involved the calculation of $\mathrm{f}^{2}$ from observed $\mathrm{R}^{2}$, after inputting the number of predictors and deciding on an alpha level at 0.05 . Observed power for the hierarchical regression analyses reported in the study are presented in Table 31. All regression analyses had a post-hoc power greater than 0.9. 
Table 30: Bivariate Correlations and 95\% Confidence Intervals for the Results of Hypothesis 1

\begin{tabular}{lll}
\hline Variables & $\begin{array}{l}\text { Bivariate } \\
\text { correlation }\end{array}$ & $\begin{array}{l}\mathbf{9 5 \%} \\
\text { Confidence Interval }\end{array}$ \\
\hline A1C-average, ADDQoL score & $\mathrm{r}=-0.19, \mathrm{n}=376, \mathrm{p}<0.000$ & $-0.285649,-0.090603$ \\
A1C-recent, ADDQoL score & $\mathrm{r}=-0.20, \mathrm{n}=353, \mathrm{p}<0.000$ & $-0.29816,-0.097654$ \\
A1C-average, SF-PCS score & $\mathrm{r}=-0.047, \mathrm{n}=347, \mathrm{p}=0.388$ & $-0.151535,0.058574$ \\
A1C-recent, SF-PCS score & $\mathrm{r}=-0.06, \mathrm{n}=324, \mathrm{p}=0.276$ & $-0.167865,0.049284$ \\
A1C-average, SF-MCS score & $\mathrm{r}=-0.08, \mathrm{n}=347, \mathrm{p}=0.123$ & $-0.183737,0.025499$ \\
A1C-recent, SF-MCS score & $\mathrm{r}=-0.05, \mathrm{n}=324, \mathrm{p}=0.366$ & $-0.158101,0.059285$ \\
\hline
\end{tabular}


Table 31: Observed Power of the Hierarchical Regressions Models

\begin{tabular}{lll}
\hline Hypothesis & Model Description & Observed power
\end{tabular}

3 Predicting ADDQoL score using avg. A1C

0.95

$R^{2}=0.13$, adjusted $R^{2}=0.09$,

$F(14,290)=3.18, p<0.000$

4

Predicting SF- PCS score using avg. A1C

0.99

$R^{2}=0.25$, adjusted $R^{2}=0.21$,

$F(14,264)=6.14, p<0.000$

4

Predicting SF- MCS score using avg. A1C

$R^{2}=0.14$, adjusted $R^{2}=0.09$,

$F(14,264)=2.93, p<0.000$

3

Predicting ADDQoL score using recent A1C

0.94

$R^{2}=0.14$, adjusted $R^{2}=0.09$,

$F(14,270)=3.08, p<0.000$

4

Predicting SF- PCS score using recent A1C

0.99

$R^{2}=0.24$, adjusted $R^{2}=0.20$,

$F(14,244)=5.51, p<0.000$

4

Predicting SF- MCS score using recent A1C

0.96

$R^{2}=0.16$, adjusted $R^{2}=0.11$,

$F(14,244)=3.2, p<0.000$ 


\section{CHAPTER FIVE: DISCUSSION AND CONCLUSIONS}

This chapter discusses the findings of each study hypothesis and draws conclusions. The chapter also discusses the limitations of the study and makes recommendations for future research.

\section{Discussion for Objective A}

The dimensionality, internal consistency, and construct validity of the SF-12 and the ADDQoL in the study were assessed using the procedures detailed in the Chapter 3.

\section{The ADDQoL in Type 2 Diabetes Patients}

Given the high internal consistency reliability of the scale comprised of the 18 life-domains of the ADDQoL, the satisfactory factor loading of majority the 18 lifedomains on a single factor, and the substantial proportions of variance in all the items explained by this factor, it was concluded to support the one-factor structure for the ADDQoL. Type 2 diabetes patients with A1C levels above 7.0 had poorer QoL (as indicated by lower ADDQoL scores) as compared to those with A1C levels equal to or below 7.0. Also, insulin users were found to have significantly lower ADDQoL scores.

The average weighted ADDQoL score correlated significantly with the diabetes complications score. This indicated greater negative impact of diabetes on QoL in people with more diabetes-related complications. There was a significant difference in ADDQoL scores between groups that had no ICD-9 diagnosis for diabetes-related complications 
versus those who had at least one such complication. Type 2 diabetes patients with a greater number of diabetes-related complications had significantly poorer ADDQoL scores as compared to those patients with no such complications. This supports the construct validity of the ADDQoL. However, there was no significant association with the Charlson comorbidity score, which is an index of general comorbid disease status. It is possible that this was a result of the disease-specific nature of the ADDQoL.

There are other points that can make the case for the use of the ADDQoL to assess the impact of diabetes on QoL. While Type 2 diabetes patients in the study indicated an overall positive outlook towards life, the ADDQoL was able to detect a negative influence of diabetes on their QoL. The ADDQoL has an overview item about current general QoL, and was seen to be a good indicator of general health status. The item showed a statistically significant positive correlation with the PCS and the MCS ( $r=$ 0.488, $\mathrm{n}=344, \mathrm{p}<0.000$ for PCS and $\mathrm{r}=0.559, \mathrm{n}=344, \mathrm{p}<0.000$ for MCS). This general item was able to distinguish between obese and non-obese patients $[\mathrm{t}(363)=3.45$, $\mathrm{p}=0.001$, and had a statistically significant negative correlation with the Charslon comorbidity index $(r=-0.123, \mathrm{n}=375, \mathrm{p}<0.017)$.

Both of these results were non-significant when the ADDQoL average weighted score was used in place of the general QoL overview item. The overview item on general QoL had a mean of $0.81( \pm 1.12)$. On the same scale, the mean of the second overview item assessing the impact of diabetes on QoL was $-1.31( \pm 1.00)$, while the average weighted impact ADDQoL score that was calculated was found to be-1.95( $₫ 1.76)$. Thus, the ADDQoL could show how respondents' general QoL differed from the overall impact that diabetes had on their QoL. Also, this suggests that the domains included in the 
ADDQoL generate a total score that is able to further detect the negative effects that diabetes has on various aspects of life, as reflected in the average weighted impact ADDQoL score.

\section{The SF-12 in Type 2 Diabetes Patients}

Given the high percentage of variance explained by the forced two-factor solution, and the strong factor loadings of the subscales on those factors, it was concluded to support the two-factor structure for the SF-12. As indicated in an earlier section, five subscales of the SF-12 were identified from confirmatory factor analysis to load on one factor, while three subscales were identified to load on the second factor, and both the subscales had high internal consistency reliability. From established research, the subscale 'vitality' has been considered to load on the MCS, but the results from the first part of the confirmatory factor analysis rather showed that the subscale loaded on the PCS. This discrepancy can be explained by understanding that the PCS and the MCS summary measures of the SF-12 are a linear combination of the eight domains measuring distinct health constructs (Ware, Kosinki, Bowker and Gandek, 2002). During development, each item of the SF-12 was selected because it contained unique reliable variance estimating physical or mental health, and the scoring algorithm provided in the SF-12 scoring manual for the PCS and MCS is reflective of this. Internal consistency method of estimating reliability of the SF-12 sub scales using Cronbach's alpha indicated that the SF-PCS and the SF-MCS were both highly reliable.

The ADDQoL was unable to demonstrate any significant differences in QoL between Type 2 diabetes patients who were obese versus those who were not. However, 
with the generic SF-12, both PCS and MCS indicated significantly poorer QoL in obese patients. PCS score was significantly negatively correlated to the Charlson comorbidity score, while both PCS and MCS scores were significantly lower in patients who had one or more hospitalizations in the past one year, as compared to those who did not have any such hospitalizations. Since PCS and MCS were indicated significant differences in QoL between groups defined on the basis of these general health status indicators, the construct validity of the SF-12 was supported. PCS scores were significantly lower in the insulin-treated group as compared to the group not using insulin, as well as in the group that had at least one ICD-9 diagnosis for a diabetes-related complication as compared to the group that had none. This indicated sensitivity of the PCS to aspects of QoL related to diabetes.

\section{Discussion for Objective B}

\section{Hypothesis 1a}

The null hypothesis that A1C level and ADDQoL score are not correlated was rejected. The Spearman's correlation was significant, and in a negative direction. This

result was true for both recent A1C levels as well as average A1C levels in the past year. This indicates that as A1C level rises, QoL, as represented by low ADDQoL scores declines in this sample of patients. However, the magnitude of the correlation was low, suggesting a weak association between A1C and QoL. 


\section{Hypothesis 1b}

The null hypothesis that A1C level and PCS score of the SF-12 are not correlated could not be rejected because the correlation between the two was not significant in this sample of patients. Similarly, the null hypothesis that A1C level and MCS score of the SF-12 are not correlated, could not be rejected.

\section{Hypothesis 2}

The null hypothesis was that there is no difference in the correlations between A1C level and ADDQoL score, and A1C level and the PCS and MCS scores of the SF12. Using recent A1C levels, this hypothesis had to be rejected due to significant differences in the correlations $\mathrm{r}(\mathrm{A} 1 \mathrm{C}, \mathrm{ADDQ} \mathrm{L})$ versus $\mathrm{r}(\mathrm{A} 1 \mathrm{C}, \mathrm{PCS})$, as well as $\mathrm{r}(\mathrm{A} 1 \mathrm{C}$, ADDQoL) versus r(A1C, MCS), as shown by the significant Hotelling's t-statistic. As concluded for an earlier hypothesis, the association of QoL with A1C itself was weak.

Using average A1C levels, this hypothesis had to be rejected for the difference between r(A1C, ADDQoL) versus r(A1C, PCS), due to significant Hotelling's t-statistic. However, we failed to reject the hypothesis of no significant difference in the correlations r(A1C, ADDQoL) versus r(A1C, MCS).

\section{Hypothesis 3}

As mentioned in an earlier section, A1C was transformed into a dichotomous variable based on the ADA's recommended control level of an A1C of 7.0 or less. The null hypothesis that A1C is not a significant predictor of ADDQoL scores could not be rejected. A1C was not a significant predictor in all hierarchical regression models that 
were themselves significant. This was true for models using average A1C as the independent variable (IV) of interest, as well as for models using recent A1C. Most disease severity variables, including diabetes complications score, and insulin use status were not significant predictors of ADDQoL scores. A summary of the regression models predicting ADDQoL score, including model fit and significant variables, is presented in Table 32. In hierarchical regression models, the predictors significantly influencing ADDQoL scores were duration of diabetes, number of ER visits in the past year, health insurance type, and age. Those people with Type 2 diabetes above 60 years of age, having fewer number of ER visits in the past year, having fewer number of years of diabetes, and having a private health insurance plan had significantly higher ADDQoL scores. 
Table 32: Summary of Hierarchical Regression Models in Hypotheses 3 and 4

\begin{tabular}{|c|c|c|}
\hline Hypothesis & $\begin{array}{l}\text { Model } \\
\text { Description }\end{array}$ & Significant Variables \\
\hline 3 & $\begin{array}{l}\text { Predicting ADDQoL score } \\
\text { using average A1C } \\
R^{2}=0.13 \text {, adjusted } R^{2}=0.09 \\
F(14,290)=3.18, p<0.000\end{array}$ & $\begin{array}{l}\text { Number of ER visits } \\
\text { Age } \\
\text { Diabetes duration }\end{array}$ \\
\hline 4 & $\begin{array}{l}\text { Predicting SF- PCS score } \\
\text { using average A1C } \\
R^{2}=0.25 \text {, adjusted } R^{2}=0.21 \text {, } \\
F(14,264)=6.14, p<0.000\end{array}$ & $\begin{array}{l}\text { Obesity status } \\
\text { Number of hospital visits } \\
\text { Education }\end{array}$ \\
\hline 4 & $\begin{array}{l}\text { Predicting SF- MCS score } \\
\text { using average A1C } \\
R^{2}=0.14 \text {, adjusted } R^{2}=0.09 \\
F(14,264)=2.95, p<0.000\end{array}$ & $\begin{array}{l}\text { Obesity status } \\
\text { Age }\end{array}$ \\
\hline 3 & $\begin{array}{l}\text { Predicting ADDQoL score } \\
\text { using recent A1C } \\
R^{2}=0.14 \text {, adjusted } R^{2}=0.09, \\
F(14,270)=3.17, p<0.000\end{array}$ & $\begin{array}{l}\text { Number of ER visits } \\
\text { Private Insurance } \\
\text { Age }\end{array}$ \\
\hline 4 & $\begin{array}{l}\text { Predicting SF- PCS score } \\
\text { using recent A1C } \\
R^{2}=0.24, \text { adjusted } R^{2}=0.20 \\
F(14,244)=5.51, p<0.000\end{array}$ & $\begin{array}{l}\text { Obesity status } \\
\text { Number of hospital visits } \\
\text { Private Insurance } \\
\text { Education }\end{array}$ \\
\hline 4 & $\begin{array}{l}\text { Predicting SF- MCS score } \\
\text { using recent A1C } \\
R^{2}=0.16 \text {, adjusted } R^{2}=0.11 \text {, } \\
F(14,244)=3.19, p<0.000\end{array}$ & $\begin{array}{l}\text { Obesity status } \\
\text { Age }\end{array}$ \\
\hline
\end{tabular}




\section{Hypothesis 4}

A summary of the regression models predicting the SF-PCS score and the SFMCS score respectively, including model fit and significant variables, was presented in Table 32. The null hypothesis that A1C is not a significant predictor of SF-12 PCS scores and SF-12 MCS scores could not be rejected. A1C was not a significant predictor in all hierarchical regression models that were themselves significant. This was true for models using average A1C as the IV of interest, as well as for models using recent A1C. Obesity status was a significant predictor of PCS and MCS scores in all models. Having a college degree, not being obese, having fewer number of (or no) hospitalizations, and having a private health insurance plan were significantly associated with higher PCS scores. Being

older than 60 years of age and not being obese were significantly associated with higher MCS scores.

An overview discussion of the findings of the study is presented in the next section. 


\section{Overall Discussion of Findings}

It is a generally accepted norm that larger study samples are better than smaller samples (all other things being equal) because larger samples tend to minimize the probability of errors, maximize the accuracy of population estimates, and increase the generalizability of the results. Large sample sizes can produce a statistically significant result even though there is limited or no practical importance associated with the finding. In statistical significance testing, the p-value helps us draw conclusions about the probability that the effect has any positive (or negative) value. If a statistically significant negative effect is observed, then it can be said that the true value of the effect is likely to be negative.

However, another viewpoint is that researchers should make conclusions about the probability that the effect being tested is substantially positive (or negative), or in other words, the probability of clinical or practical significance. When research is published for use by clinicians in their practice, it is important to take into account the probability that the effect being tested is large enough in magnitude to be termed important in terms of its clinical implication. It may also be important to provide information on the smallest possible value of the effect that may produce a clinically pertinent outcome. On the other hand, clinicians reading such published work should also understand the origin and interpretation of statistical significance.

The results of this study can also be examined through such contrasting viewpoints. An A1C provides a more than a generally accurate and reliable method to routinely assess the level of mean blood glucose and the relative level of diabetes control. 
A1C levels are also used to judge the effectiveness of treatment, and assess the risk for development of possible acute and chronic complications typically associated with less than optimal diabetes control. But when the outcome under consideration is a complex construct like QoL, factors other than the effect of complications have to be studied. Patients with Type 2 diabetes face a variety of issues pertaining to their physical, emotional and social functioning, discussed in detail in an earlier section. Indeed, valid and reliable instruments purporting to measure QoL in patients with diabetes will take into account the impact of such factors associated with diabetes on QoL of patients. Jenkinson (1994) suggested that patients' perspectives can differ from what biomedical measures may indicate in terms of their disease status. When translated to the present study, this may mean that patients' views on the condition of their life may differ from what their A1Cs suggest. On another note, Bradley (2001) argues that if patients feel that their health is poor, they may or may not perceive impairment in their QoL.

The results of the study suggest that A1C has a weak relationship with QoL, as seen through the low magnitude of negative correlation between the two variables even though the relationship was statistically significant. This could be explained by suggesting that glycemic control status as represented by A1C may not be a symptomatic indicator of the factors that influence the QoL of Type 2 diabetes patients. It is likely that this relationship is being mediated through other variables that were studied and which were seen to significantly influence QoL. Understanding these factors will help formulate a treatment regimen that can not only optimize metabolic parameters but also QoL.

A diabetes-specific measure like the ADDQoL was able to detect differences in the glycemic control status of patients with Type 2 diabetes in univariate analyses, 
something that the generic measure, the SF-12, could not. Considering that one of the major goals of diabetes management is glycemic control, this may be an important finding, although the association of QoL with A1C itself was weak, as indicated by the results of the study. Most of the diabetes severity indicator variables (A1C, insulin use, diabetes complications score) were not found to be significant predictors of the ADDQoL score using hierarchical regression models. However, the number of ER visits in the past year was found to significantly influence ADDQoL across regression models using recent and average $\mathrm{A} 1 \mathrm{C}$, and duration of diabetes was found to be a significant predictor in the model using average A1C. It can be thought that the effects of diabetes severity may manifest themselves in acute health situations leading to ER visits. In this study, we enumerated the number of diabetes complications based on ICD-9 classification; this produced complication scores that may not be representative of the severity of complications. Insulin users reported having diabetes for a significantly longer duration than non-users [mean of 15.4 yrs. Vs mean of 6.6 yrs., $t(334)=-9.91, p<0.000$ ]. It is possible that such insulin users have reconciled to themselves being on insulin and/ or have learned to cope with the demands of treatment in a manner that it does not significantly affect their current QoL. It may have been useful to collect information on the number of years that Type 2 diabetes patients have been on insulin, to better explain this.

Epidemiological research shows that a high percentage of patients with Type 2 diabetes tend to be obese, and 64\% of respondents in this study were obese. But since successive regression models showed that obesity status was not a significant predictor of ADDQoL scores, it may be reasoned that many of the obese respondents have perceived 
their life to be in good standing as they manage their diabetes, and hence have high scores on the ADDQoL. This could reflect on the ability of the ADDQoL average weighted impact score to report the unique effects of diabetes QoL, by not being confounded by the effects of other highly comorbid conditions like obesity. On the other hand, it is likely that patients themselves did not perceive the factors associated with obesity as influencing their QoL related to diabetes.

Regression models using generic QoL as the dependent variable conveyed just the opposite, with non-obese respondents having significantly higher PCS and MCS scores, after controlling for other factors. Number of hospital visits was another significant predictor of PCS scores. Respondents with at least one hospitalization had a significantly higher Charlson comorbidity index than those with no hospitalizations [3.06 Vs 0.7, $\mathrm{t}(382)=-7.82, \mathrm{p}<0.00]$. However, Charlson index and the number of hospitalizations together as predictors in the model explaining QoL did not lead to a multicollinearity situation, allowing the inclusion of both variables in the regression models. The Charlson index gives greater importance to disease conditions that lead to mortality including a large number of cardiovascular conditions, but it may not account for conditions comorbid to diabetes that may also influence QoL, like depression and others.

In a recently published report of diabetes-related quality of care measures in a national sample of 30 U.S. academic medical centers, 34.1\% patients (including Type1 and Type 2 diabetes patients) were found to be at the recommended A1C goal of $<7 \%$ (Grant, Buse and Meigs, 2005). In the same study, the mean A1C of patients in the general medicine and endocrinology clinics was 8.1(ㄹ2.1) and 7.9(ㅃ1.8) respectively, while the proportion of patients who were obese in the two clinics were $41.9 \%$ and $32.9 \%$ 
respectively. Results such as those presented here can be attributed to the unique nature of the study sample. The patients in the current study, also from an academic medical center in the state of West Virginia, and were in better glycemic control with a mean A1C of 7.24 ( \pm 1.3$)$; but the proportion of patients who were obese was much higher, at $62.1 \%$. About 55\% of respondents were in excellent glycemic control, and another 33\% were in good control. To make accurate conclusions on the relationship between A1C and scores on the ADDQoL and the SF-12, an adequate spread of data points on all these variables would be desirable.

In hierarchical regression models, the same set of predictors were able to explain a greater proportion of variance in PCS scores than ADDQoL scores. This may be a result of the ability of the SF-12 to reflect the impairment of QoL due to the high prevalence of comorbid obesity among the respondents with Type 2 diabetes. This result can reflect on the basic structure of the two types of QoL instruments. The process of item generation for QoL instruments is iterative; it uses a combination of theory, primary data collection, and statistical analyses. Hence, the ADDQoL as it stands today consists of questions that probe patients on a wide range of issues important to diabetes, and that were decided upon from the process mentioned above. These items as a whole may be unable to detect changes in diabetes QoL in a confounding condition of obesity within the Type 2 diabetes population. On the other hand the SF-12, with dedicated physical and mental health component summary scores, contains questions which may be sensitive to the widespread comorbidity of obesity in the current study's sample of Type 2 diabetes patients. 


\section{Study Limitations}

All measurements in the study were planned and implemented to protect the integrity of study results, but there were potential limitations inherent in the study design. Limitations are discussed below:

The study employed a cross-sectional design that can establish associations between the variables of interest at a single point in time, and has limited capability in identifying any causal relationships.

Patients were recruited into the study at a convenience site, at the outpatient clinics of a university hospital setting, limiting the generalizability of the study findings to other settings.

Only patients with Type 2 diabetes were included in the study; however patients with Type 1 diabetes are also affected by the management of the disease, but were not contacted for the purpose of this study.

The study was an analysis of patients recruited from three different clinics: Family Medicine, MGP and Endocrinology. Different levels of care in these clinics may result in differences in QoL reported by patients.

It is likely that participation on the survey may be influenced by the nature of the relationship between a patient and his/her physician.

Since this was a study of the QoL of patients with Type 2 diabetes in one period in time, patients' responses to the QoL questionnaire would have reflected his or her views at that particular instant. Another point to consider is that individual QoL measures ask questions on issues related to well being on different life domains as the respondent 
perceives them in a particular period of time. In the SF-12, this period is the previous four weeks. The ADDQoL does not prescribe a definite time interval; it measures the 'current' effects of diabetes on QoL. Different patients may be dealing with different diabetesrelated issues at the time they respond to the QoL questionnaires. Some of the respondents may have had the disease for many years and their responses could in some way reflect their cumulative experiences in managing the disease. Others who are newly diagnosed with the disease, may respond to the questionnaire with a different level and type of experience in dealing with their diabetes.

Since the study primarily assessed the relationship between QoL and A1C (among others), it was necessary to include those only patients for whom information on both these variables was available. Results of the relationship between baseline QoL and clinical values could be affected by specific patient characteristics. Importantly, there were variances in the times at which patients had their lab values taken. The criteria used in the sampling procedure discussed in the methods section was designed to address this issue, although the same criteria may have caused an inadvertent inclusion of patients who comply with physicians' recommendation for having an A1C done. Patients who generally do not would have been excluded. It is possible that those patients have poorer glycemic control and the absence of their QoL and clinical data may indicate a bias in the results.

Independent-samples t-tests analyses were performed to ascertain whether there were differences in recent and average A1C levels between responders and nonresponders to our survey. There were no significant differences in recent A1C values between the two groups. However, non-responders had significantly higher average A1C 
values $[7.4( \pm 1.56)]$ than responders $[7.2( \pm 1.30)](\mathrm{p}=0.041)$. It is not known whether this difference in average A1C value between the two groups is clinically significant. However, from this result it cannot be ruled out that Type 2 diabetes patients with better average A1C values responded to our survey.

The study employed a single mail-out of a booklet of measures. Along with the ADDQoL and the SF-12, different measures of interest to other researchers were included. In keeping with prevailing trends about using multiple measures, the generic SF-12 was been placed before the diabetes-specific ADDQoL. It is likely a respondent's answer may have been influenced by the answers to the previous measures, or by the real-life situations discussed in earlier measures. In addition, the size of the booklet may have imposed some respondent burden, discouraging some patients from responding completely or accurately.

The study incorporates medical history variables and health status indicators that were obtained from administrative databases and medical chart reviews. The study may be influenced by errors in coding these secondary databases.

Quality of life measured in the course of the study is a self-reported measure. Patients responding to the QoL questionnaires may tend to give socially desirable responses. Some patients may provide answers that they perceive will reflect positively on them, while on the other hand, other patients may report answers that they perceive will reflect extreme hardships they face. Thus, patients could have provided biased responses in a QoL survey. 


\section{Study Conclusions}

In the assessment of QoL, we are faced with a selection between generic and disease-specific measures, or using both types of measures to complement each other. The study indicates the utility of the ADDQoL and the SF-12 scores in performing QoL assessments in populations with Type 2 diabetes, and confirms the construct validity and reliability of thee instruments. The complementary use of a generic QoL measure along with a diabetes-specific measure seems essential in view of the high prevalence of the comorbid obesity.

The results of the study suggest that the A1C has a weak relationship with QoL. This provides evidence that patients’ perspectives may be different from what a biomedical indicator like A1C may indicate in terms of glycemic control.

\section{Directions for Future Research}

Quality of life is a complex psychosocial concept, and patients with diabetes are affected by many issues in the day-to-day management of the disease. The study attempted to take this into account by collecting data on variables that were

representative of these issues. Hence demographic, medical history, and health status and disease severity variables were collected to explain the way they may influence QoL.

Apart from the objective collection of diabetes severity indicators from medical records, subjective indices can be calculated. This can be done by using physicians’ opinions on the extent of severity of a diabetes complication, and calculating a weighted 
complications score. Other indicators of disease severity include indices based on prescription drug use and insulin dosage. Additionally, it may be useful to obtain information on the duration of insulin usage in Type 2 diabetes patients.

There are other psychosocial indicators that could contribute to a greater understanding of the QoL of patients with Type 2 diabetes. This includes variables describing the engagement of patients in diabetes self-management behaviors recommended by their healthcare providers, and the coping styles that patients embrace in facing the situations arising from their diabetes. Self-report of depressive symptoms may also help explain why patients may not adhere to recommended behaviors. Future studies could measure these variables and assess the extent to which they add to the explanatory power of regression models with diabetes-specific QoL as the dependent variable.

It is likely that all of these factors influence QoL through interdependent pathways that mediate the effect of other variables on QoL. Some of these relations have been proposed in the discussions section. A statistical technique that can test these interdependent relationships is path analysis, which requires an a priori model depicting hypothesized relationships among different sets of variables as they influence QoL in diabetes patients. While the whole model can be tested for adequacy of fit with the observed data, individual direct relationships between variables can be tested for their significance, including mediating pathways. 


\section{BIBLIOGRAPHY}

American Diabetes Association (2001). Clinical practice recommendations. Diabetes Care, 24, Suppl 1, S5.

American Diabetes Association. (2005). Standards of medical care in diabetes. Diabetes Care, 28, Suppl 1, S4-S36.

Anderson, J.P., Kaplan, R.M., Berry, C.C., Bush, J.W.\& Rumbaut, R.G. (1989). Interday reliability of function assessment for a health status measure. The quality of wellbeing scale. Medical Care, 27, 1076-1083.

Anderson, R.M., Fitzgerald, J.T., Wisdom, K., Davis, W.K. \& Hiss, R.G. (1997). A comparison of global versus disease-specific quality-of-life measures in patients with NIDDM. Diabetes Care, 20, 299-305.

Bergner, M., Bobbitt, R.A., Carter, W.B. \& Gilson B.S. (1981). The Sickness Impact Profile: development and final revision of a health status measure. Medical Care, 19, 787-805.

Boyer, J.G. \& Earp, J.A. (1997). The development of an instrument assessing the quality of life of people with diabetes. Medical Care, 35, 440-453.

Bradley, C. (1996). Measuring quality of life in diabetes. In S.M. Marshall, P.D. Home \& R.A. Rizza (Eds.) Diabetes Annual (10, pp. 207-227). Amsterdam: Elsevier Science.

Bradley, C., Todd, C., Gorton,T., Symonds, E., Martin, A. \& Plowright, R. (1999). The development of an individualized Questionnaire measure of perceived impact of diabetes on quality of life: the ADDQoL. Quality of life Research, 8, 79-91.

Bradley, C. (2001) Importance of differentiating health status tools from quality of life. The Lancet, 357, 7-8.

Bradley, C. \& Speight, J. (2002). Patient perceptions of diabetes and diabetes therapy: assessing quality of life. Diabetes Metabolism Research and Reviews, 18, Suppl 3, S64-S69.

Bryant, F.B.\& Yarnold, P.R. (1995). Principal components analysis and exploratory and confirmatory factor analysis. In L.G. Grimm and P.R.Yarnold (Eds.), Reading and understanding multivariate analysis. Washington D.C.: American Psychological Association.

Bott, U. Muhlhauser, I., Overmann, H. \& Berger, M. (1998). Validation of a diabetesspecific quality of life scale for patients with type 1 diabetes. Diabetes Care, 21, 757-769. 
Boyer, J.G., \& Earp, J.A. (1997). The development of an instrument for assessing the quality of life of people with diabetes. Diabetes-39. Medical Care, 35, 440-453.

Brown, S.A. (1990). Studies of educational interventions and outcomes in diabetic adults: a Meta-Analysis Revisited. Patient Education and Counseling, 16(3), 189-215.

Buckley, A. \& Goldstein, D. Keeping Score. (1993). The Diabetes Educator, 19, $242-$ 243.

Burroughs, T.E., Desikan, R., Waterman, B.M., Gilin, D. \& McGill, J. (2004). Development and validation of the Diabetes Quality of Life Brief Clinical Inventory. Diabetes Spectrum, 17, 41-49.

Carey, M.O., Jorgensen, R.S., Weinstock R.S., Sprafkin, R.P., Lantinga L.J., Carnrike C.L.M., Baker, M.T. \& Meisler, S.A.W. (1991). Reliability and validity of the appraisal of diabetes scale. Journal of Behavioral Medicine, 14, 43-51.

Centers for Disease Control and Prevention (2003). National diabetes fact sheet: general information and national estimates on diabetes in the United States, 2003. Atlanta, GA: U.S. Department of Health and Human Services, Centers for Disease Control and Prevention.

Centers for Disease Control and Prevention. (2002). Behavioral risk factor surveillance system online prevalence data, 1995-2002. Division of Adult and Community Health, National Center for Chronic Disease Prevention and Health Promotion.

Centers for Disease Control and Prevention. (n.d.). Body mass index formula for adults. Retrieved January 25, 2005, from the World Wide Web http://www.cdc.gov/nccdphp/dnpa/bmi/bmi-adult-formula.htm.

Charlson, M.E., Pompei, P., Ales, K.L. \& MacKenzie, C.R. (1987). A new method of classifying prognostic comorbidity in longitudinal studies: development and validation. Journal of Chronic Diseases, 40, 372-83.

Cohen, J. \& Cohen, P. (1983). Applied multiple regression/ correlation analysis for the behavioral sciences. ( $2^{\text {nd }}$ ed.). Hillsdale, NJ: Erbaum.

Cohen, J. (1988). Statistical power analysis for the behavioral sciences. (2nd ed.). Hillsdale, NJ: Erbaum.

DAFNE Study Group. (2002). Training in flexible, intensive insulin management to enable dietary freedom in people with type 1 diabetes: dose adjustment for normal eating (DAFNE) randomised controlled trial. British Medical Journal, 325, 746749. 
The Diabetes Control and Complications Trial Research Group (1993). The effect of intensive treatment of diabetes on the development of long-term complications in insulin-dependent diabetes mellitus. New England Journal of Medicine, 329, 977986.

The Diabetes Control and Complications Trial Research Group (1996). Influence of intensive diabetes treatment on quality-of-life outcomes in the diabetes control and complications trial. Diabetes Care, 19, 195-203.

D'Hoore, W., Bouckaert, A., \& Tilquin, C. (1996). Practical considerations on the use of the Charlson comorbidity index with administrative databases. Journal of Clinical Epidemiology, 49(12), 1429-1433.

Dunn, S.M., Smartt, H., Beeney, L. \& Turtle, J. (1986). Measurement of emotional adjustment in diabetic patients: validity and reliability of ATT39. Diabetes Care, 9, 480-89.

The Epidemiology of Diabetes Interventions and Complications Research Group (1999). Design, implementation, and preliminary results of a long-term follow-up of the Diabetes Control and Complications Trial cohort. Diabetes Care, 22, 99-111.

Erdfelder, E., Faul, F., \& Buchner, A. (1996). GPOWER: A general power analysis program. Behavior Research Methods, Instruments, \& Computers, 28, 1-11.

Faul, F. \& Erdfelder, E. (1992). GPOWER: A priori, post hoc, and compromise power analysis for MS DOS (computer program). Bonn, FRG: Bonn University, Dept. of Psychology.

Fitzgerald, J.T., Davis, W.K., Connell, C.M., Hess, G.E., Funnell, M.M. \& Hiss, R.G. (1996). Development and validation of the Diabetes Care Profile. Evaluation \& The Health Professions, 19, 208-230.

Garratt, A.M., Fitzpatrick, R., \& Schmidt, L. (2002). Patient-assessed health outcome measures for diabetes: a structured review. Diabetic Medicine, 19(1), 1-11.

Grant W.G., Buse, J.B. \& James, B. (2005). Quality of diabetes care in U.S. academic medical centers: Low rates of medical regimen change. Diabetes Care, 28: 337442.

Grootenhuis, P.A., Snoek, F.J., Heine, R.J. \& Bouter, L.M. (1994). Development of a type 2 diabetes symptom checklist: a measure of symptom severity. Diabetic Medicine, 11, 253-61.

Guttmann-Bauman, I., Strugger, M., Flaherty, B. P., \& McEvoy, R. C. (1998). Metabolic control and quality of life assessment in adolescents with IDDM. Diabetes Care, 21, 915-918. 
Hammond, G.S. \& Aoki, T.T. (1992). Measurement of health status in diabetic patients: diabetes impact measurement scales. Diabetes Care, 15, 469-477.

Hareendran, A. (2004, Spring special issue 3). Patient-reported outcomes: When do they add value? Patient Reported Outcomes Newsletter, pp.3.

Hogan, P., Dall, T. \& Nikolov, P.; The American Diabetes Association (2003). Economic costs of diabetes in the US in 2002. Diabetes Care, 26(3), 917-932.

Hopkins, W.G. (2004). A new view of statistics: Generalizing to a population. Retrieved February 20, 2005, from the World Wide Web http://www.sportsci.org/resource/stats/generalize.html.

Huck, S.W. \& Cormier, W.H. (1996). Reading statistics and research. $\left(2^{\text {nd }}\right.$. ed.). NY: Harper Collins.

Hunt, S.M., McEwen, J. \& McKenna, S.P. (1985). Measuring health status: a new tool for clinicians and epidemiologists. Journal of the Royal College of General Practitioners, 35, 185-88.

Jacobson, A., Barofsky, I., Cleary, P. \& Rand, L. (1998). Reliability and validity of a diabetes quality of life measure of the Diabetes Control and Complications Trial (DCCT). Diabetes Care, 11, 725-732.

Jacobson, A., De Groot, M., \& Samson, J.A. (1994). The evaluation of two measures of quality of life in patients with type 1 and type 2 diabetes. Diabetes Care, 17(4), 267-274.

Jacobson, A.M. (1997). Quality of life in patients with diabetes mellitus. Seminars in Clinical Neuropsychiatry, 2(1), 82-93.

Jenkinson, C. (1994). Measuring health and medical outcomes: an overview. In: Measuring Health and Medical Outcomes. (pp. 1-6). London: UCL Press.

Jenkinson, C., Layte, R., Jenkinson, D., Lawrence, K., Petersen, S., Paice C. \& Stradling J. (1997). A Shorter Form Health Survey: Can the SF-12 replicate results from the SF-36 in longitudinal studies? Journal of Public Health Medicine, 19(2), 179-186.

Johnson, J.A. \& Maddigan, S.L. (2004). Performance of the RAND-12 and SF-12 summary scores in type 2 diabetes. Quality of Life Research, 13, 449-456.

Kaplan, R.M. (1990). Behavior as the central outcome in health care. American Psychology, 14, 1211-1220.

Klein, R., Klein, B. E., Moss, S. E., Davis, M. D., \& DeMets, D. L. (1984). The Wisconsin epidemiologic study of diabetic retinopathy. II. Prevalence and risk of 
diabetic retinopathy when age at diagnosis is less than 30 years. Archives of Ophthalmology, 102, 520-526.

Klein, B.E., Klein, R., \& Moss, S.E.(1998). Self-rated health and diabetes of long duration: the Wisconsin epidemiologic study of diabetic retinopathy. Diabetes Care, 21, 236-240.

Klein, R. \& Moss, S. (1995). A comparison of the study populations in the Diabetes Control and Complications Trial and the Wisconsin Epidemiologic Study of Diabetic Retinopathy. Archives of Internal Medicine, 155, 745-754.

Knapp, T. (1996). The overemphasis on power analysis. Nursing Research, 45(6); 379.

Kochanek, K.D. \& Smith, B.L. (2004). Deaths: Preliminary data for 2002. National vital statistics reports, 52(13). Hyattsville, MD: National Center for Health Statistics.

Lloyd, C. E., Matthews, K. A., Wing, R. R., \& Orchard, T. J. (1992). Psychosocial factors and complications of IDDM. The Pittsburgh epidemiology of diabetes complications study - VIII. Diabetes Care, 15, 166-172.

Mannucci, E., Ricca V., Bardini, G. \& Rotella, C.M. (1996). Well-being enquiry for diabetics: a new measure of diabetes-related quality of life. Diabetes Nutrition and Metabolism, 9, 89-102.

Meadows, K.A., Abrams, S. \& Sandbaek, A. (2000). Adaptation of the Diabetes Health Profile (DHP-1) for use with patients with Type 2 diabetes mellitus: psychometric evaluation and cross-cultural comparison. Diabetic Medicine, 17, 572-580.

Meadows, K, Steen, N., McColl, E., Eccles, M., Shiels, C., Hewison, J., \& Hutchinson, A. (1996). The Diabetes Health Profile (DHP): a new instrument for assessing the psychological profile of insulin and psychometric evaluation. Quality of Life Research, 5, 242-254.

National Diabetes Information Clearinghouse (2003). National Diabetes Statistics. Retrieved August 8, 2003, from the World Wide Web http://diabetes.niddk.nih.gov/dm/pubs/statistics/.

Nerenz, D.R., Repasky, D., Whitehouse, F.W. \& Kahkonen, D.M. (1992). Ongoing assessment of health status in patients with diabetes mellitus. Medical Care, 5,(Suppl.) 112-114.

Nunnally, J. C., \& Bernstein, I. H. (1994). Psychometric theory. ( $3^{\text {rd }}$ ed.). New York: McGraw-Hill. 
Parkerson, G.R. Jr, Gehlbach, S.H., Wagner, E.H., James, S.A., Clapp, N.E., \& Muhlbaier, L.H. (1981). The Duke-UNC Health Profile: an adult health status instrument for primary care. Medical Care, 19(8), 806-28.

Pedhazur, E. J., \& Schmelkin, L. P. (1991). Measurement, design, and analysis: An integrated approach. Hillsdale, NJ: Erlbaum.

Polonsky, W.H. (2000). Understanding and assessing diabetes-specific quality of life. Diabetes Spectrum, 13(1), 36.

Polonsky, W.H., Anderson, B.J., Lohrer, P.A., Welch, G., Jacobson, A.M. \& Schwartz, C. (1995). Assessment of diabetes-specific distress. Diabetes Care, 18, 754-60.

Rohlfing, C.L., Wiedmeyer, H.M., Little, R.R., England, J.D., Tennill, A. \& Goldstein, D.E. (2002). Defining the relationship between plasma glucose and HbA 1c: analysis of glucose profiles and HbA1C in the Diabetes Control and Complications Trial. Diabetes Care, 25, 275-278.

Rose, M., Fliege, H., Hildebrandt, M., Schirop, T., \& Klapp, B. F. (2002). The network of psychological variables in patients with diabetes and their importance for quality of life and metabolic control. Diabetes Care, 25, 35-42.

Rubin, R.R. (2000). Diabetes and quality of Life. Diabetes Spectrum, 13(1), 21.

Rubin, R.R., \& Peyrot, M. (1999). Quality of life and diabetes. Diabetes Metabolism Research and Reviews, 15, 205-218.

Shannon, D. M., \& Davenport, M. A. (2002). Using SPSS to solve statistical problems. Upper Saddle River, NJ: Prentice-Hall.

Smith, A.H. \& Bates, M.N. (1992). Confidence limit analyses should replace power calculations in the interpretation of epidemiologic studies. Epidemiology, 3(5); 449-52.

Snoek, F.J. (2000). Quality of Life: A closer look at measuring patients well-being. Diabetes Spectrum, 13(1), 24.

Sonnaville, J. J., Snoek, F. J., Colly, L. P., Deville, W., Wijkel, D., \& Heine, R. J. (1998). Well-being and symptoms in relation to insulin therapy in type 2 diabetes. Diabetes Care, 21, 919-924.

Speight, J. \& Bradley, C., (2000). ADDQoL indicates negative impact of diabetes on quality of life despite high levels of satisfaction with treatment. Diabetologia, 43(Suppl. 1), A225 (Abstract 864). 
Stewart, A.L., Hays, R.D. \& Ware, J.E. (1988). The MOS short-form general health survey. Reliability and validity in a patient population. Medical Care, 26(7), 724735.

Tabachnick, B. G., \& Fidell, L. S. (2001). Using multivariate statistics. (4 ${ }^{\text {th }}$ ed.). New York: HarperCollins.

Testa, M.A. (2000). Quality of life assessment in diabetes research: Interpreting the magnitude and meaning of treatment effects. Diabetes Spectrum, 13(1), 29.

United Kingdom Prospective Diabetes Study Group (1998). Intensive blood-glucose control with sulphonyl ureas or insulin compared with conventional treatment and risk of complications in patients with type 2 diabetes (UKPDS 33). Lancet, 352, 837-853.

United Kingdom Prospective Diabetes Study Group (1999). Quality of life in type 2 diabetic patients is affected by complications but not by intensive policies to improve blood glucose or blood pressure control (UKPDS 37). Diabetes Care, 22, 1125-1136.

U.S. Department of Health and Human Services. (2000). Healthy People 2010: Understanding and improving health. ( $2^{\text {nd }}$ ed.).Washington, D.C.: U.S. Government Printing Office.

Van der Does, F. E. E., De Neeling, J., Snoek, F.J., Kostense, P.J., Grootenhuis, P.A., Bouter, L.M. \& Heine, R.J. (1996). Symptoms and well-being in relation to glycemic control in type 2 diabetes. Diabetes Care, 19, 204-210.

The WHOQOL Group. (1998). The World Health Organization Quality of Life Assessment (WHOQOL): Development and general psychometric properties. Social Science and Medicine, 46, 1569-1585.

Ware, J.E. \& Sherbourne, C. (1992). The MOS 36-item short-form health survey (SF-36) 1: Conceptual framework and item selection. Medical Care, 30, 473-483.

Ware, J.E., Snow, K.K., Kosinski, M., \& Gandek, B. (1993). SF-36 health survey: manual and interpretation guide. Boston, MA: Health Institute, New England Medical Center.

Ware, J.E., Snow, K.K., Kosinski, M., \& Gandek, B. (2000). SF-36 Health Survey: Manual and interpretation guide. Lincoln, RI: QualityMetric Inc.

Ware, J.E., Kosinski, M., \& Keller, S.D. (1994). SF-36 physical and mental health summary scales: a user manual. Boston, MA: Health Institute, New England Medical Center. 
Ware, J.E., Kosinski, M., \& Keller, S.D. (1996). A 12-item Short Form health survey: Construction of scales and preliminary tests of reliability and validity. Medical Care, 34(3), 220-233.

Ware, J.E., Kosinski, M., \& Bayliss, M.S. (1995). Comparison of the methods for scoring and statistical analysis of SF-36 Health Profile and Summary Measures: Summary of results from the Medical Outcomes Study. Medical Care, 33, 264-279.

Weinberger, M., Kirkman, M. S., Samsa, G. P., Cowper, P. A., Shortliffe, E. A., Simel, D. L. \& Feussner, J.R. (1994). The relationship between glycemic control and health-related quality of life in patients with non-insulin-dependent diabetes mellitus. Medical Care, 32, 1173-1181.

West Virginia Department of Health and Human Resources (2001). West Virginia Healthy People 2010 Objectives. Retrieved March 22, 2004, from the World Wide Web http://www.wvdhhr.org/bph/hp2010/objective/5.htm.

West Virginia Department of Health and Human Resources (2002). Obesity: Facts, figures, guidelines. Retrieved March 20, 2004, from the World Wide Web http://www.wvdhhr.org/bph/oehp/obesity/contents.htm.

West Virginia Department of Health and Human Resources (2003). The burden of diabetes in West Virginia. Retrieved August 22, 2003, from the World Wide Web http://www.wvdhhr.org/bph/oehp/diabetes/burden/.

Wildes, K.R., Greisinger, A. \& O’Malley, K.J. (2003). Critical review of quality of life measures for patients with diabetes: Report of the measurement excellence initiative. Houston center for quality of care and utilization studies at the Houston VA medical center. Retrieved January 17, 2004, from the World Wide Web http://www.measurementexperts.org/criticalReview.htm.

Wilkinson, L., \& Task Force on Statistical Inference, APA Board of Scientific Affairs. (1999). Statistical methods in psychology journals: Guidelines and explanations. American Psychologist, 54, 594-604.

World Health Organization (2002). The cost of diabetes. Retrieved August 8, 2003, from the World Wide Web http://www.who.int/mediacentre/factsheets/fs236/en/.

Woodcock, A.J., Julious, S.A., Kinmoth, A.L., \& Campbell, M.J. (2001). Problems with the performance of the SF-36 among people with type 2 diabetes in general practice. Quality of Life Research, 10(8), 661-670.

Zumbo, B.D. \& Hubley, A.M. (1998). A note on misconceptions concerning prospective and retrospective power. The Statistician, 47(2), 385-388. 


\section{APPENDICES}

Appendix A: Physician Cover Letter

Appendix B: Measures Booklet

Appendix C: Reminder Card 


\title{
Appendix A: Physician Cover Letter
}

\author{
WestVirginiaUniversityHospitals \\ October , 2004 \\ Dear :
}

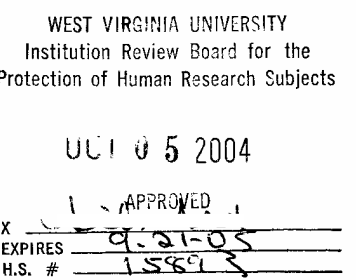

West Virginia University's (WVU) patient care clinics are very focused on insuring the quality of care for diabetes patients who are treated within the institution. Therefore, the Departments of Medicine and Family Medicine, and the School of Pharmacy, have joined together to conduct a research study to determine where the focus of care needs to be directed to enable us to ensure that you are receiving the best care possible for your diabetes. As a person with diabetes, you are aware of the difficulties of managing an illness that requires many complex actions for medications or insulin, diet, blood glucose monitoring, and exercise. In order to improve the quality of care that diabetes patients are receiving at WVU, please give us your input by completing the attached questionnaire. The study may be useful in the training of diabetes health care providers. Your input will be a source of tremendous help in providing general information which will be used by health care providers to help others who have your same health concerns.

The information that you provide, when participating in the study, will be kept as confidential as legally possible. The questionnaire has an identification number for mailing purposes only. This is so we may check your name off the mailing list when your questionnaire is returned. Once your questionnaire is received, your answers will be analyzed anonymously in combination with those of all other respondents.

You do not have to answer every question, and participation in the questionnaire is voluntary. You may choose not to participate at any time; however, after you have provided the information, it will become anonymous and you will be unable to withdraw your data since there will be no way to identify individual information. If you choose not to participate, this will not jeopardize in any way your relationship with me or with the WVU patient care clinics.

So, please take about twenty minutes to complete the questionnaire and return it in the enclosed reply envelope by October ,2004. The study coordinators thank you in advance for your time and your contribution to a greater understanding of the health concerns of patients with diabetes. If you have any questions, please do not hesitate to contact Michele Garlick in Medical Staff Affairs at 304-598-4156 at WVU, or Principal Investigator, Jan Kavookjian in the School of Pharmacy at 304-293-1453.

Sincerely,

Name of Physician, MD

Department of

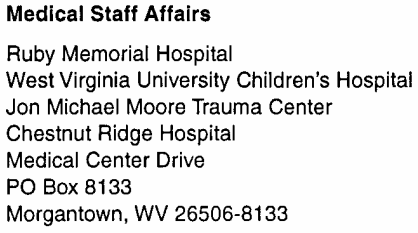




\section{Appendix B: Measures Booklet}

\section{We value your input!!}

- Please respond to all of the questions in this packet that apply to you. Skip sections that do not apply. Example: skip insulin sections if you are not on insulin

- Remember, there are no right or wrong answers; we just want to know how you are managing your diabetes, and how you feel about your life now.

- When you finish answering the questionnaire, please return it in the enclosed postage paid envelope, and mail it back to us.

Thank you very much; your participation is important to us.

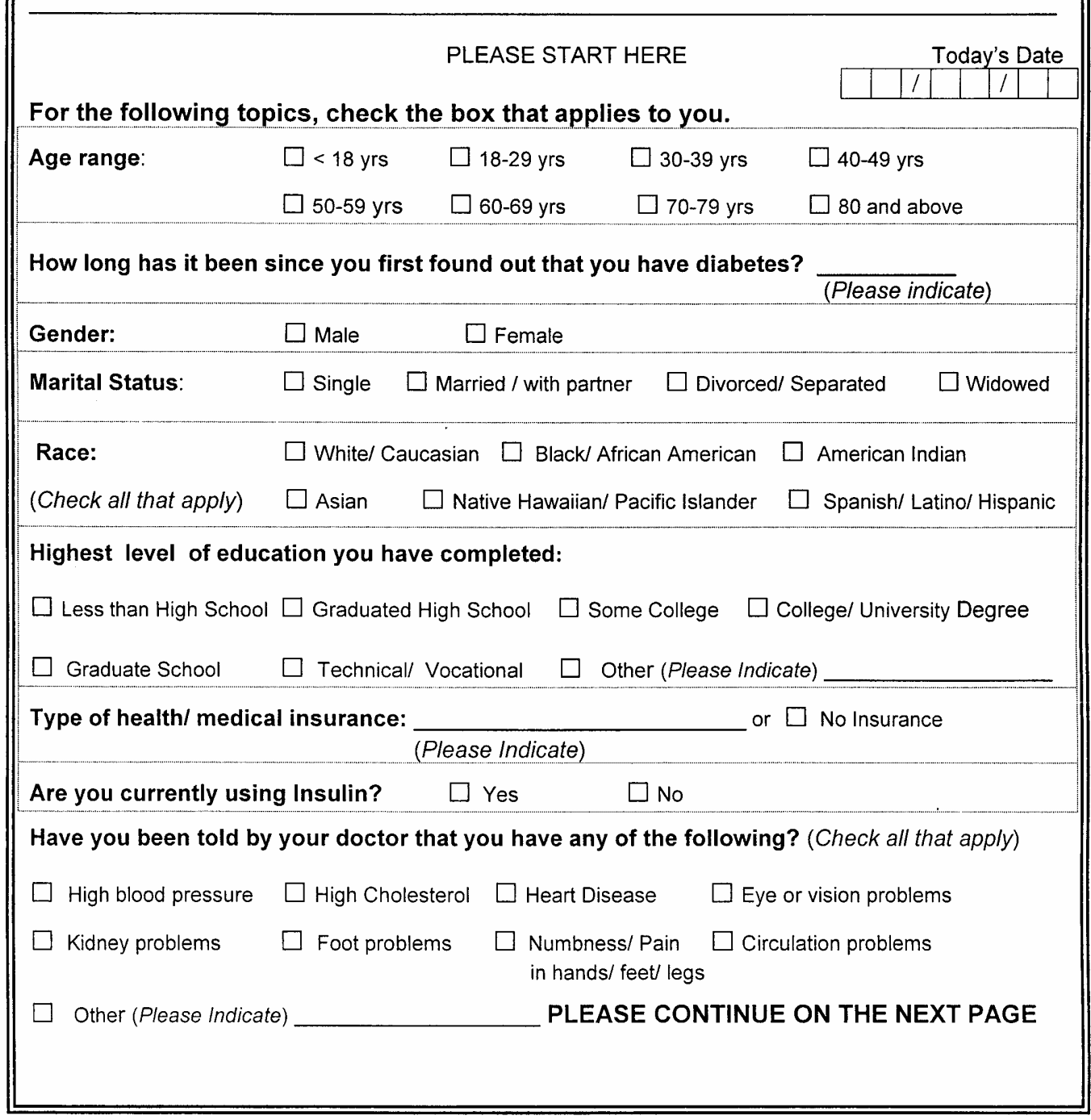




\section{How are you managing your Diabetes? ${ }^{1}$}

\section{Definition of Medicine Taking}

Taking your medicine exactly as prescribed means taking all of your diabetes medicine(s) as your doctor or pharmacist instructed you. This means taking the right number of pills, at the right times, for the right number of times every day.

Based on the definition above, do you always take your oral diabetes medicine(s) at the right times with the right number of pills, for the number of times required every day? (Circle the one best answer).

a. No, I do not currently take my medicine exactly as prescribed, and I do not intend to start within the next 6 months.

b. No, I do not currently take my medicine exactly as prescribed, but I plan to start within the next 6 months.

c. No, I do not currently take my medicine exactly as prescribed, but I plan to start in the next month.

d. Yes, I take my medicine exactly as prescribed, but I have been for less than 6 months.

e. Yes, I take my medicine exactly as prescribed and I have been for more than 6 months.

\section{Definition of Insulin Taking}

Taking your insulin exactly as prescribed means taking your insulin according to the directions given to you by your doctor or pharmacist. This means taking the right number of units of insulin at the right times for the right number of times required every day.

Based on the definition above, do you always take your insulin at the right times, with the right number of units, for the number of times required every day? (Circle the one best answer).

a. No, I do not currently take my insulin exactly as prescribed, and I do not intend to start within the next 6 months.

b. No, I do not currently take my insulin exactly as prescribed, but I plan to start within the next 6 months.

c. No, I do not currently take my insulin exactly as prescribed, but I plan to start within the next month.

d. Yes, I take my insulin exactly as prescribed, but I have been for less than 6 months.

e. Yes, I take my insulin exactly as prescribed and I have been for more than 6 months.

\section{Definition of Diabetes Diet}

"Diabetes Diet" means eating all of your food and drinks exactly according to the directions given to you for each meal and snack every day, $100 \%$ of the time. This includes your control of the balance of carbohydrates, proteins, and fats, and the timing of meals and snacks to help control your blood sugar levels. This means eating the right kinds of food in the exact amounts at the right times of the day every day.

Based on the definition above, do you always eat and drink at the right times with the exact amounts for the number of times required every day, following the instructions for the right balance of carbohydrates, proteins and fats $100 \%$ of the time? (Circle the one best answer).

a. No, I do not currently follow my diabetes diet exactly as instructed, and I do not intend to start within the next 6 months.

b. No, I don't currently follow my diabetes diet exactly as instructed, but I plan to start within the next 6 months

c. No, I don't currently follow my diabetes diet exactly as instructed, but I plan to start within the next month.

d. Yes, I follow my diabetes diet exactly as instructed, but I have been for less than 6 months.

e. Yes, I follow my diabetes diet exactly as instructed and I have been for more than 6 months. 


\section{Definition of Blood Sugar Checking}

Checking your blood sugar means you checking the amount of sugar in your blood, using strips and a meter, at the prescribed times, the required number of times per day, every day, exactly according to the instructions given to you.

Based on the definition above, do you always check your blood sugar level in exactly the way you were instructed? (Circle one).

a. No, I do not currently check my blood sugar exactly as instructed, and I do not intend to start within the next 6 months.

b. No, I don't currently check my blood sugar exactly as instructed, but I plan to start within the next 6 months.

c. No, I don't currently check my blood sugar exactly as instructed, but I plan to start in the next month.

d. Yes, I check my blood sugar exactly as instructed, but I have been for less than 6 months.

e. Yes, I check my blood sugar exactly as instructed and I have been for more than 6 months.

\section{Definition of Physical Activity:}

Physical activity means walking, vacuuming, jogging, digging in the garden, climbing stairs or any other physical activity where exertion is similar to these. Regular physical activity means having 30 minutes or more per day in the above activities MOST days of the week. For example, you could take one 30 minutes walk, jog, bike, or swim, OR three 10 minutes walks, OR 15 minutes of vacuuming, 10 minutes of digging, and 5 minutes of climbing.

\section{Do you have regular physical activity according to this definition? (Circle the one best} answer).

a. No, I do not currently have regular physical activity, and I do not intend to start within the next 6 months.

b. No, I don't currently have regular physical activity, but I plan to start within the next 6 months.

c. No, I don't currently have regular physical activity, but I plan to start within the next month.

d. Yes, I currently have regular physical activity, but I have been for less than 6 months.

e. Yes, I currently have regular physical activity and I have been for more than 6 months.

How often do you have regular physical activity according to this definition?
a.Never
b. Rarely
c. Sometimes
d. Usually
e. Always

\section{Definition of Vigorous Exercise:}

Vigorous exercise includes activities such as brisk walking, jogging, swimming, aerobic dancing, biking, rowing, etc. Activities that are not as active, such as bowling, or playing golf with a cart, would not be considered exercise. Regular exercise $=3$ times or more per week for at least 20 minutes each time.

Do you have regular exercise according to this definition? (Circle the one best answer.)

a. No, I do not currently have regular exercise, and I do not intend to start within the next 6 months.

b. No, I don't currently have regular exercise, but I plan to start within the next 6 months.

c. No, I don't currently have regular exercise, but I plan to start within the next month.

d. Yes, I currently have regular exercise, but I have been for less than 6 months.

e. Yes, I currently have regular exercise, and I have been for more than 6 months.

How often do you exercise according to this definition?
a.Never
b. Rarely
c. Sometimes
d. Usually
e. Always

PLEASE CONTINUE ON THE NEXT PAGE 


\section{Your Health and Well-Being}

We would like to know your views about your own health. This information will help keep track of how you feel and how well you are able to do your usual activities. For each of the following questions, please mark an $\square$ in the one box that best describes your answer. ${ }^{2}$

1. In general, would you say your health is:

\begin{tabular}{|ccccc|}
\hline Excellent & Very good & Good & Fair & Poor \\
$\square 1$ & $\square 2$ & $\square 3$ & $\square 4$ & $\square 5$
\end{tabular}

2. The following questions are about activities you might do during a typical day. Does your health now limit you in these activities? If so, how much?

\begin{tabular}{|ccc|}
\hline Yes, & Yes, & No, not \\
limited & limited & limited \\
a lot & a little & at all
\end{tabular}

a Moderate activities, such as moving a table,

pushing a vacuum cleaner, bowling, or playing golf ......... $\square 1 \ldots \ldots \ldots \ldots \square 2 \ldots \ldots \ldots \square 3$

b Climbing several flights of stairs.

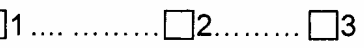

3. During the past 4 weeks, how much of the time have you had any of the following problems with your work or other regular daily activities as a result of your physical health?

\begin{tabular}{|ccccc|}
\hline $\begin{array}{c}\text { All of } \\
\text { the }\end{array}$ & the & Some & A little & None of \\
time & time & of the & of the & the \\
time & time & time
\end{tabular}
a Accomplished less than you would like
$\square 1 \ldots$
$\square 2 \ldots \ldots$.
$3 \ldots \ldots \square+\ldots \square 5$
b Were limited in the kind of work or other activities...
$1 \ldots .$.
$\square 2 \ldots \ldots$
3

4. During the past 4 weeks, how much of the time have you had any of the following problems with your work or other regular daily activities as a result of any emotional problems (such as feeling depressed or anxious)?

\begin{tabular}{|ccccc|}
\hline All of & Most of & Some & A little & None of \\
the & the & of the & of the & the \\
time & time & time & time & time
\end{tabular}
a Accomplished less than you would like ..................
b Did work or other activities less carefully than usual
$\square 1 \ldots . . .$.

5. During the past 4 weeks, how much did pain interfere with your normal work (including both work outside the home and housework)?

\begin{tabular}{|ccccc|}
\hline Not at all & A little bit & Moderately & Quite a bit & Extremely \\
$\square 1$ & $\square 2$ & $\square 3$ & $\square 4$ & $\square 5$
\end{tabular}

PLEASE CONTINUE ON THE BACK 
6. These questions are about how you feel and how things have been with you during the past 4 weeks. For each question, please give the one answer that comes closest to the way you have been feeling. How much of the time during the past 4 weeks...

\begin{tabular}{|ccccc|}
\hline $\begin{array}{c}\text { All } \\
\text { of the }\end{array}$ & $\begin{array}{c}\text { Most } \\
\text { of the }\end{array}$ & $\begin{array}{c}\text { Some } \\
\text { of the }\end{array}$ & $\begin{array}{c}\text { A little } \\
\text { of the }\end{array}$ & $\begin{array}{c}\text { None } \\
\text { of the }\end{array}$ \\
time & time & $\begin{array}{c}\text { time } \\
\text { time }\end{array}$ & $\begin{array}{c}\text { time } \\
\end{array}$
\end{tabular}

a Have you felt calm and peaceful? ................ $\square 1 \ldots \ldots . \square 2 \ldots \ldots . \square 3 \ldots \ldots \square 4 \ldots \ldots \square 5$

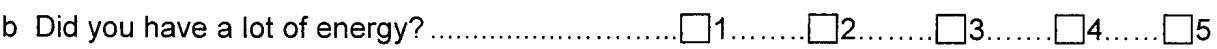

c Have you felt downhearted and depressed? ...... $\square 1 \ldots \ldots \ldots \square 2 \ldots \ldots \square 3 \ldots \ldots \square 4 \ldots \ldots \square 5$

7. During the past 4 weeks, how much of the time has your physical health or emotional problems interfered with your social activities (like visiting friends, relatives, etc.)?

\begin{tabular}{ccccc|}
\hline $\begin{array}{c}\text { All of the } \\
\text { time }\end{array}$ & $\begin{array}{c}\text { Most of the } \\
\text { time }\end{array}$ & $\begin{array}{c}\text { Some of the } \\
\text { time }\end{array}$ & $\begin{array}{c}\text { A little of the } \\
\text { time }\end{array}$ & $\begin{array}{c}\text { None of the } \\
\text { time }\end{array}$ \\
$\square 1$ & $\square 2$ & $\square 3$ & $\square 4$ & $\square 5$
\end{tabular}

Thank you! Now we would like to ask you about your quality of life and the effects of your diabetes on your quality of life. Your quality of life is how good or bad you feel your life to be. Please check an option that best indicates your response on each scale. ${ }^{3}$

I) In general, my present quality of life is:

\begin{tabular}{l|l|l|c|c|c|} 
excellent & very good & $\begin{array}{c}\text { neither good } \\
\text { nor bad }\end{array}$ & bad & very bad & extremely bad \\
\hline
\end{tabular}

For the next statement please consider the effects of your diabetes, its management and any complications you may have.

II) If I did not have diabetes, my quality of life would be:

\begin{tabular}{|c|c|c|c|c|c|c|}
\hline $\begin{array}{l}\text { very much } \\
\text { better }\end{array}$ & much better & a little better & the same & a little worse & much worse & $\begin{array}{c}\text { very much } \\
\text { worse }\end{array}$ \\
\hline
\end{tabular}

Please respond to the more specific statements on the pages that follow. For each statement, please consider the effects of your diabetes, its management and any complications you may have on the aspect of life described by the statement. 
In each of the following boxes:

a) Check an option to show how diabetes affects this aspect of your life;

b) Check an option to show how important this aspect of your life is to your quality of life.

Some statements have a "not applicable" option. Please shade this "not applicable" circle if that aspect of life does not apply to you.

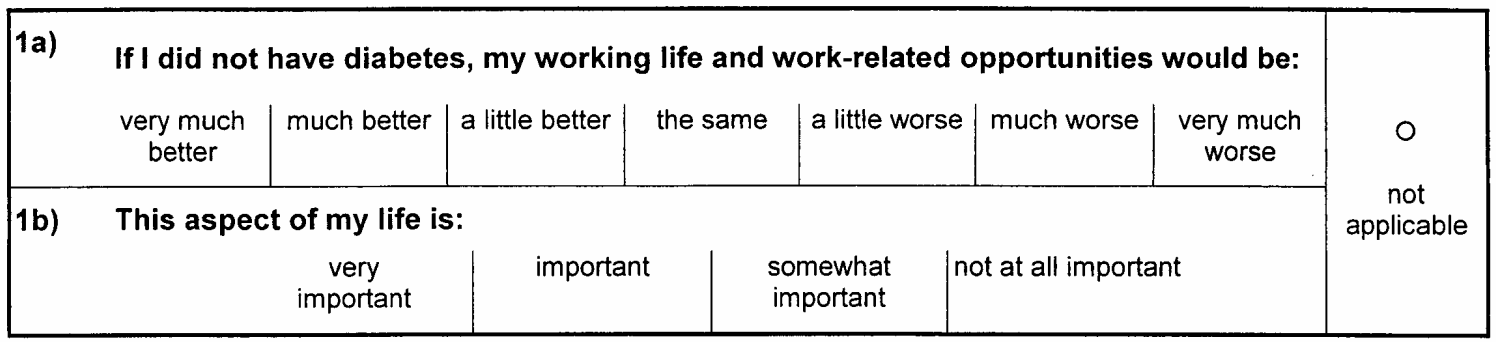

2a) If I did not have diabetes, my family life would be:

\begin{tabular}{|c|c|c|c|c|c|c|c|c|}
\hline & $\begin{array}{l}\text { very much } \\
\text { better }\end{array}$ & much better & a little better & the same & a little worse & much worse & $\begin{array}{c}\text { very much } \\
\text { worse }\end{array}$ & \\
\hline \multirow[t]{2}{*}{ 2b) } & \multicolumn{7}{|c|}{ This aspect of my life is: } & applicable \\
\hline & & $\begin{array}{c}\text { very } \\
\text { important }\end{array}$ & \multicolumn{2}{|c|}{ important } & $\begin{array}{l}\text { somewhat } \\
\text { important }\end{array}$ & \multicolumn{2}{|c|}{ not at all important } & \\
\hline
\end{tabular}

3a) If I did not have diabetes, my friendships and social life would be:

\begin{tabular}{c|c|c|c|c|c|c|}
$\begin{array}{c}\text { very much } \\
\text { better }\end{array}$ & much better & a little better & the same & a little worse & much worse & $\begin{array}{c}\text { very much } \\
\text { worse }\end{array}$ \\
\hline
\end{tabular}

3b) This aspect of my life is:

\begin{tabular}{c|l|l|l}
$\begin{array}{c}\text { very } \\
\text { important }\end{array}$ & important & $\begin{array}{c}\text { somewhat } \\
\text { important }\end{array}$ & not at all important \\
\hline
\end{tabular}

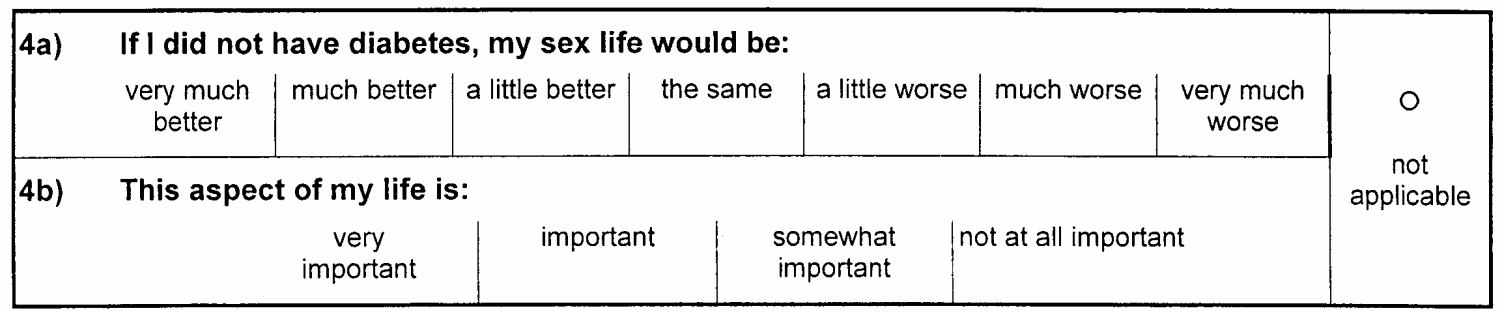

PLEASE CONTINUE ON THE BACK 


\section{5a) If I did not have diabetes, my physical appearance would be:}

\begin{tabular}{|c|c|c|c|c|c|c|}
\hline $\begin{array}{l}\text { very much } \\
\text { better }\end{array}$ & much better & a little better & the same & a little worse & much worse & $\begin{array}{c}\text { very much } \\
\text { worse }\end{array}$ \\
\hline
\end{tabular}

\section{5b) This aspect of my life is:}

\begin{tabular}{c|c|c|c|c|c|c|c|}
$\begin{array}{c}\text { very } \\
\text { important }\end{array}$ & important & $\begin{array}{c}\text { somewhat } \\
\text { important }\end{array}$ & not at all important \\
\hline
\end{tabular}

6a) If I did not have diabetes, the things I could do physically would be:

\begin{tabular}{c|c|c|c|c|c|c}
$\begin{array}{c}\text { very much } \\
\text { increased }\end{array}$ & $\begin{array}{c}\text { much } \\
\text { increased }\end{array}$ & $\begin{array}{c}\text { a little } \\
\text { increased }\end{array}$ & the same & $\begin{array}{c}\text { a little } \\
\text { decreased }\end{array}$ & $\begin{array}{c}\text { much } \\
\text { decreased }\end{array}$ & $\begin{array}{c}\text { very much } \\
\text { decreased }\end{array}$ \\
\hline
\end{tabular}

6b) This aspect of my life is:

\begin{tabular}{l|l|l|l}
$\begin{array}{c}\text { very } \\
\text { important }\end{array}$ & important & $\begin{array}{c}\text { somewhat } \\
\text { important }\end{array}$ \\
\hline
\end{tabular}

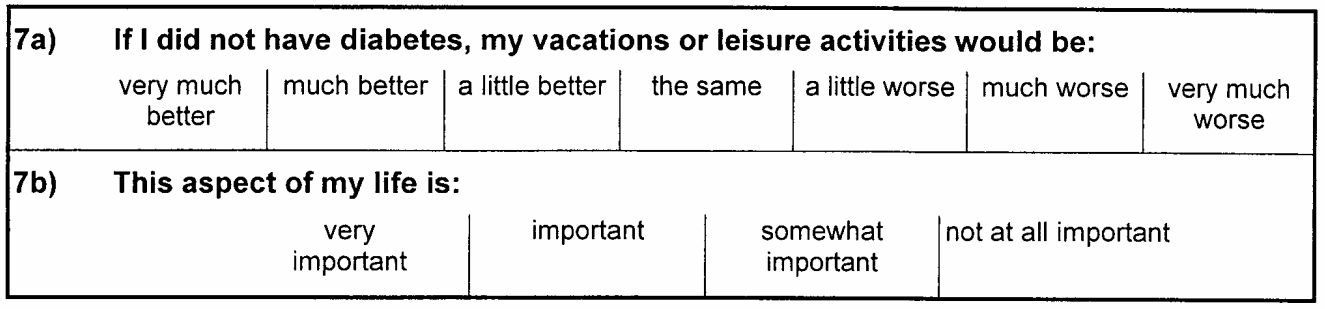

8a) If I did not have diabetes, ease of traveling (local or long distance) would be:

\begin{tabular}{c|c|c|c|c|c|c}
$\begin{array}{c}\text { very much } \\
\text { better }\end{array}$ & much better & a little better & the same & a little worse & $\begin{array}{c}\text { much worse } \\
\text { very much } \\
\text { worse }\end{array}$
\end{tabular}

8b) This aspect of my life is:

\begin{tabular}{l|l|l|l}
$\begin{array}{c}\text { very } \\
\text { important }\end{array}$ & important & $\begin{array}{c}\text { somewhat } \\
\text { important }\end{array}$ \\
\hline
\end{tabular}

9a) If I did not have diabetes, my confidence in my ability to do things would be:

\begin{tabular}{|c|c|c|c|c|c|c|}
\hline $\begin{array}{l}\text { very much } \\
\text { increased }\end{array}$ & $\begin{array}{c}\text { much } \\
\text { increased }\end{array}$ & $\begin{array}{c}\text { a little } \\
\text { increased }\end{array}$ & the same & $\begin{array}{c}\text { a little } \\
\text { decreased }\end{array}$ & $\begin{array}{c}\text { much } \\
\text { decreased }\end{array}$ & $\begin{array}{l}\text { very much } \\
\text { decreased }\end{array}$ \\
\hline
\end{tabular}

9b) This aspect of my life is:

\begin{tabular}{l|l|l|l}
$\begin{array}{c}\text { very } \\
\text { important }\end{array}$ & important & $\begin{array}{c}\text { somewhat } \\
\text { important }\end{array}$ & not at all important
\end{tabular}


10a) If I did not have diabetes, my motivation to achieve things would be:

\begin{tabular}{|c|c|c|c|c|c|c|}
\hline $\begin{array}{l}\text { very much } \\
\text { increased }\end{array}$ & $\begin{array}{c}\text { much } \\
\text { increased }\end{array}$ & $\begin{array}{c}\text { a little } \\
\text { increased }\end{array}$ & the same & $\begin{array}{c}\text { a little } \\
\text { decreased }\end{array}$ & $\begin{array}{c}\text { much } \\
\text { decreased }\end{array}$ & $\begin{array}{l}\text { very much } \\
\text { decreased }\end{array}$ \\
\hline
\end{tabular}

10b) This aspect of my life is:

\begin{tabular}{l|l|l|l}
$\begin{array}{c}\text { very } \\
\text { important }\end{array}$ & important & $\begin{array}{l}\text { somewhat } \\
\text { important }\end{array}$ & not at all important
\end{tabular}

\begin{tabular}{|c|c|c|c|c|c|c|c|}
\hline \multirow[t]{2}{*}{ 11a) } & \multicolumn{7}{|c|}{ If I did not have diabetes, the way society at large reacts to me would be: } \\
\hline & $\begin{array}{l}\text { very much } \\
\text { better }\end{array}$ & much better & a little better & the same & a little worse & much worse & $\begin{array}{l}\text { very much } \\
\text { worse }\end{array}$ \\
\hline 11b) & This aspe & $\begin{array}{l}\text { of my life is } \\
\text { very } \\
\text { important }\end{array}$ & importa & & $\begin{array}{l}\text { mewhat } \\
\text { nportant }\end{array}$ & ot at all importa & \\
\hline
\end{tabular}

\begin{tabular}{|c|c|c|c|c|c|c|c|}
\hline \multirow[t]{2}{*}{ 12a) } & \multicolumn{7}{|c|}{ If I did not have diabetes, my worries about the future would be: } \\
\hline & $\begin{array}{l}\text { very much } \\
\text { decreased }\end{array}$ & $\begin{array}{c}\text { much } \\
\text { decreased }\end{array}$ & $\begin{array}{c}\text { a little } \\
\text { decreased }\end{array}$ & the same & $\begin{array}{c}\text { a little } \\
\text { increased }\end{array}$ & $\begin{array}{l}\text { much } \\
\text { increased }\end{array}$ & $\begin{array}{l}\text { very much } \\
\text { increased }\end{array}$ \\
\hline \multirow[t]{2}{*}{ 12b) } & This aspec & of my life i & \multirow{2}{*}{\multicolumn{3}{|c|}{ important }} & \multirow{2}{*}{\multicolumn{2}{|c|}{ ot at all important }} \\
\hline & & $\begin{array}{c}\text { very } \\
\text { important }\end{array}$ & & & & & \\
\hline
\end{tabular}

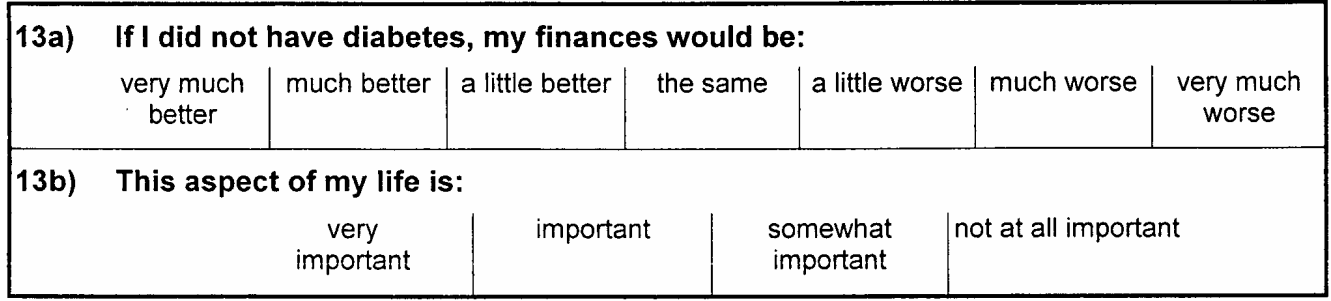

14a) If I did not have diabetes, my need to depend on others for things I would like to do for myself would be:

\begin{tabular}{c|c|c|c|c|c|c|}
$\begin{array}{c}\text { very much } \\
\text { decreased }\end{array}$ & $\begin{array}{c}\text { much } \\
\text { decreased }\end{array}$ & $\begin{array}{c}\text { a little } \\
\text { decreased }\end{array}$ & the same & $\begin{array}{c}\text { a little } \\
\text { increased }\end{array}$ & $\begin{array}{c}\text { much } \\
\text { increased }\end{array}$ & $\begin{array}{c}\text { very much } \\
\text { increased }\end{array}$ \\
\hline
\end{tabular}

14b) This aspect of my life is:

\begin{tabular}{c|c|c|c|}
$\begin{array}{c}\text { very } \\
\text { important }\end{array}$ & important & $\begin{array}{l}\text { somewhat } \\
\text { important }\end{array}$ & not at all important \\
\hline
\end{tabular}

PLEASE CONTINUE ON THE BACK 


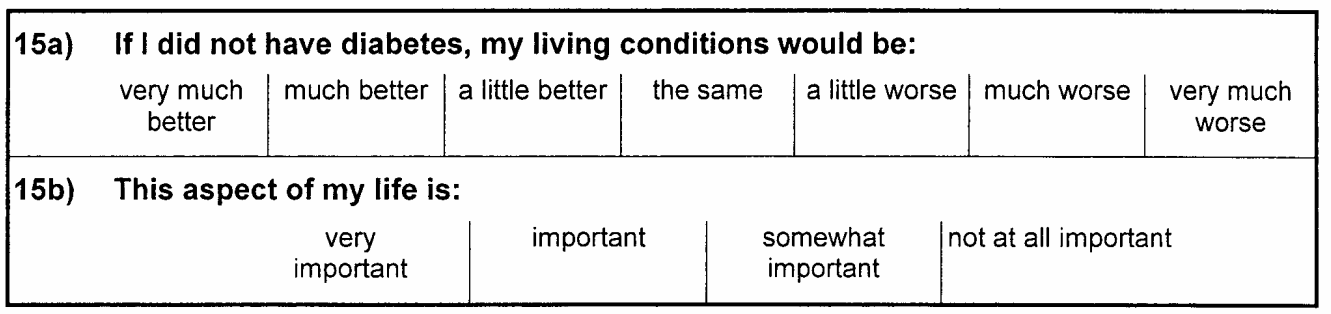

\begin{tabular}{|c|c|c|c|c|c|c|c|}
\hline \multirow[t]{2}{*}{ 16a) } & \multicolumn{7}{|c|}{ If I did not have diabetes, my freedom to eat as I wish would be: } \\
\hline & $\begin{array}{l}\text { very much } \\
\text { increased }\end{array}$ & $\begin{array}{c}\text { much } \\
\text { increased }\end{array}$ & $\begin{array}{c}\text { a little } \\
\text { increased }\end{array}$ & the same & $\begin{array}{c}\text { a little } \\
\text { decreased }\end{array}$ & $\begin{array}{c}\text { much } \\
\text { decreased }\end{array}$ & $\begin{array}{l}\text { very much } \\
\text { decreased }\end{array}$ \\
\hline \multirow[t]{2}{*}{ 16b) } & This aspe & of my life & \multirow{2}{*}{\multicolumn{2}{|c|}{ important }} & & \multirow{2}{*}{\multicolumn{2}{|c|}{ lot at all important }} \\
\hline & & $\begin{array}{c}\text { very } \\
\text { important }\end{array}$ & & & $\begin{array}{l}\text { lewhat } \\
\text { ortant }\end{array}$ & & \\
\hline
\end{tabular}

\section{7a) If I did not have diabetes, my enjoyment of food would be:}

\begin{tabular}{c|c|c|c|c|c|c|}
$\begin{array}{c}\text { very much } \\
\text { increased }\end{array}$ & $\begin{array}{c}\text { much } \\
\text { increased }\end{array}$ & $\begin{array}{c}\text { a little } \\
\text { increased }\end{array}$ & the same & $\begin{array}{c}\text { a little } \\
\text { decreased }\end{array}$ & $\begin{array}{c}\text { much } \\
\text { decreased }\end{array}$ & $\begin{array}{c}\text { very much } \\
\text { decreased }\end{array}$
\end{tabular}

17b) This aspect of my life is:

\begin{tabular}{c|c|c|c|}
$\begin{array}{c}\text { very } \\
\text { important }\end{array}$ & important & $\begin{array}{c}\text { somewhat } \\
\text { important }\end{array}$ & not at all important \\
\hline
\end{tabular}

18a) If I did not have diabetes, my freedom to drink as I wish (e.g. sweetened hot and cold drinks, fruit juice, alcohol) would be:

\begin{tabular}{|c|c|c|c|c|c|c|}
\hline $\begin{array}{l}\text { very much } \\
\text { increased }\end{array}$ & $\begin{array}{c}\text { much } \\
\text { increased }\end{array}$ & $\begin{array}{c}\text { a little } \\
\text { increased }\end{array}$ & the same & $\begin{array}{c}\text { a little } \\
\text { decreased }\end{array}$ & $\begin{array}{c}\text { much } \\
\text { decreased }\end{array}$ & $\begin{array}{l}\text { very much } \\
\text { decreased }\end{array}$ \\
\hline
\end{tabular}

18b) This aspect of my life is:

\begin{tabular}{l|l|l|l}
$\begin{array}{c}\text { very } \\
\text { important }\end{array}$ & important & $\begin{array}{l}\text { somewhat } \\
\text { important }\end{array}$ & not at all important
\end{tabular}


Below is a list of some of the ways you may have felt or behaved. Please indicate how often you have felt this way during the past week: (Check or circle any one number on each line) ${ }^{4}$

\begin{tabular}{|c|c|c|c|c|c|}
\hline & During the PAST WEEK.......... & $\begin{array}{c}\text { Rarely, or } \\
\text { none of } \\
\text { the time } \\
\text { (less than } 1 \\
\text { day) } \\
\end{array}$ & $\begin{array}{c}\text { Some, or } \\
\text { a little } \\
\text { of the time } \\
\text { (1-2 days) }\end{array}$ & $\begin{array}{c}\text { Occasionally, or } \\
\text { a moderate } \\
\text { amount of time } \\
\text { (3-4 days) }\end{array}$ & $\begin{array}{c}\text { All } \\
\text { of the } \\
\text { time } \\
\text { (5-7 days) }\end{array}$ \\
\hline 1. & $\begin{array}{l}\text { I was bothered by the things that usually } \\
\text { don't bother me }\end{array}$ & 0 & 1 & 2 & 3 \\
\hline 2. & $\begin{array}{l}\text { I did not feel like eating; my appetite was } \\
\text { poor }\end{array}$ & 0 & 1 & 2 & 3 \\
\hline 3. & $\begin{array}{l}\text { I felt that I could not shake off the blues even } \\
\text { with help from my family }\end{array}$ & 0 & 1 & 2 & 3 \\
\hline 4. & I felt that I was just as good as other people & 0 & 1 & 2 & 3 \\
\hline 5. & $\begin{array}{l}\text { I had trouble keeping my mind on what I was } \\
\text { doing }\end{array}$ & 0 & 1 & 2 & 3 \\
\hline 6. & I felt depressed & 0 & 1 & 2 & 3 \\
\hline 7. & I felt that everything I did was an effort & 0 & 1 & 2 & 3 \\
\hline 8. & I felt hopeful about the future & 0 & 1 & 2 & 3 \\
\hline 9. & I though my life had been a failure & 0 & 1 & 2 & 3 \\
\hline 10. & I felt fearful & 0 & 1 & 2 & 3 \\
\hline 11. & My sleep was restless & 0 & 1 & 2 & 3 \\
\hline 12. & I was happy & 0 & 1 & 2 & 3 \\
\hline 13. & I talked less than usual & 0 & 1 & 2 & 3 \\
\hline 14. & I felt lonely & 0 & 1 & 2 & 3 \\
\hline 15. & People were unfriendly & 0 & 1 & 2 & 3 \\
\hline 16. & I enjoyed life & 0 & 1 & 2 & 3 \\
\hline 17. & I had crying spells & 0 & 1 & 2 & 3 \\
\hline 18. & I felt sad & 0 & 1 & 2 & 3 \\
\hline 19. & I felt that people disliked me & 0 & 1 & 2 & 3 \\
\hline 20. & I could not "get going" & 0 & 1 & 2 & 3 \\
\hline
\end{tabular}


How you feel is very important to us. Let's sum up your views on how you feel. Kindly indicate your response by checking (or placing a cross) in the box against the ONE most appropriate statement in $\mathrm{EACH}$ of these five categories.

\begin{tabular}{|c|c|}
\hline 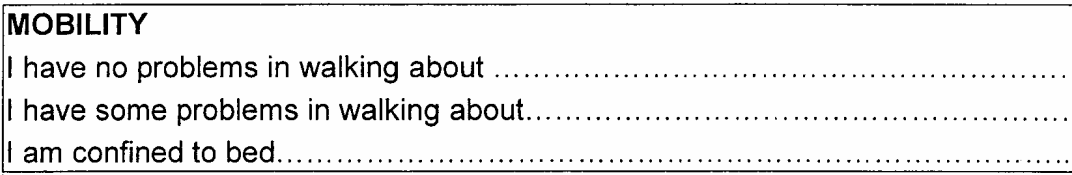 & $\begin{array}{c}\text { Check any one } \\
\square\end{array}$ \\
\hline 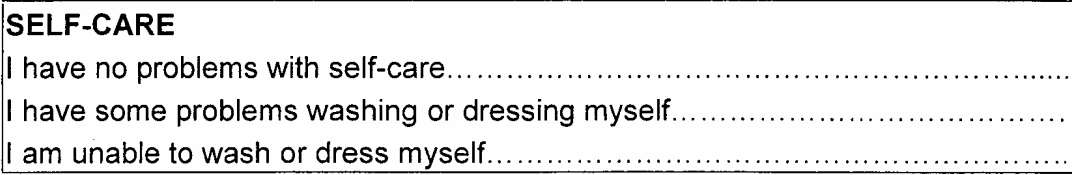 & $\begin{array}{c}\text { Check any one } \\
\square \\
\square \\
\square\end{array}$ \\
\hline 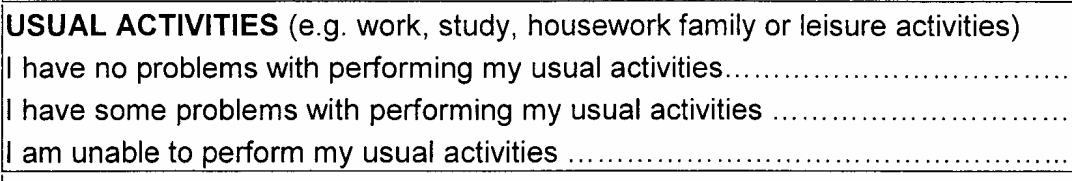 & $\begin{array}{c}\text { Check any one } \\
\square \\
\square \\
\square\end{array}$ \\
\hline 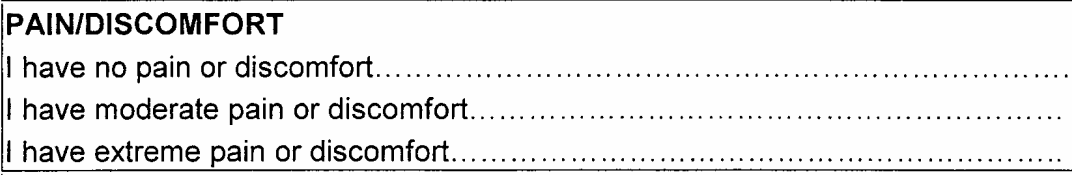 & $\begin{array}{l}\text { Check any one } \\
\square \\
\square \\
\square\end{array}$ \\
\hline 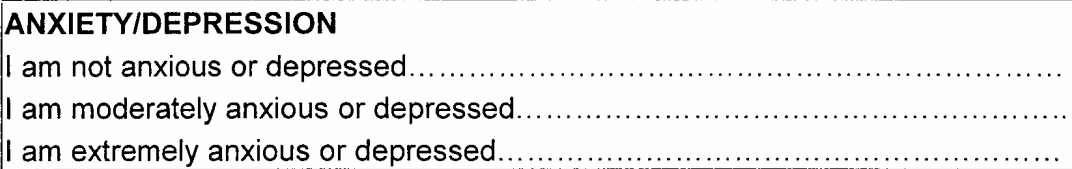 & $\begin{array}{l}\text { Check any one } \\
\square \\
\square \\
\square\end{array}$ \\
\hline
\end{tabular}

\section{Kindly read this:}

We have drawn a scale that looks like a thermometer on which the best state you can imagine is marked 100 and the worst state you can imagine is marked 0 . We would like you to indicate on this scale how good or bad your own health is today, in your opinion.

Please do so by drawing a line from the black box to whichever point on the scale indicates how good or bad your health state is.

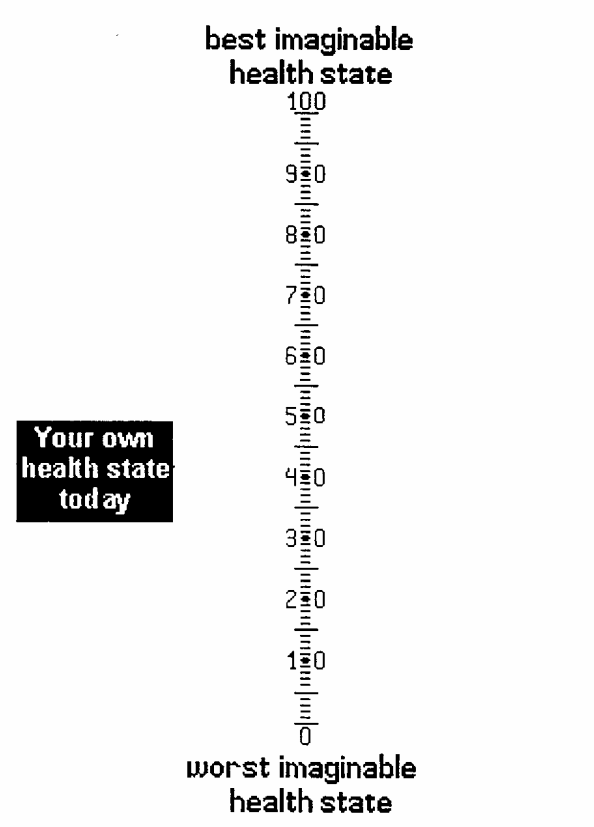

PLEASE CONTINUE ON THE NEXT PAGE 
Thank you for sharing with us your views on your health and well-being. Now, think about an issue that has been important in your life recently (over the past six months), a problem or challenge you faced, or a needed change. Indicate how often you engaged in each of the following behaviors regarding this issue/problem/needed change by circling the best response after each question based on the following scale: ${ }^{6}$

\begin{tabular}{|c|c|c|c|c|}
\hline 1 & 2 & 3 & 4 & 5 \\
\hline Not at all & Once or twice & Sometimes & Often & Almost Always \\
\hline
\end{tabular}

\begin{tabular}{|c|c|c|c|c|c|c|}
\hline 1 & Did you think of different ways to deal with the problem? & 1 & 2 & 3 & & \\
\hline 2 & Did you tell yourself things to make yourself feel better? & 1 & 2 & 3 & 4 & \\
\hline 3 & Did you talk with your spouse or other relative about the problem? & 1 & 2 & 3 & & \\
\hline 4 & Did you make a plan of action and follow it? & 1 & 2 & 3 & 4 & \\
\hline 5 & Did you try to forget the whole thing? & 1 & 2 & 3 & & \\
\hline 6 & $\begin{array}{l}\text { Did you feel that time would make a difference, that the only thing to do } \\
\text { was wait? }\end{array}$ & 1 & 2 & 3 & 4 & \\
\hline 7 & Did you try to help others with a similar problem? & 1 & 2 & 3 & 2 & \\
\hline 8 & Did you take it out on other people when you felt angry or depressed? & 1 & 2 & 3 & & \\
\hline 9 & Did you try to step back from the situation and be more objective? & 1 & 2 & 3 & 4 & \\
\hline 10 & Did you remind yourself how much worse things could be? & 1 & 2 & 3 & 4 & \\
\hline 11 & Did you talk with a friend about the problem? & 1 & 2 & 3 & & \\
\hline 12 & Did you know what had to be done and try hard to make things work? & 1 & 2 & 3 & 4 & \\
\hline 13 & Did you try not to think about the problem? & 1 & 2 & 3 & 2 & \\
\hline 14 & Did you realize that you had no control over the problem? & 1 & 2 & 3 & 2 & \\
\hline 15 & Did you get involved in new activities? & 1 & 2 & 3 & 4 & \\
\hline 16 & Did you take a chance and do something risky? & 1 & 2 & 3 & 2 & \\
\hline 17 & Did you go over in your mind what you would say or do? & 1 & 2 & 3 & 2 & \\
\hline 18 & Did you try to see the good side of the situation? & 1 & 2 & 3 & 2 & \\
\hline 19 & Did you talk with a professional person? & 1 & 2 & 3 & 2 & \\
\hline 20 & Did you decide what you wanted and try hard to get it? & 1 & 2 & 3 & 2 & \\
\hline 21 & $\begin{array}{l}\text { Did you daydream or imagine a better time or place than the one you } \\
\text { were in? }\end{array}$ & 1 & 2 & 3 & 2 & \\
\hline 22 & Did you think that the outcome would be decided by fate? & 1 & 2 & 3 & 2 & \\
\hline 23 & Did you try to make new friends? & 1 & 2 & 3 & 2 & \\
\hline 24 & Did you keep away from people in general? & 1 & 2 & 3 & & \\
\hline 25 & Did you try to anticipate how things would turn out? & 1 & 2 & 3 & 2 & \\
\hline
\end{tabular}

PLEASE CONTINUE ON THE BACK 


\begin{tabular}{|c|c|c|c|c|}
\hline 1 & 2 & 3 & 4 & 5 \\
\hline Not at all & Once or twice & Sometimes & Often & Almost Always \\
\hline
\end{tabular}

\begin{tabular}{|c|c|c|c|c|c|}
\hline 26 & $\begin{array}{l}\text { Did you think about how you were much better off than other people with } \\
\text { similar problems? }\end{array}$ & 1 & 2 & 3 & 4 \\
\hline 27 & $\begin{array}{l}\text { Did you seek help from persons or groups with the same type of } \\
\text { problem? }\end{array}$ & 1 & 2 & 3 & 4 \\
\hline 28 & Did you try at least two different ways to solve the problem? & 1 & 2 & 3 & 4 \\
\hline 29 & $\begin{array}{l}\text { Did you try to put off thinking about the situation even though you } \\
\text { knew you would have to at some point? }\end{array}$ & 1 & 2 & 3 & 4 \\
\hline 30 & Did you accept it; nothing could be done? & 1 & 2 & 3 & 4 \\
\hline 31 & Did you read more often as a source of enjoyment? & 1 & 2 & 3 & 45 \\
\hline 32 & Did you yell or shout to let off steam? & 1 & 2 & 3 & 4 \\
\hline 33 & Did you try to find some personal meaning in the situation? & 1 & 2 & 3 & 4 \\
\hline 34 & Did you try to tell yourself that things would get better? & 1 & 2 & 3 & 45 \\
\hline 35 & Did you try to find out more about the situation? & 1 & 2 & 3 & 4 \\
\hline 36 & Did you try to learn to do more things on your own? & 1 & 2 & 3 & 4 \\
\hline 37 & Did you wish the problem would go away or somehow be over with? & 1 & 2 & 3 & 4 \\
\hline 38 & Did you expect the worst outcome? & 1 & 2 & 3 & 4 \\
\hline 39 & Did you spend some time in recreational activities? & 1 & 2 & 3 & 4 \\
\hline 40 & Did you cry to let your feelings out? & 1 & 2 & 3 & 4 \\
\hline 41 & Did you try to anticipate the new demands that would be placed on you? & 1 & 2 & 3 & 4 \\
\hline 42 & $\begin{array}{l}\text { Did you think about how this event could change your life in a positive } \\
\text { way? }\end{array}$ & 1 & 2 & 3 & 4 \\
\hline 43 & Did you pray for guidance and/or strength? & 1 & 2 & 3 & 4 \\
\hline 44 & Did you take things a day at a time, one step at a time? & 1 & 2 & 3 & 4 \\
\hline 45 & Did you try to deny how serious the problem really was? & 1 & 2 & 3 & 4 \\
\hline 46 & Did you lose hope that things would ever be the same? & 1 & 2 & 3 & 4 \\
\hline 47 & Did you turn to work or other activities to help you manage things? & 1 & 2 & 3 & 4 \\
\hline 48 & $\begin{array}{l}\text { Did you do something that you didn't think would work, but at least } \\
\text { you were doing something? }\end{array}$ & 1 & 2 & 3 & 4 \\
\hline
\end{tabular}


This section will help us further understand your responses. Please CIRCLE what you believe as TRUE or FALSE. ?

\begin{tabular}{|c|c|c|c|}
\hline & & True & False \\
\hline 1 & It is sometimes hard for me to go on with my work if I am not encouraged & $T$ & $\mathrm{~F}$ \\
\hline 2 & I sometimes feel resentful when I don't get my way & $T$ & $\mathrm{~F}$ \\
\hline 3 & $\begin{array}{l}\text { On a few occasions, I have given up doing something because I thought to } \\
\text { little of my ability }\end{array}$ & $\mathrm{T}$ & $\mathrm{F}$ \\
\hline 4 & $\begin{array}{l}\text { There have been times when I felt like rebelling against people in authority } \\
\text { even though I knew they were right }\end{array}$ & $T$ & $\mathrm{~F}$ \\
\hline 5 & No matter who I'm talking to, I'm always a good listener & $T$ & $\mathrm{~F}$ \\
\hline 6 & There have been occasions when I took advantage of someone & $T$ & $F$ \\
\hline 7 & I'm always willing to admit when I make a mistake & $T$ & $\mathrm{~F}$ \\
\hline 8 & I sometimes try to get even rather than forgive and forget & T & $\mathrm{F}$ \\
\hline 9 & I am always courteous (polite), even to people who are disagreeable & $\mathrm{T}$ & $\mathrm{F}$ \\
\hline 10 & $\begin{array}{l}\text { I have never been irritated when people expressed ideas very different from } \\
\text { my own }\end{array}$ & $\mathrm{T}$ & $\mathrm{F}$ \\
\hline 11 & $\begin{array}{l}\text { There have been times when I was quite jealous of the good fortune of } \\
\text { others }\end{array}$ & $T$ & $\mathrm{~F}$ \\
\hline 12 & I am sometimes irritated by people who ask favors of me & $T$ & $\mathrm{~F}$ \\
\hline 13 & I have never purposely said something that hurt someone's feelings & $T$ & $\mathrm{~F}$ \\
\hline
\end{tabular}


We would like you to share the thoughts you may have had about exercising during the past week. Below is a list of thoughts that people sometimes have when they consider whether or not to exercise. Please read each thought carefully. Then, next to each thought, please indicate how frequently you had thought during the past week. You may use the following scale. $^{9}$

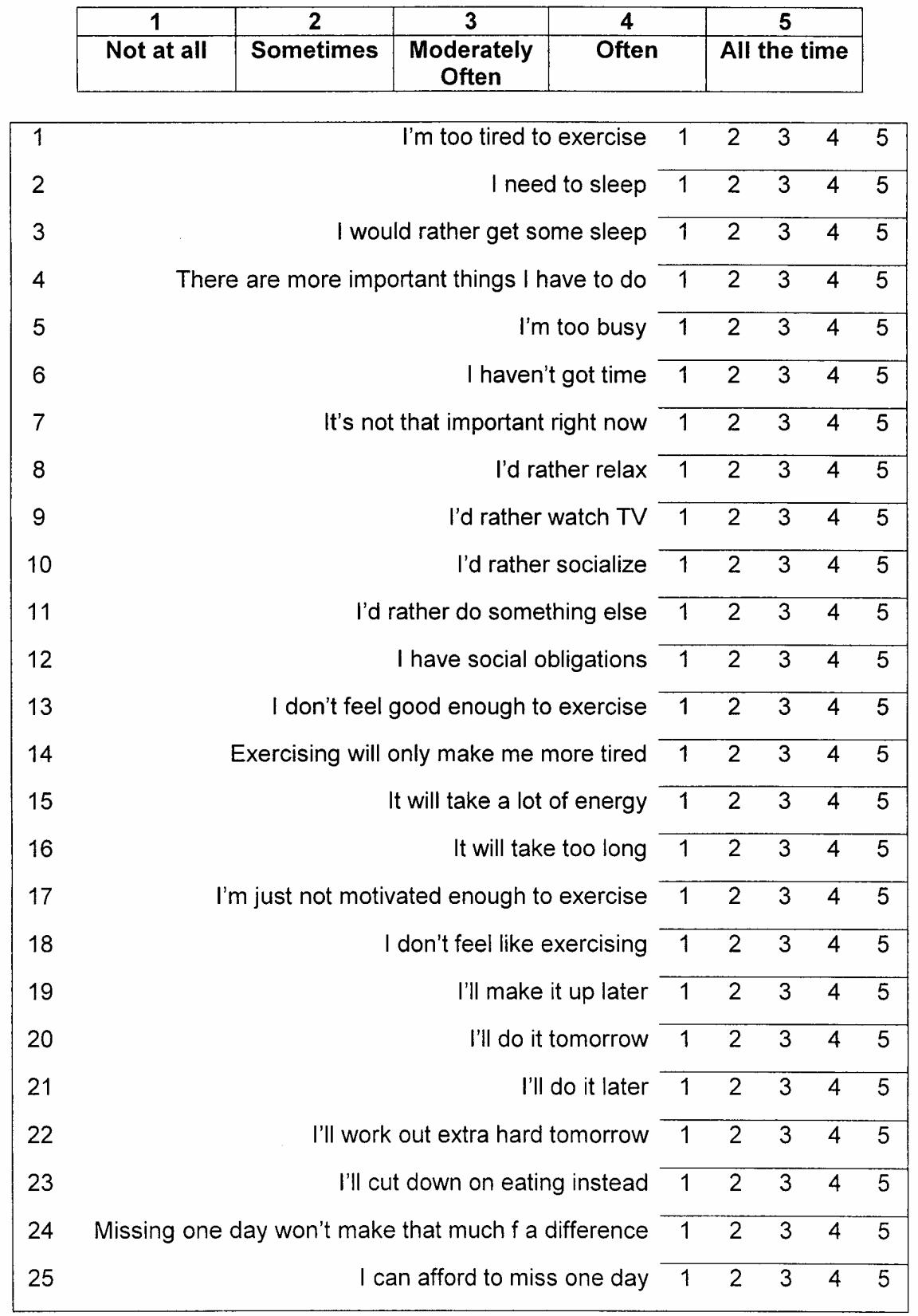


Finally, we know that people exercise for a variety of reasons. When people are asked why they exercise, their answers are sometimes based on the reasons they believe they should have for exercising. What we want to know are the reasons people actually have for exercising. Please respond to the items below as honestly as possible.

\section{IF YOU NEVER EXERCISE, PLEASE SKIP THIS SECTION AND GO TO THE LAST INSTRUCTIONS PAGE}

To what extent is each of the following an important reason that you have for exercising? Use the scale below, ranging form 1 to 7 , in giving your answers.

\begin{tabular}{|c|c|c|c|c|c|c|}
\hline 1 & 2 & 3 & 4 & 5 & 6 & 7 \\
\hline $\begin{array}{c}\text { Not at all } \\
\text { important }\end{array}$ & & & $\begin{array}{c}\text { Moderately } \\
\text { important }\end{array}$ & & $\begin{array}{c}\text { Extremely } \\
\text { important }\end{array}$ \\
\hline
\end{tabular}

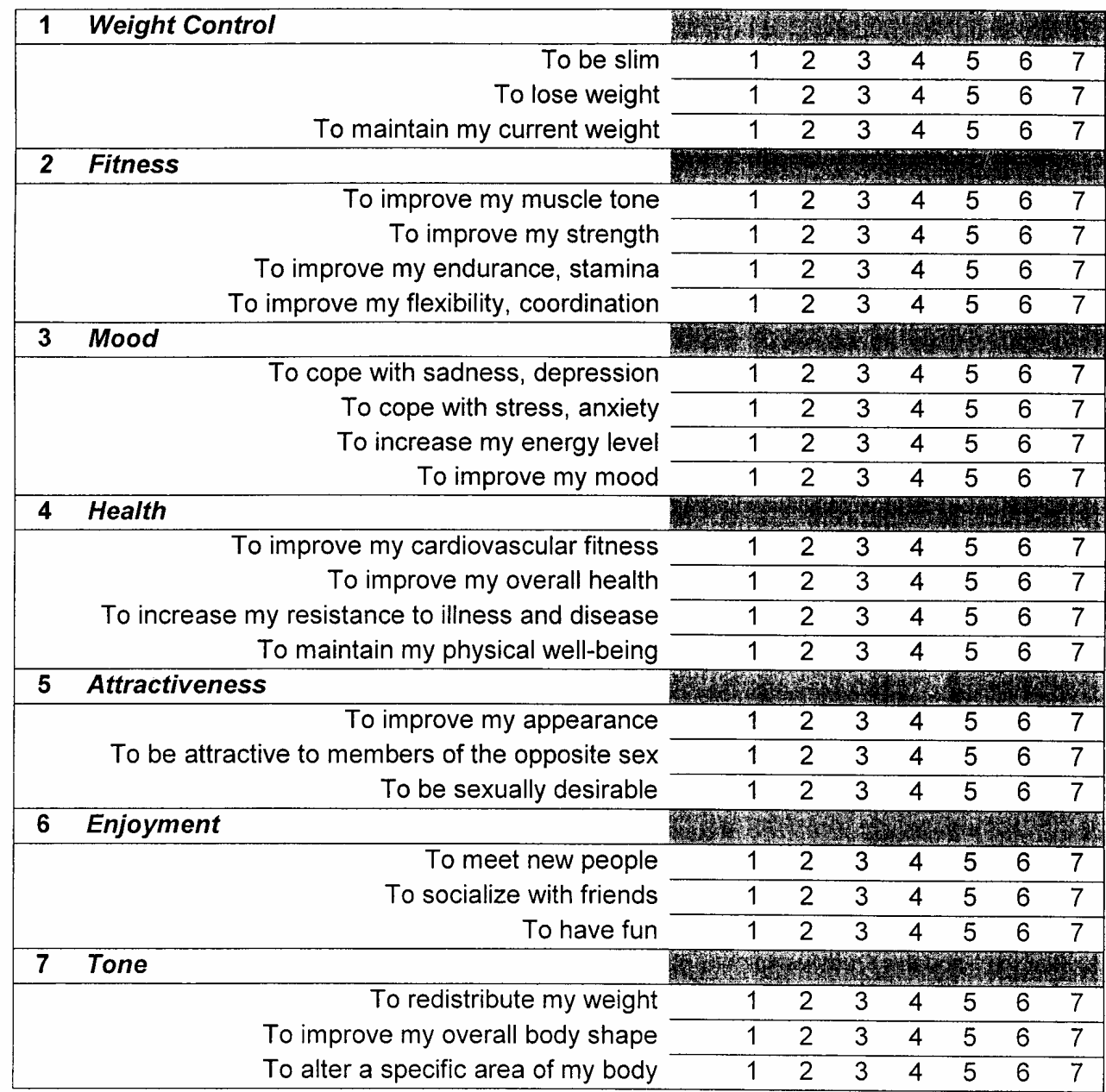




\section{Thank you very much for your time and effort}

in answering these questions!

Please mail it back in the postage-paid envelope provided to you.

1. (๑) 2001, Not for duplication without permission of Jan Kavookjian, MBA, PhD, West Virginia University

2. SF-12v2 ${ }^{\text {TM }}$ Health Survey (c) 1994, 2002 by QualityMetric Incorporated and Medical Outcomes Trust. All Rights Reserved.

SF-12® a registered trademark of Medical Outcomes Trust.

(SF12v2 Standard, US Version 2.0)

3. Audit of Diabetes Dependant Quality of Life (ADDQoL) (Bradley C., 1999)

4. Center for Epidemiologic Studies Depression Scale (CES-D)

5. The EuroQol group

6. Coping Responses Inventory (Moos, 1993)

7. Marlowe-Crown Short Form (Reynolds, 1982)

8. Exercise Thoughts Questionnaire (ETQ) (Kendierski and Johnson, 1993)

9. Reasons for Exercise Inventory 


\section{Appendix C: Reminder Card}

November, 2004

Dear Patient,

Last week a questionnaire concerning the care of people with diabetes was mailed to you along with a letter from your physician or care provider. We hope you found the topic of interest and importance.

If you have already returned the questionnaire, we thank you very much for your help. We know you are busy. Information that you and others provide will be used to help develop solutions for problems identified. If you have not yet filled out the questionnaire, it is hoped you will find a few minutes over the next few days for this. Your participation is entirely voluntary, but we feel it is essential to the quality of the study. Please note that all information will be kept as confidential as legally possible.

If you did not receive a letter from your physician containing the questionnaire packet, or have misplaced it, please contact Dr. Jan Kavookjian at WVU 304-293-1453 and another will be sent out right away.

Again, thank you very much for your assistance. 


\section{CURRICULUM VITAE}

\section{Murali Sundaram, MS, MBA}

Graduate Research Assistant, Dept. of Pharmaceutical Systems and Policy

West Virginia University School of Pharmacy

PO Box 9510, Room 1122B, HSC North

Morgantown, WV 26506-9510

304-685-3106 (Cell Phone)

304-293-2529 (Fax)

msundaram@hsc.wvu.edu

\section{Academic Qualifications}

2005 - Master of Science, School of Pharmacy, West Virginia University, USA.

Thesis title: Study "Quality of Life and Clinical Outcomes in Patients With Type 2 Diabetes at the Primary Care Clinics at the West Virginia University Hospital”.

2002 onwards - Graduate (Ph.D.) student in Department of Pharmaceutical Systems and Policy, School of Pharmacy, West Virginia University, USA.

1999-2001 - Post Graduate Diploma in Pharmaceutical Management (PGDPM), S.I.E.S. College of Management Studies (Indian Drug Manufacturers Association Collaboration), Bombay, India.

1995-1999 - Bachelor of the Pharmaceutical Sciences (B. Pharm.Sci.), The Bombay College of Pharmacy, University of Bombay, India.

\section{Professional Experience}

2002-2003 - Research Assistant, AIMS (Accessible Intelligent Medication Strategies) - an educational outreach intervention, West Virginia University School of Pharmacy.

2002-2004 - Research Fellow, ODAIS (Office of Drug Abuse and Intervention Studies) affiliated with CDC-funded Prevention Research Center, West Virginia University.

2001-2002 - Marketing Executive, IMS India.

2000-2001 - Summer Intern and Summer Research Coordinator, Novartis India Ltd.

\section{Publications and Presentations}

Madhavan SS, Sundaram M, Kamat S, D'Souza AO. Physician Attitudes Towards Academic Detailing and Other Drug Cost Containment Strategies in a State Health Insurance Program. Podium presentation at the Eighth Annual International ISPOR conference, May 18-21, 2003, Crystal City, VA. Recipient of best student presentation award.

Sundaram $\mathbf{M}$ and Smith MJ. Utilization Patterns of Drugs and Healthcare Services Among Recipients With Diabetes in a Medicaid Population. Poster presented at the Ninth Annual International ISPOR Conference, May 16-19, 2004, Crystal City, VA. Recipient of poster finalist award. 
Kavookjian J, Sundaram M. Glycemic Control as a Clinical Outcome Variable: The Impact of Non-Standardized Measures. Poster accepted for presentation at the West Virginia University School of Dentistry Research Day, Morgantown, WV, February 8, 2005.

Sundaram M and Kavookjian J. Quality of Life (SF12), Clinical Outcomes, and Comorbid Conditions in Patients With Type 2 Diabetes: A Population Study. Poster presentation at the Tenth Annual International ISPOR Conference, May 15-18, 2005, Washington, D.C.

Kavookjian J and Sundaram M. Clinical predictors and co-morbid conditions in a population study of motivation for exercise and depression in Type 2 diabetes. Poster presentation at the $65^{\text {th }}$ Annual ADA Scientific Sessions, June 10-14, 2005, San Diego, CA.

Sundaram M and Smith MJ. Utilization and Costs of Outpatient Services and Prescription Medications for Diabetes Among Recipients With Diabetes With Versus Without Comorbid Depression in a Medicaid Population. Poster presentation at the $41^{\text {st }}$ Annual Meeting of the Drug Information Association, June 21-24, 2005, Washington D.C. Recipient of Student Travel Award.

Sundaram $\mathbf{M}$ and Smith MJ. Impact of Co-morbid Depression on the Utilization of Drugs and Healthcare Services Among Recipients With Diabetes in a Medicaid Population. Abstract submitted to the 21st International Conference on Pharmacoepidemiology and Therapeutic Risk Management, August 21-24, 2005, Nashville, TN.

Sundaram M, Kavookjian J, Patrick JH, Madhavan SS, Miller LA, Scott V. Quality of Life and Clinical Outcomes in Patients With Type 2 Diabetes. Abstract submitted to the $12^{\text {th }}$ Annual Scientific Conference of the International Society for Quality of Life Research, October 19-22, 2005, San Fransisco, CA.

Madhavan SS, Sundaram M, Kamat S, Kavookjian J, D'Souza AO. Physicians’ Perceptions Towards Cost-containment Strategies and Educational Interventions for Cost-effective Prescribing. Manuscript in progress.

Sundaram $\mathbf{M}$ and Smith MJ. Impact of Co-morbid Depression on the Utilization of Drugs and Healthcare Services Among Recipients With Diabetes With in a Medicaid Population. Manuscript in progress.

\section{Computer Proficiency}

Statistical Software: SAS ${ }^{\circledR}$, SPSS ${ }^{\circledR}$, AMOS ${ }^{\circledR}$

Database Packages: Microsoft Access, Microsoft FoxPro V6.0

Decision Analysis software: DATA® TreeAge

Bibliographical software: Reference Manager

Office: MS Word, MS Excel, MS Powerpoint.

\section{Professional Affiliations}

2002 - Gerontological Society of America (GSA) - WVU Student Chapter

2003 onwards - International Society for Pharmacoeconomics and Outcomes Research (ISPOR)

2005 onwards - International Society for Quality of Life Research

2005 onwards - International Society for Pharmacoepidemiology

2005 onwards - Rho Chi Honor Society 


\section{Recent Academic Awards, Fellowships and Honors}

2005 - Recipient of Student Travel Award, 41 ${ }^{\text {st }}$ Drug Information Association Annual Meeting 2004 - Recipient of Poster Finalist Award, Ninth Annual International ISPOR conference 2003 - Recipient of Best Student Podium Presenter, Eighth Annual International ISPOR conference 2002 onwards - Research Assistantship, Office of Drug Abuse and Intervention Studies (ODAIS) affiliated with CDC-funded Prevention Research Center, West Virginia University 2001 - Best Summer Project Award (Pharma Marketing category), S.I.E.S. College of Management Studies

\section{Positions Held}

Vice President, WVU ISPOR Student Chapter (2004-2005)

Secretary, WVU ISPOR Student Chapter (2005-2006)

Placement coordinator, at Management School (2000 - 2001)

Member, Academic Committee at Management School (1999 - 2000)

\section{References}

Available upon request 